\title{
Diagnosis, Prevention, and Treatment of Cardiovascular Diseases in People With Type 2 Diabetes and Prediabetes - A Consensus Statement Jointly From the Japanese Circulation Society and the Japan Diabetes Society -
}

Eiichi Araki, MD, PhD; Atsushi Tanaka, MD, PhD; Nobuya Inagaki, MD, PhD; Hiroshi Ito, MD, PhD; Kohjiro Ueki, MD, PhD; Toyoaki Murohara, MD, PhD; Kenjiro Imai, MD, PhD; Masataka Sata, MD, PhD; Takehiro Sugiyama, MD, PhD; Hideki Ishii, MD, PhD; Shunsuke Yamane, MD, PhD; Takashi Kadowaki, MD, PhD; Issei Komuro, MD, PhD; Koichi Node, $\mathrm{MD}, \mathrm{PhD}$ on behalf of the Directors of the JCS and JDS

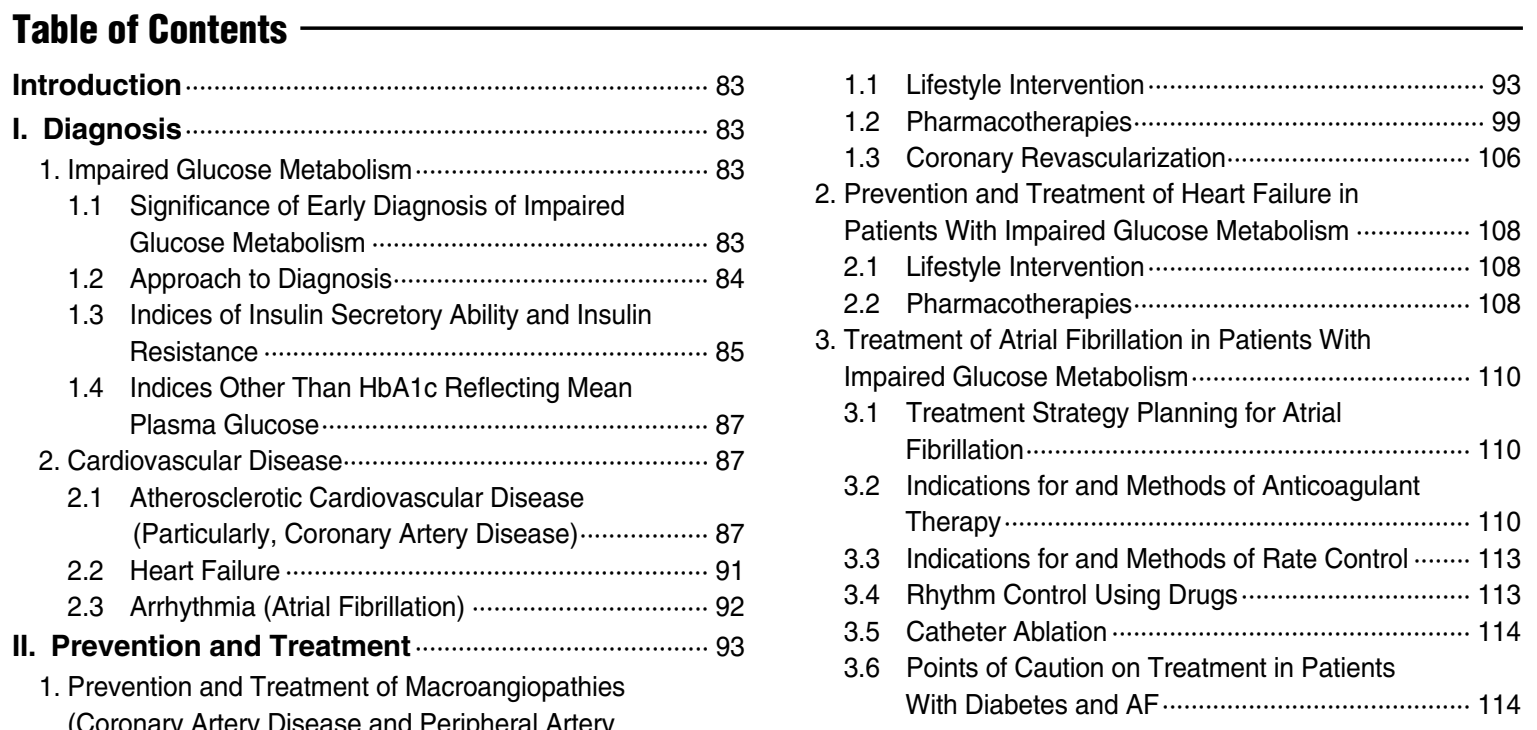

(Coronary Artery Disease and Peripheral Artery

Disease) in Patients With Impaired Glucose

Metabolism.

J-STAGE Advance Publication released online November 30, 2020

Key Words: Cardiovascular disease; Consensus Statements; Diabetes

This statement is based on the "Diagnosis, Prevention, and Treatment of Cardiovascular Diseases in People With Type 2 Diabetes and Pre-Diabetes: A Consensus Statement Jointed from The Japanese Circulation Society and The Japan Diabetes Society" (ISBN978-4-524-22818-8), which was published in Japanese by Nankodo Co., Ltd. (CThe Japanese Circulation Society, The Japan Diabetes Society, 2020) and is jointly published in Diabetology International (official English journal of the JDS: https://doi.org/10.1007/s13340-020-00471-5) and the Circulation Journal (official English journal of the JCS).

Department of Metabolic Medicine, Faculty of Life Sciences, Kumamoto University, Kumamoto (E.A.); Department of Cardiovascular Medicine, Saga University, Saga (A.T., K.N.); Department of Diabetes, Endocrinology and Nutrition, Kyoto University Graduate School of Medicine, Kyoto (N.I., S.Y.); Department of Cardiovascular Medicine, Okayama University Graduate School of Medicine, Dentistry and Pharmaceutical Sciences, Okayama (H. Ito.); Diabetes Research Center, Research Institute, National Center for Global Health and Medicine, Tokyo (K.U.); Department of Cardiology, Nagoya University Graduate School of Medicine, Nagoya (T.M.); Diabetes and Metabolism Information Center, Research Institute, National Center for Global Health and Medicine, Tokyo (K.I., T.S.); Department of Cardiovascular Medicine, Tokushima University Graduate School, Tokushima (M.S.); Department of Cardiology, Fujita Health University Bantane Hospital, Nagoya (H. Ishii.); Toranomon Hospital, Tokyo (T.K.); and Department of Cardiovascular Medicine, Graduate School of Medicine, The University of Tokyo, Tokyo (I.K.), Japan

Mailing address: Koichi Node, MD, PhD, Department of Cardiovascular Medicine, Saga University, 5-1-1 Nabeshima, Saga 849-8501, Japan. E-mail: node@cc.saga-u.ac.jp

All rights are reserved to the Japanese Circulation Society. For permissions, please e-mail: cj@j-circ.or.jp

ISSN-1346-9843 




2.2 Criteria for Referral of Patients in Whom Substantial Changes in Diabetes Treatment Are Desirable (Cotreat After Referral or Consider Continuing Diabetes Treatment With a Cardiologist After a Certain Time Period) ……....115

2.3 Criteria for Referral of Patients in Whom

Continued Diabetes Management by a

Diabetologist is Desirable (Also With

Consideration of Continued Cotreatment by

Both Specialists) …….......................................... 115

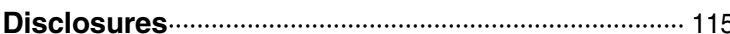



\section{Introduction}

The most important goal of diabetes treatment is to prevent the onset of complications, thereby extending the healthy life span of the patient. Therefore, it is necessary to properly diagnose diabetes and the risk factors for its complications, to appropriately implement preventive measures, and to simultaneously perform comprehensive therapeutic intervention, as needed.

In recent years, new evidence has been accumulating of the disease concept and treatment strategies of diabetes and its associated complications, causing a paradigm shift in some clinical practices. Thus, there has been a need to gather and update such evidence and for clinicians to extensively share that information. In particular, diabetes and cardiovascular diseases are very closely associated, from their pathologies to prognoses. For the achievement of treatment goals, it is critical to deepen the mutual understanding between cardiologists and diabetologists regarding the latest evidence and the current state of clinical practice, because of the overlapping of these departments, and to apply the acquired information appropriately to routine clinical practice. Information sharing can be achieved by developing a consensus based on the latest evidence of shared clinical practice that goes beyond the framework of each clinical department. This process can be expected to result in improved quality of care. In the USA and Europe, the cardiology and diabetes associations periodically publish joint statements. Partly in view of this fact, the Japanese Circulation Society and the Japan Diabetes Society are publishing this joint statement on the diagnosis, prevention, and treatment of cardiovascular diseases in Japanese patients with impaired glucose metabolism, including impaired glucose tolerance.

This statement has 3 major sections: (I) diagnosis, (II) prevention and treatment, and (III) criteria of patient referral. It is a consensus statement that was developed independently in Japan based on the latest evidence and clinical practice guidelines. This statement assumes its use and application in a wide range of clinical settings such as in guidelines for routine clinical practice of general practitioners, in guidelines for information sharing among specialists and for their mutual understanding, and in criteria involving patient referrals between departments.

We hope that this statement will be helpful in providing evidence-based high-quality care and achieving the preventive and therapeutic goals of cardiovascular disease management in patients with impaired glucose metabolism.

\section{Diagnosis}

\section{Impaired Glucose Metabolism}

\subsection{Significance of Early Diagnosis of Impaired Glucose Metabolism}

\subsubsection{Glycemic Control and Cardiovascular Risk in Diabetes}

The United Kingdom Prospective Diabetes Study (UKPDS) was conducted in patients with a short history of type 2 diabetes and showed that each $1 \%$ reduction in hemoglobin A1c $(\mathrm{HbA} 1 \mathrm{c})$ was associated with a $14 \%$ risk reduction of myocardial infarction. ${ }^{1}$ The post-trial, 10 -year observational study examined patients who had received intensive sulfonylurea (SU) or insulin therapy during the trial and those who received conventional glucose control (dietary therapy). The intensive SU or insulin therapy group had a signifi- cantly reduced risk of microangiopathy, myocardial infarction, diabetes-related death, and death from any cause compared with the conventional therapy group, even though both groups had similar post-trial HbAlc. ${ }^{2}$ The Diabetes Control and Complications Trial (DCCT) showed that strict glycemic control was effective in preventing the onset and progression of complications of diabetes in young patients aged 13-39 years with type 1 diabetes. In the DCCT post-trial observational study, all-cause death was not reduced until 15 years after intervention (cause of death: cardiovascular disease in $22.4 \%$ of all deaths) but subsequently reduced significantly. ${ }^{3}$ These results of largescale clinical studies indicate that the effect of maintaining a good glycemic control is sustained over the long term even after the intervention ends. The term "metabolic memory" or "legacy effect" is used to describe prolonged benefits of good glycemic control because a long time period 




Figure 1. Approach to the diagnosis of impaired glucose metabolism and recommendation criteria for a 75-g oral glucose tolerance test (OGTT). HbA1c, hemoglobin A1c.

is required for its effect to become evident, suggesting the importance of early intervention of glycemic control. In contrast, strict glycemic control increases the risk of hypoglycemia. Although strict glycemic control reduces cardiovascular events, multiple reports have indicated that it does not reduce or can actually increase cardiovascular death or all-cause death in patients with a long history. ${ }^{4-7}$ In particular, caution is required in glycemic control methods and goal settings in elderly patients with diabetes who are vulnerable to hypoglycemia. However, in order to prevent the development and progression of atherosclerotic cardiovascular diseases, it is important to diagnose diabetes early after onset and maintain proper glycemic control.

\subsubsection{Postprandial Hyperglycemia and Cardiovascular Risk}

The Diabetes Epidemiology Collaborative analysis Of Diagnostic criteria in Europe (DECODE), ${ }^{\mathbf{8}}$ Diabetes Epidemiology Collaborative analysis Of Diagnostic criteria in Asia (DECODA), ${ }^{9}$ and the Funagata study ${ }^{\mathbf{1 0}}$ examined the relationship between cardiovascular risks and impaired glucose metabolism using a 75-g oral glucose tolerance test (OGTT). The results of these studies showed that impaired fasting glucose (IFG) was not associated with an increased cardiovascular risk. However, the impaired glucose tolerance (IGT) group with high 2 -h plasma glucose level in a 75-g OGTT had a significantly increased risk of cardiovascular death. At present, the meal tolerance test has not been standardized and there is no clear evidence that directly shows a relationship between actual postprandial hyperglycemia and cardiovascular risk. However, the Study to Prevent Non-Insulin-Dependent Diabetes Mellitus (STOP-NIDDM) demonstrated that an intervention for postprandial hyperglycemia using an $\alpha$-glucosidase inhibitor reduced the development of cardiovascular events in an IGT group. ${ }^{11}$ It is considered to be of great importance to diagnose and begin an intervention in patients at the stage of IGT.

\subsection{Approach to Diagnosis (Figure 1)}

\subsubsection{When Diabetes is Diagnosable With a One-Time Blood Test Without an OGTT}

An OGTT is useful in the diagnosis of diabetes but not required. Diabetes can be definitively diagnosed from the results of a one-time blood test if the plasma glucose level satisfies the criteria of "early-morning fasting glucose $\geq 126 \mathrm{mg} / \mathrm{dL}$ " or "casual glucose $\geq 200 \mathrm{mg} / \mathrm{dL}$ ", and "HbA1c $\geq 6.5 \%$." Caution is required when performing glucose tolerance tests in a patient with marked hyperglycemia, which may further increase the glucose levels.

\section{1.2.2 When the 75-g 0GTT Is Recommended}

If the patient cannot be diagnosed with diabetes from plasma glucose and HbA1c levels, it is recommended to determine a more detailed metabolic state by performing a 75-g OGTT. The reason for performing this test is that such patients might include those with IGT and at a high-risk for cardiovascular events, those in whom the present suspicion of diabetes cannot be denied, and those with a high-risk of future diabetes. It is particularly desirable to perform this test in patients with high arteriosclerosis risk factors such as hypertension, dyslipidemia, and obesity.

(i) When the test is strongly recommended (present suspicion of diabetes cannot be denied)

A 75-g OGTT is strongly recommended if the patient satisfies any 1 of the following:

(1) Fasting plasma glucose level of $110-125 \mathrm{mg} / \mathrm{dL}$

(2) Casual plasma glucose level of $140-199 \mathrm{mg} / \mathrm{dL}$

(3) HbA1c level of $6.0-6.4 \%$ (excluding those with clear symptoms of diabetes).

(ii) When the test is desirable (high-risk for future diabetes) A 75-g OGTT is desirable if the patient satisfies 1 of the following:

(1) Fasting plasma glucose level of $100-109 \mathrm{mg} / \mathrm{dL}$ (high normal)

(2) $\mathrm{HbA} 1 \mathrm{c}$ level of $5.6-5.9 \%$

(3) Strong family history of diabetes and/or obesity.

\subsubsection{Procedure for a 75-g OGTT}

(1) The patient fasts at least $10 \mathrm{~h}$ from the day before the test until the morning of the test. A blood sample is collected while fasting and the plasma glucose level is measured.

(2) After blood collection while fasting. the patient drinks a glucose solution ( $75 \mathrm{~g}$ anhydrous glucose dissolved in water or the equivalent amount of partially hydrolyzed starch (e.g., Trelan-G®)). 




Figure 2. Decision criteria based on fasting plasma glucose and a 75-g oral glucose tolerance test (OGTT). IFG, impaired fasting glucose; IGT, impaired glucose tolerance.

(3) A blood sample is collected at $30 \mathrm{~min}, 1 \mathrm{~h}$, and $2 \mathrm{~h}$ after glucose loading and the blood glucose levels are measured.

Although the plasma glucose levels at $30 \mathrm{~min}$ and $1 \mathrm{~h}$ after loading are not included in the diagnostic criteria of diabetes, these levels are useful in detecting the high-risk group for diabetes. The measurement of insulin levels in a 75-g OGTT makes it possible to examine the early insulin secretion and patterns of insulin secretion and is useful for evaluation of pathology and risk of diabetes.

\section{1.2.4 Classification of Glucose Metabolic State by 75-g OGTT Result}

Glucose tolerance of patients can be classified as normal type, borderline type, or diabetic type based on the 75-g OGTT results - a combination of the fasting glucose level and the 2-h level in the 75-g OGTT (Figure 2).

(a) "Diabetic type": (1) or (2) below

(1) Early-morning fasting plasma glucose level $\geq 126 \mathrm{mg} / \mathrm{dL}$

(2) 2-h plasma glucose level $\geq 200 \mathrm{mg} / \mathrm{dL}$ in a 75 -g OGTT If patients have the diabetic type of glucose metabolism and satisfy the following conditions, they are diagnosed as having diabetes.

- Two confirmations of diabetic type:

- Once indicating "diabetic type," and

- Result of a test performed on another day is (1) or (2) above, or a casual glucose level $\geq 200 \mathrm{mg} / \mathrm{dL}$, or HbAlc $\geq 6.5 \%$.

A diagnosis of diabetes can be made.

- One confirmation of diabetic type + symptoms of chronic hyperglycemia:

- Result of a 75-g OGTT indicating "diabetic type" and

- Chronic hyperglycemic symptoms such as dipsia, polydipsia, weight loss, and diabetic retinopathy.

A diagnosis of diabetes can be made.

(b) "Normal type": (3) and (4) below

(3) Early-morning fasting plasma glucose level $\leq 110 \mathrm{mg} / \mathrm{dL}$

(4) 2-h plasma glucose level $<140 \mathrm{mg} / \mathrm{dL}$ in a 75 -g OGTT

Even in patients with the normal type, if the 1-h plasma glucose level in a 75 -g OGTT is $\geq 180 \mathrm{mg} / \mathrm{dL}$, the risk of transition to diabetes is higher than that in patients with a glucose level $<180 \mathrm{mg} / \mathrm{dL}$. ${ }^{12,13}$ Such normal type patients should be managed as borderline type patients.

(c) "Borderline type": patients who do not have a "diabetic type" or "normal type"

IFG is defined as 2-h plasma glucose level in 75-g OGTT of $<140 \mathrm{mg} / \mathrm{dL}$ and fasting plasma glucose level of 110 $125 \mathrm{mg} / \mathrm{dL}$. Impaired glucose tolerance (IGT) is defined as 2-h plasma glucose levels in 75-g OGTT of $140-199 \mathrm{mg} / \mathrm{dL}$. Thus, the patients can be distinguished. IGT can be a risk factor for heart disease, ${ }^{10}$ as mentioned before. Thus, if patients have risk factors such as hypertension, dyslipidemia, and obesity, then intervention for these factors is also aggressively implemented.

If the urinary glucose is positive in a medical examination (e.g., at school), measurement of fasting or casual plasma glucose level and HbA1c level should be performed. If the diagnosis cannot be confirmed by these results, then a 75-g OGTT should be considered as an additional test using the aforementioned recommendation criteria as the reference.

\section{I1.3 Indices of Insulin Secretory Ability and Insulin Resistance}

Diabetes is defined as a "group of metabolic diseases with a cardinal symptom of chronic hyperglycemia, which is caused by insufficient insulin action". In type 1 diabetes, the causes of hyperglycemia and metabolic failure are pancreatic $\beta$-cell destruction, and impaired or depleted insulin secretion. The majority of these patients require insulin injections to sustain life (insulin-dependent). In type 2 diabetes, insufficient insulin secretion results from genetic factors combined with environmental factors. The genetic factors cause decreased insulin secretion and insulin resistance (IR) and the environmental factors include overeating, physical inactivity, obesity, and stress. Many patients with type 2 diabetes do not require insulin therapy to sustain life (non-insulin-dependent). To maintain good glycemic control, some patients need insulin therapy combined with dietary therapy, exercise therapy, and oral pharmacotherapy. In patients with impaired glucose metabolism, it is important to evaluate insulin secretory 


\begin{tabular}{|c|c|c|}
\hline & Insulin-dependent state & Non-insulin-dependent state \\
\hline Characteristics & $\begin{array}{l}\text { Insulin secretion is absolutely deficient, and insulin therapy is } \\
\text { required to sustain life. }\end{array}$ & $\begin{array}{l}\text { Insulin secretion is not absolutely deficient. } \\
\text { Therefore, insulin therapy is not required to } \\
\text { sustain life but might be selected for glycemic } \\
\text { control in some cases. }\end{array}$ \\
\hline Reference values & $\begin{array}{l}\text { Fasting blood C-peptide }<0.6 \mathrm{ng} / \mathrm{mL} \\
24-\mathrm{h} \text { urinary C-peptide } \leq 20 \mu \mathrm{g} / \text { day }\end{array}$ & \\
\hline Points of caution & $\begin{array}{l}\text { Insulin-dependent state cannot be ruled out even if the values } \\
\text { exceed the above reference values. Comprehensive determination } \\
\text { should be made based on performance status and metabolic } \\
\text { conditions. } \\
\text { Evaluation of insulin secretory ability is difficult in patients with } \\
\text { reduced renal function due to delayed C-peptide excretion, } \\
\text { causing its increased blood level and decreased urinary level. }\end{array}$ & $\begin{array}{l}\text { Insulin secretory ability might become decreased } \\
\text { over time even in non-insulin-dependent patients } \\
\text { with ongoing treatment. Insulin secretory ability } \\
\text { should be evaluated if decline in glycemic } \\
\text { control is observed, and when insulin dose } \\
\text { reduction or withdrawal is considered. }\end{array}$ \\
\hline
\end{tabular}

Adapted from Japan Diabetes Society (author/editor). Treatment guide for diabetes 2018-2019. Tokyo: Bunkodo, $2018^{14}$ (in Japanese).

ability and IR for selection of treatment strategy. The indices described below can be calculated using information such as the results of a fasting blood test and a 75-g OGTT.

\section{1.3.1 Indices of Insulin Secretory Ability}

Insulin secretion consists of basal secretion and bolus secretion. The former occurs continuously, even in the fasting state, and the latter elevates with an increase in blood glucose levels and digestive hormones due to food intake. Both basal secretion and bolus secretion are decreased or absent in type 1 diabetes, an insulin-dependent state. Decreased or delayed bolus secretion occurs first in type 2 diabetes.

\section{(a) Insulinogenic Index}

The insulinogenic index is the ratio of plasma insulin increase to plasma glucose increase at $30 \mathrm{~min}$ after loading in a 75-g OGTT (see equation below). This index is a marker of early secretory ability after loading (early-phase secretory ability) in insulin bolus secretion. Patients with diabetes have an insulinogenic index of $\leq 0.4$. Even if individuals have a borderline type, they have a high rate of progression to diabetes if their insulinogenic index is $\leq 0.4$.

Insulinogenic index $=$

[ $\Delta$ plasma insulin value $(30 \mathrm{~min}$ post-load value $0 \mathrm{~min}$ value $)(\mu \mathrm{U} / \mathrm{mL})] /$

[ $\Delta$ plasma glucose value $(30 \mathrm{~min}$ post-load value $0 \mathrm{~min}$ value $)(\mathrm{mg} / \mathrm{dL})]$

\section{(b) C-Peptide}

In patients with diabetes, a 75-g OGTT is not usually performed after definitive diagnosis. The measurement of plasma insulin levels cannot be used to evaluate insulin secretory ability during insulin therapy because plasma insulin levels are affected by the injected insulin. C-peptide is produced by the cleavage of proinsulin in the pancreatic $\beta$ cells and is secreted in equimolar concentrations with insulin. Serum and urinary C-peptide levels are used to evaluate insulin secretory ability, particularly its changes over time, and to estimate insulin dependence. If the fasting serum C-peptide level is $<0.6 \mathrm{ng} / \mathrm{mL}$ and the $24-\mathrm{h}$ urinary C-peptide level is $\leq 20 \mu \mathrm{g} / \mathrm{day}$, it is highly probable that the patient is insulin-dependent (Table 1). If patients have IR due to obesity or metabolic failure due to soft-drink overconsumption, some of them will be insulin-dependent even if they do not satisfy the above criteria of C-peptide levels. The C-peptide level is only an estimate of insulin dependence. It is important to note that the C-peptide level is only a reference and a comprehensive evaluation is necessary to determine insulin dependence. Excretion of $\mathrm{C}$-peptide is delayed in patients with reduced renal function. As a result, its blood level increases and its urinary level decreases, making the evaluation of insulin secretory ability difficult.

\section{(c) Slowly Progressive Type 1 Diabetes}

Patients with acute-onset type 1 diabetes generally develop ketosis or ketoacidosis within 3 months after the appearance of hyperglycemic symptoms and become insulin-dependent. In contrast, if patients have slowly progressive type 1 diabetes (or slowly progressive insulin-dependent diabetes mellitus [SPIDDM]), insulin secretion is not markedly decreased at the time of diabetes diagnosis. However, the insulin secretory ability gradually reduces over a few months to a few years, resulting in insulin-dependent diabetes. As SPIDDM progresses, patients become positive for islet cellspecific autoantibodies, such as glutamic acid decarboxylase (GAD) antibody and islet cell cytoplasmic antibody (ICA). If worsening of glycemic control occurs without particular cause in patients with type 2 diabetes and ongoing treatment, then C-peptide and GAD antibody levels should be measured and the possibility of SPIDDM needs to be considered.

\subsubsection{Index of Insulin Resistance Homeostasis Model Assessment of Insulin Resistance (HOMA-IR)}

HOMA-IR is a simple index of IR. It is calculated from the early-morning fasting plasma insulin level and plasma glucose level. If the fasting plasma glucose level is $\leq 140 \mathrm{mg} / \mathrm{dL}$, the HOMA-IR value correlates well with the values of IR obtained using other methods.

\section{HOMA-IR =}

(fasting insulin $(\mu \mathrm{U} / \mathrm{mL}) \times$ fasting plasma glucose $(\mathrm{mg} / \mathrm{dL})) / 405$

A HOMA-IR value of $\leq 1.6$ is determined to be normal and $\geq 2.5$ signifies IR. If patients have a plasma glucose level $>140 \mathrm{mg} / \mathrm{dL}$ or have ongoing insulin therapy, IR cannot be evaluated accurately. 
Table 2. Characteristics of a Discrepancy Between Hemoglobin A1c (HbA1c) and Average Plasma Glucose

\begin{tabular}{|l|l|l|}
\hline \multicolumn{1}{|c|}{ HbA1c level is higher } & \multicolumn{1}{|c|}{ HbAc1c level is lower } & Neither \\
\hline - Rapidly improved diabetes & - Rapid onset and exacerbation of diabetes & - Hemoglobinopathy \\
- Iron-deficient state & $\begin{array}{l}\text { - Recovery phase of iron deficiency anemia } \\
\text { - Hemolysis (decreased lifespan of red blood cells) }\end{array}$ & \\
& $\begin{array}{l}\text { - After blood loss (increased erythropoiesis), and } \\
\text { after blood transfusion } \\
\end{array}$ & - Renal anemia with ongoing erythropoietin treatment \\
& - Liver cirrhosis & \\
\hline
\end{tabular}

Adapted from Japan Diabetes Society (author/editor). Treatment guide for diabetes 2018-2019. Tokyo: Bunkodo, $2018^{14}$ (in Japanese).

\subsection{Indices Other Than HbA1c Reflecting Mean Plasma Glucose}

$\mathrm{HbAlc}$ reflects the mean plasma glucose level of the patient during the previous 1-2 months and shows very little variation in the same patient. It is included in the diagnostic criteria because of its great importance as an index of glycemic control and in the determination of impaired glucose metabolism. On the other hand, the HbA1c value sometimes does not accurately reflect the mean plasma glucose level, such as when there is a rapid improvement or decline in glycemic control and when there is anemia (Table 2) ${ }^{14}$ In such situations, it is necessary to diagnose impaired glucose metabolism by comprehensive evaluation of fasting and casual plasma glucose levels and the results of a 75-g OGTT.

Although not used in the diagnosis of impaired glucose metabolism, glycated albumin and 1,5-anhydroglucitol (described below) are indices that mainly reflect plasma glucose changes after therapeutic intervention. Caution is required in the interpretation of the results because each of these indices has conditions under which they do not accurately reflect plasma glucose changes.

\section{1.4.1 Glycated Albumin (GA) (Reference Range: $11-16 \%)$}

Plasma GA reflects the mean plasma glucose level of approximately the past 2 weeks. It is useful in determining short-term therapeutic effect when treatment has changed, and in evaluating the mean plasma glucose level in patients with anemia or hemoglobinopathy whose HbAlc value deviates from the mean plasma glucose level. The GA level decreases when the albumin half-life is shortened, such as in patients with nephrotic syndrome or hyperthyroidism, causing the GA value to deviate from the actual average plasma glucose level.

\section{1.4.2 1,5-Anhydroglucitol (1,5-AG) (Reference Range: $\geq 14.0 \mu \mathrm{g} / \mathrm{mL}$ )}

The blood concentration of 1,5-AG decreases as urinary glucose excretion increases. Thus, the 1,5-AG level decreases in the hyperglycemic state, which is opposite to HbAlc and GA. It also decreases when there is a transient increase in blood glucose, and its increase is gradual once the value becomes low. Thus, patients become positive for 1,5-AG (low value) from the stage of IGT, in which patients only show postprandial hyperglycemia. On the other hand, changes in glycemic control are not well reflected by the 1,5-AG value in patients with a large amount of urinary glucose excretion. Sodium-glucose cotransporter 2 (SGLT2)-inhibitors, which have been used in clinical practice in recent years, selectively inhibit SGLT2 in the proximal renal tubules, inhibiting the reabsorption and promoting the excretion of urinary glucose. Thus, 1,5-AG cannot be used to evaluate the mean blood glucose level in patients taking SGLT2-inhibitors.

\section{Cardiovascular Disease}

\subsection{Atherosclerotic Cardiovascular Disease (Particularly, Coronary Artery Disease)}

Patients with diabetes are a high-risk group for coronary artery disease (CAD), stroke, and peripheral artery disease (PAD). A Finnish study reported that patients with type 2 diabetes without previous myocardial infarction had the same risk for coronary events as patients without diabetes but with previous myocardial infarction. ${ }^{15} \mathrm{~A}$ meta-analysis has shown that patients with type 2 diabetes had a $1.5-$ 3.6-fold increase in CAD and stroke compared with healthy subjects. ${ }^{16}$ These cardiovascular events can be the cause of death in patients with diabetes. If patients can be diagnosed as having a high-risk for arteriosclerotic lesions before the occurrence of acute myocardial infarction or sudden cardiac death, such an occurrence can be prevented by promoting improvement of lifestyle habits and implementing aggressive pharmacotherapeutic intervention.

Presently, exercise ECG is used widely for screening of CAD. This test induces myocardial ischemia to diagnose coronary stenosis but is not without problems. Even if there is coronary arteriosclerosis, patients are sometimes diagnosed as being normal if the stenosis is not significant. Many coronary events occur due to occlusion by a thrombus or rupture of a stenotic lesion that was not sufficiently severe to cause myocardial ischemia. ${ }^{17,18}$ Consequently, the focus is now on the individual's risk stratification for coronary events and being identified as high-risk.

\section{2.1.1 Screening Tests}

(a) Relationship Between Test Results and Progression of Arteriosclerosis Determined by Prediabetic Condition

Figure 3 shows the relationship between various tests and progression of arteriosclerosis over time. Although IR can be observed 10 years or more before diabetes onset, the plasma glucose level is normal because of increased insulin secretion. Endothelial dysfunction develops from this stage. When insulin secretion is decreased, the plasma glucose level increases and diabetes develops. Vascular stiffness increases at approximately this time, and systolic blood pressure increases in particular. If the duration of diabetes is prolonged or if diabetes becomes severe, an atheroma forms and the risk of cardiovascular events further increases. 


\begin{tabular}{|c|c|}
\hline Vascular endothelial dysfunction & Arteriosclerosis (early stage) \\
\hline Flow-mediated dilation (FMD) & Arterial stiffness (PWV and CAVI) \\
\hline Reactive hyperemic index (RHI) & Carotid duplex (IMT) \\
\hline
\end{tabular}

Arteriosclerosis (advanced stage)



Figure 3. Significance of arteriosclerosis tests and their relationships with diabetes stages. Vascular endothelial function decline starts in the prediabetic stage, and vascular stiffness increases (sclerosis). When diabetes develops, a patient becomes prone to vascular occlusion due to atheroma formation. Cardiovascular events can occur starting in the prediabetic stage. The risk becomes higher as the duration of diabetes becomes longer. ABI, ankle-brachial index; CAVI, cardio-ankle vascular index; CT, computed tomography; IMT, intima-media thickness; MDCT, multidetector row CT; PWV, pulse wave velocity.

\section{(b) Blood Tests}

Coronary events increase with increasing HbAlc, but there are 2 points of caution regarding the relationship between them. First, even if the HbAlc is within the normal range, a cardiovascular event can occur. Second, even if diabetes treatment reduces the $\mathrm{HbAlc}$, the risk of a cardiovascular event does not necessarily decrease. ${ }^{19}$ The risk factors for cardiovascular events are considered to be dyslipidemia (fasting hyperlipidemia and low high-density lipoprotein cholesterolemia), elevated low-density lipoprotein cholesterol (LDL-C), and progression of chronic kidney disease (CKD: elevated serum creatinine, reduced estimated glomerular filtration rate (eGFR), and amount of urinary albumin). ${ }^{20} \mathrm{~A}$ few scoring systems have been proposed to predict coronary event occurrence from these factors (e.g., SCORE risk chart, Framingham (coronary artery disease) risk score, and ACC/AHA ASCVD risk calculator). ${ }^{21-23}$ For example, the Framingham risk score estimates the 10 -year risk of CAD and is calculated based on sex, age, total cholesterol, high-density lipoprotein cholesterol (HDL-C), systolic blood pressure, and a history of smoking. ${ }^{22}$ This score is useful in medical care because it can be calculated easily using the internet.

Arteriosclerosis is also an inflammatory disease. If there is an unstable plaque, it has been shown that the level of high-sensitivity C-reactive protein (hsCRP), which reflects vascular microinflammation, increases. An increase in hsCRP is associated with increased risk of a cardiovascular event and death. ${ }^{24}$ It has been shown that patients with hsCRP $\geq 0.2 \mathrm{mg} / \mathrm{L}$ have an increased risk of cardiovascular events compared with patients with lower values. ${ }^{25}$

\section{(c) 12-Lead ECG}

Recording the 12-lead ECG is the simplest test. If it is normal, then past myocardial infarction can be almost ruled out. On the other hand, even if patients are asymptomatic, they can be suspected of having myocardial infarction if there are pathologic Q-waves and negative T-waves. In some cases, non-specific ECG changes occur due to conditions such as left ventricular hypertrophy, and this test is not necessarily highly sensitive. However, a 12-lead ECG should be recorded annually because it enables diagnosis of arrhythmia, such as atrial fibrillation, left ventricular hypertrophy, and abnormalities associated with heart failure (HF), such as left atrial overload. Holter ECG increases the diagnostic efficiency for myocardial infarction but the diagnostic sensitivity of CAD is not high (19-62\%). ${ }^{\mathbf{2 6}}$

\section{(d) Vascular Endothelial Function Test}

A decrease in endothelial function is a change that is observed at the earliest stage of arteriosclerosis. Endothelial function quantifies, as vascular smooth muscle relaxation, the endothelial nitric oxide (NO) production in response to the shear stress of blood flow. ${ }^{27}$ At present, endothelial function can be assessed by flow-mediated dilation (FMD) and the reactive hyperemic index (RHI) using endothelial pulse amplitude testing (EndoPAT). For FMD, ultrasound is used to measure the brachial arterial diameter at rest and during reactive hyperemia. This hyperemia occurs after inducing ischemia in the forearm for $5 \mathrm{~min}$ using a cuff balloon followed by its rapid deflation. FMD is the change in diameter divided by the diameter at rest. For RHI, a PAT probe is placed on a fingertip of each hand and then the arterial flow in one upper arm is interrupted for $5 \mathrm{~min}$. The RHI compares the pulse wave of the fingertip on each side after reperfusion. Both FMD and RHI decrease as the risk for cardiovascular events increases. They have been reported to predict future cardiovascular events in high-risk 
patients. ${ }^{28}$ The benefit of FMD and RHI is that their use might prevent the progression of arteriosclerosis because their decrease is reversible if early therapeutic intervention is implemented.

\section{(e) Carotid Ultrasound}

This test can be performed easily and inexpensively. The intima-media thickness (IMT) of the carotid artery is used widely as a marker for atherosclerosis. The IMT measurement methods are as follows.

(1) IMT measurements of the common carotid artery, carotid bifurcation, and internal carotid body.

(2) Automatic IMT measurement of the common carotid artery.

IMT has been reported to be significantly thickened at $0.71-0.98 \mathrm{~mm}$ in patients with type 2 diabetes compared with $0.66-0.85 \mathrm{~mm}$ in patients without diabetes. ${ }^{29}$ Increased IMT is an independent predictor of coronary event, stroke, and PAD. ${ }^{30,31}$ IMT measurement has been recommended as a screening test for cardiovascular disease in patients with diabetes. ${ }^{32}$ In cardiovascular risk stratification, IMT measurement is considered useful for calculating carotid total plaque area and to add to the Framingham risk score. ${ }^{33}$

The limitations of carotid ultrasound are measurement error among examiners and reproducibility, and evaluation difficulty due to large individual differences in the shape of the carotid body and bifurcation. Therefore, it is presently difficult to establish standardized values for risk stratification.

\section{(f) Evaluation of Coronary Artery Calcification Using Unenhanced MDCT}

Arterial wall calcification develops only during arteriosclerosis and does not occur with the degeneration of aging. ${ }^{34}$ That is, coronary artery calcification suggests the presence of an arteriosclerotic lesion. Coronary artery calcification can be easily evaluated using unenhanced multidetector row computed tomography (MDCT). The imaging is performed during a breath-hold for a few seconds and results in low radiation exposure $(<1 \mathrm{mSv})$. Quantitative scores are calculated automatically. Quantitative evaluation of coronary artery calcification is often performed using the Agatston score based on the extent of the calcified lesion and CT score. ${ }^{35}$ Other methods of evaluation include the use of volume score and mass score.

An Agatston score for normal is " 0 ". If the score is 0 , then CAD is ruled out and the subsequent 10 -year risk of cardiovascular events is very low even in patients with diabetes. ${ }^{36}$ There is abundant data on the relationships between Agatston score and vital prognosis, and between the score and cardiovascular events. This score is considered to have a higher predictive ability of future cardiovascular events when compared with the Framingham risk score or compared with coronary risk factors such as hypertension, diabetes, dyslipidemia, history of smoking, and family history. The Agatston score may be considered an index of the level of arteriosclerosis in the overall coronary artery. ${ }^{37}$ A higher score indicates a higher probability of coronary artery stenosis and occlusion, providing a reason to consider an exercise stress test and contrast-enhanced cardiac CT. An Agatston score $<100$ is considered to indicate a low-risk (coronary event risk of 2.1-fold more than that of a 0 score $(95 \%$ confidence interval (CI): 1.6 2.9)); a score of 100-400 indicates a moderate risk (coronary event risk of 4.2 -fold more than that of a 0 score $(95 \% \mathrm{CI}$ :
2.5-7.2)); and a score $>400$ indicates a high-risk (coronary event risk of 7.2 -fold more than that of a 0 score $(95 \% \mathrm{CI}$ : 3.9-13.0)). ${ }^{36}$ Similar relationships are also seen in patients with diabetes, ${ }^{38,39}$ but patients with diabetes have a higher incidence of cardiovascular events than patients without diabetes with the same score. ${ }^{40}$ The 2016 American Diabetes Association's Standards of Care did not recommend routine testing of coronary artery calcification in view of cost and effectiveness. ${ }^{41}$ However, it should be considered for ruling out CAD in moderate-risk patients or for risk stratification.

Another index is the change in coronary artery calcification score over time. A higher rate of Agatston score increase has been indicated to result in a higher risk of cardiovascular event.42,43 In particular, patients with an increase $\geq 30 \%$ per year have a high-risk of cardiovascular events.

\section{(g) Pulse Wave Velocity}

The pathological change of vascular "stiffening" is the foundation of arteriosclerosis. Vascular stiffness increases with age, so the term "vascular age" is sometimes used. Such stiffness is affected by arteriosclerosis risk factors. ${ }^{\mathbf{4 4 , 4 5}}$ When the ankle-brachial pressure index (ABI) is measured, an index of vascular stiffness is also measured (i.e., pulse wave velocity (PWV) or cardio-ankle vascular index (CAVI)). The CAVI is considered an index that is unaffected by blood pressure. An increase in vascular stiffness means an increase in the risk of cardiovascular events and is the cause of systolic hypertension. ${ }^{\mathbf{4 6 , 4 7}}$ If vascular age is estimated at screening of patients with diabetes, their understanding of the disease can be improved and the level of vascular age can trigger therapeutic intervention. Thus, a test for PWV is recommended.

\section{(h) Ankle-Brachial Pressure Index}

The ABI is calculated as ankle systolic blood pressure/ upper-arm systolic blood pressure. It is used for screening of PAD. ABI measurement is indicated with a Class I recommendation in patients with symptoms such as intermittent claudication. It is indicated with a Class IIa recommendation in patients aged 50-64 years with risk factors for atherosclerosis (e.g., diabetes, history of smoking, dyslipidemia, and hypertension) or with a family history of PAD, and in patients aged $<50$ years with diabetes and 1 additional risk factor for atherosclerosis. ${ }^{48}$ An ABI value of 1.00-1.40 is normal and the cutoff is often $<0.90 . .^{49,50} \mathrm{It}$ is considered a biomarker for "atherosclerosis extending to the peripheral arteries" when $<0.9$, thereby becoming an index of high risk. It has been reported that coronary events increase as the ABI decreases and that its predictive accuracy is higher than that of the Framingham risk score. ${ }^{37}$ In a meta-analysis study, low ABI had a sensitivity and specificity of $16.5 \%$ and $92.7 \%$, respectively, for predicting a coronary event, and $41.0 \%$ and $87.9 \%$, respectively, for predicting cardiovascular death. ${ }^{\mathbf{5 1}}$ Although sensitivity was low, specificity was high. In the ACC/AHA guidelines based on expert opinion, ABI $<0.9$ is recommended for risk evaluation of patients with moderate risk. ${ }^{23,52}$ An ABI $<0.40$ suggests the presence of severe arteriosclerosis of the lower leg. An ABI $\geq 1.4$ is also abnormal, suggesting abnormally increased vascular stiffness, such as in patients with chronic kidney failure or a stenotic lesion in the brachial artery. The disadvantage of ABI is that it cannot be measured if the systolic blood pressure is $\leq 40 \mathrm{mmHg}$ 




Figure 4. Flowchart for diagnosis of coronary artery disease and risk stratification in patients with diabetes. Refer to the main text for details. ABI, ankle-brachial index; CAVI, cardio-ankle vascular index; CT, computed tomography; IMT, intima-media thickness; MDCT, multidetector row CT; PWV, pulse wave velocity.

because of a peripheral artery occlusion.

\section{(i) Exercise and Pharmacologic Stress Tests}

Exercise ECG is often performed for screening of CAD using the Master two-step, treadmill or bicycle ergometer test. However, its sensitivity, specificity, and diagnostic accuracy are not high. It is difficult to make a determination using the stress test in patients with an ECG abnormality, such as non-specific ST-T wave changes or left bundle branch block. In such patients, it is useful to perform exercise or pharmacologic (adenosine) myocardial perfusion scintigraphy, or exercise or dobutamine stress echocardiography.

Stress myocardial perfusion scintigraphy and exercise stress echocardiography have much higher diagnostic accuracy for CAD compared with exercise ECG. In addition, these tests provide information on stenotic coronary arteries. Diagnostic accuracy and specificity are $80-90 \%$ and $75-90 \%, 53$ respectively, for pharmacologic myocardial perfusion scintigraphy, and $81 \%$ and $85 \%$, respectively, for dobutamine stress echocardiography, indicating their diagnostic similarity..$^{54}$

A point of caution is that negative findings of these stress tests do not rule out coronary atherosclerosis. Such findings simply mean that there is no stenotic lesion that induces myocardial ischemia. It should be understood that a diagnosis of "normal" cannot be made based on such negative findings.

\subsubsection{Flowchart for Diagnosis of CAD and Risk Stratification (Figure 4)}

The "Treatment Guide for Diabetes 2016" lists non-invasive screening tests for macrovascular diseases. ${ }^{55}$ These tests are carotid ultrasound, FMD, echocardiography, exercise
ECG, stress myocardial perfusion scintigraphy, and coronary artery CT. However, the guide indicated the lack of consensus on performing these tests in individuals who are asymptomatic or have no ECG abnormality. It is necessary to be selective in testing patients so that excessive testing can be avoided. If the duration of type 2 diabetes is short or if patients are less than 40 years old, the risk of cardiovascular events is known to be low. ${ }^{56} \mathrm{~A}$ screening test for arteriosclerosis is appropriate for patients with diabetes who are at least 40 years old or have at least a 10 -year history of diabetes; and in patients with a comorbidity such as hypertension, dyslipidemia, or CKD (eGFR $<60 \mathrm{~mL} /$ $\mathrm{min} / 1.73 \mathrm{~m}^{2}$ or microalbuminuria). It is appropriate to use, as a reference, a risk score such as the Framingham, ACC/ AHA ASCVD or SCORE risk score. Physical findings and symptoms of patients are also important. Physicians should listen carefully to patients regarding atypical cardiac-related symptoms (e.g., exertional dyspnea and chest discomfort) and vascular symptoms such as carotid bruit, transient ischemic attack, and intermittent claudication. Screening for CAD is recommended if wall motion abnormalities appear in the echocardiographic examination.

For arteriosclerosis screening, it is reasonable to perform PWV, CAVI, ABI or carotid ultrasound. Evaluation of coronary artery calcification is recommended using unenhanced MDCT for patients with an ABI $<0.9$ (or $\geq 1.40$ ) even without subjective symptoms, or for patients with high PWV or CAVI for their age, or patients with increased IMT or plaque on carotid duplex. If patients have accumulated risks or if the hospital can perform MDCT imaging, the evaluation of coronary artery calcification can be prioritized by performing unenhanced MDCT as the first step. In such cases, radiation exposure risk should be considered, even if the dose is very low, and unenhanced 




Figure 5. Flowchart for diagnosis of heart failure in patients with diabetes. Refer to the main text for details. BNP, B-type natriuretic peptide; NT-proBNP, N-terminal pro-B-type natriuretic peptide.

MDCT is appropriate for patients with any of the following: a moderate risk based on the Framingham score, longstanding poor glycemic control, multiple risk factors or chest symptoms. If patients have an Agatston score $>400$ based on unenhanced MDCT, they are considered to be at high-risk. A two-step approach is advisable to screen for the presence/absence of silent myocardial ischemia using stress myocardial perfusion scintigraphy, or exercise or dobutamine stress echocardiography.

If patients are suspected of having CAD from the results of these tests, then contrast-enhanced cardiac CT is recommended. Because the negative predictive value is very high, unnecessary coronary angiography can be avoided if CAD is ruled out using cardiac CT.$^{57,58}$ If there is significant coronary stenosis, revascularization is considered using a procedure such as percutaneous coronary intervention (PCI) or coronary artery bypass grafting (CABG). Contrast-enhanced cardiac CT also enables determination of the characteristics of coronary plaques. An unstable plaque is suspected if there is enlargement of the coronary artery and microcalcification in soft plaques. ${ }^{59}$ If there is an unstable plaque, even more rigorous therapeutic intervention is required.

Patients with diabetes also need to be monitored over time. It is recommended to perform annual echocardiography as well as ABI (vascular stiffness) or carotid ultrasound to evaluate the progression of a lesion and to determine therapeutic effectiveness. If progression is evident, evaluation of coronary artery calcification is considered using unenhanced MDCT or contrast-enhanced cardiac CT. Annual contrast-enhanced cardiac CT is not recommended in consideration of radiation exposure and the effects of contrast agents.

\section{2.2 Heart Failure}

Patients with diabetes often have coexisting HF. In the epidemiological Framingham Study, the risk of HF was more than twice as high in men with diabetes than in those without and more than 5-fold higher in women with diabetes than in those without. ${ }^{60}$ Another epidemiological study showed that patients with diabetes had a higher prevalence of HF than patients without diabetes (11.8 vs. 4.5\%). ${ }^{61}$ The risk of HF was 1.2-1.7-fold higher even in patients at the stage of IGT compared with individuals with normal glucose regulation. ${ }^{\mathbf{6 2}, 63}$ In patients with diabetes, HF has also been reported as the most frequent cause for initial hospitalization. ${ }^{\mathbf{6 4}}$ Diabetes is also an independent risk factor for HF. In patients with diabetes, the risk factors for HF have been reported to be advanced age, long duration of diabetes, insulin use, history of CAD, presence of CKD (increased serum creatinine level and microalbuminuria), and poor glycemic control.61,65-67 On the other hand, patients with HF often have coexisting diabetes. The prevalence of diabetes is $25 \%$ in patients with chronic $\mathrm{HF}$ and $42 \%$ in patients with acute HF. $\mathbf{1 , 6 8 , 6 9}$

As mentioned, patients with diabetes often have coexisting $\mathrm{HF}$. One reason is that diabetes is a coronary risk factor and left ventricular systolic function can decrease due to myocardial infarction (HF with reduced ejection fraction: $\mathrm{HFrEF})$. HF with preserved ejection fraction (HFpEF) is even more prevalent. The mechanism of HFpEF involves an accumulation of glycation products in cardiomyocytes, overproduction of collagen, interstitial necrosis, impaired calcium homeostasis, myocardial microangiopathy, and impaired insulin signaling associated with myocardial hypertrophy and caused by hyperinsulinemia. ${ }^{70-73}$ Left ventricular diastolic function also decreases due to an increase in left ventricular afterload caused by increased 
vascular stiffness. When the condition progresses, the pathology is known as "diabetic cardiomyopathy".

\section{2.2.1 Flowchart for Diagnosis (Figure 5)}

For the diagnosis of HF, it is appropriate to refer to the "JCS 2017/JHFS 2017 Guideline on Diagnosis and Treatment of Acute and Chronic Heart Failure (2017 revised edition)" ${ }^{74}$ Diagnosis of HF is made by a combination of clinical symptoms and test results. With an awareness that patients with diabetes are in a high-risk group for $\mathrm{HF}$, physicians should listen to the patients for detailed symptoms while suspecting HF. Patients with HF often restrain themselves from activities, including exercising, to avoid symptoms. Patients can claim to be asymptomatic, but it is important for physicians to confirm that they are actually asymptomatic. At a periodic examination, physicians should check for symptoms such as exertional dyspnea, palpitation, fatigue, pedal edema, nocturia, paroxysmal nocturnal dyspnea, and orthopnea. It is appropriate to ask about these symptoms during history taking about the patient's daily activities. HF is sometimes discovered from physical examination. It is important not to overlook abnormal physical findings (including elevated heart rate, arrhythmia, rales, heart murmur, third heart sound, and jugular vein distension). If there are any findings suspicious of $\mathrm{HF}$, further examinations are performed using chest $\mathrm{X}$-ray (checking for conditions such as increased cardiothoracic ratio and pulmonary congestion) and 12-lead ECG (checking for conditions such as atrial fibrillation, left ventricular hypertrophy, abnormal Q-wave, and ST-T changes). If the suspicion of $\mathrm{HF}$ persists, then further screening tests are performed.

The first screening test involves the measurement of B-type natriuretic peptide (BNP) or N-terminal pro-B-type natriuretic peptide (NT-proBNP). If $\mathrm{BNP} \geq 40 \mathrm{pg} / \mathrm{mL}$ (or NT-proBNP $\geq 125 \mathrm{pg} / \mathrm{mL}$ ), there is a possibility of HF. If $\mathrm{BNP} \geq 100 \mathrm{pg} / \mathrm{mL}$ (NT-proBNP $\geq 400 \mathrm{pg} / \mathrm{mL}$ ), then there is a high possibility of HF that is a therapeutic target and a cardiologist should be consulted. Patients could be asymptomatic because they are restraining themselves from activities, such as exercising, or they could have convinced themselves that the HF symptoms are due to their age. It is also not uncommon that patients are unaware of the symptoms that are associated with HF. Annual measurement of BNP or NT-proBNP is recommended in patients with diabetes.

If $\mathrm{HF}$ is suspected from the BNP or NT-proBNP level, echocardiography is performed to make the diagnosis of the underlying heart disease and to evaluate the pathology. Tests are necessary to measure left ventricular dimension (volume) and the left ventricular ejection fraction in order to distinguish between HFpEF and HFrEF. There is much evidence that measurements of left ventricular mass index and left atrial size (left atrial volume index) are useful for risk stratification. Thus, it is appropriate to make these measurements. In HFrEF patients, it should be determined whether the reduction in left ventricular wall motion is localized or circumferential, and then the involvement of CAD should be examined. Evaluation of left ventricular diastolic function is necessary in HFrEF patients. It is essential to measure transmitral flow velocity waveforms for sinus rhythm patients. If left ventricular diastolic function deteriorates, an abnormal waveform occurs in which the E-wave amplitude decreases more than the A-wave amplitude. If it further deteriorates, the reverse occurs in which the E-wave amplitude increases more than the A-wave amplitude, resulting in a pseudonormal waveform. Early diastolic mitral annular velocity (e') is regarded as a rate at which the left ventricle lengthens in the long-axis direction during diastole and reflects left ventricular relaxation. Its normal rate is $\geq 8 \mathrm{~cm} / \mathrm{s}$. If less than this rate, left ventricular diastolic dysfunction becomes more severe as the rate further decreases. The ratio of early transmitral flow velocity (E) to e' (E/e') is an index of left ventricular filling pressure. HF symptoms becomes more intense as E/e' increases, resulting in a poor vital prognosis.

The BNP or NT-proBNP level and echocardiographic findings can be used to make a diagnosis of $\mathrm{HF}$, to evaluate the pathology, and to determine the effectiveness of HF treatment. Treatment is considered to be effective if the left ventricular myocardial infarction mass index and left atrial volume index are reduced and if the BNP or NT-proBNP levels are reduced by lifestyle improvement and pharmacotherapeutic intervention.

\section{2.3 Arrhythmia (Atrial Fibrillation)}

Atrial fibrillation (AF) is the most common and the most clinically problematic arrhythmia in patients with diabetes. In general, AF is more commonly seen in patients with diabetes than in the general population, ${ }^{75}$ and the incidence of AF increases with advanced age. ${ }^{76}$ Epidemiological studies have shown that diabetes is an independent risk factor for AF and reported that AF occurrence is increased 1.4-1.6-fold that of individuals without diabetes. ${ }^{77-79}$ Hypertension and diabetes are the common underlying diseases in AF patients. ${ }^{80}$ Diabetes with underlying IR is involved in the onset of AF through various mechanisms, including IGT, increased inflammation and oxidative stress, hypercoagulability, increased platelet activity, hypertension, and myocardial fibrosis. ${ }^{\mathbf{8 1}, \mathbf{8 2}}$ If HFpEF or HFrEF coexists with diabetes, left atrial load increases, promoting AF onset. In contrast, sporadic arrhythmias, such as premature atrial and premature ventricular contractions, seldom become a clinical problem. Ventricular tachycardia is a dangerous arrhythmia, but is rare. It is necessary to be cautious of ventricular tachycardia in patients with hypoglycemia risk and those with organic heart disease.

Diabetes increases the incidence of stroke in AF patients. The $\mathrm{CHADS}_{2}$ score $^{83}$ stratifies the risk of stroke in AF patients. This scoring system uses stroke risk factors: hypertension, age $\geq 75$ years, presence of HF, previous stroke/transient ischemic attack, and diabetes. The $\mathrm{CHA}_{2} \mathrm{DS}_{2}-\mathrm{VASc}^{84}$ score also uses diabetes as a risk factor. In the era of direct oral anticoagulants (DOACs), AF patients just by having diabetes are considered a group that could benefit from stroke prevention using DOACs.

AF can be a trigger for both stroke and HF. If patients have both type 2 diabetes and AF, they have higher rates of all-cause death, myocardial infarction, HF, and cardiovascular events compared with non-AF patients. ${ }^{\mathbf{8 5 , 8 6}}$ That is, $\mathrm{AF}$ is not merely an arrhythmia but is a biomarker of high-risk among patients with diabetes. In other words, if AF is observed in patients with diabetes, the cardiovascular risk is high. Such patients might be considered as a group that could highly benefit from comprehensive management using lifestyle improvement and pharmacotherapy. In reality, the awareness is low among physicians regarding AF in patients with diabetes, which presents a problem. 




\section{2.3.1 Flowchart for Diagnosis of AF (Figure 6)}

When patients with diabetes complain of palpitations, it is important to approach with suspicion of AF. In particular, if patients complain of palpitations due to tachycardia at the initial onset of AF, they often stop complaining when the symptoms transition to persistent AF. Therefore, AF is often considered asymptomatic. Even if there are symptoms, it is not uncommon to see non-specific symptoms such as lethargy, easy fatigability, exertional dyspnea, and (pre) syncope. Thus, both physicians and patients tend to shift their attention away from AF. Even if patients are asymptomatic, it is important to proactively diagnose $\mathrm{AF}$ because AF itself increases the risk of stroke, HF, cardiovascular events, and death.

It is important to take a history related to arrhythmia and perform a pulse check at each medical examination. Patients are advised to measure their blood pressure daily using an automated sphygmomanometer. Physicians might be able to obtain information on AF by merely asking if patients saw a measurement error message on their sphygmomanometer. It is also recommended to record 12-lead ECG at least once a year. If patients complain of palpitations during an outpatient visit, they should be aggressively evaluated using 12-lead ECG. If the symptoms had already resolved, Holter ECG should be considered. However, the results of 24-h Holter monitoring often do not lead to diagnosis. The usefulness of 72-h Holter ECG is also being examined in studies. The use of a non-looping event recorder should be considered in which an electrocardiogram is recorded by the patient pushing a button whenever symptoms are noticed. It is very important to have a mindset that $\mathrm{AF}$ is difficult to detect in patients with diabetes.

\section{Prevention and Treatment}

\section{Prevention and Treatment of Macroangiopathies (Coronary Artery Disease and Peripheral Artery Disease) in Patients With Impaired Glucose Metabolism}

\subsection{Lifestyle Intervention}

1.1.1 Physical Activity/Exercise

\section{(a) Physical Activity/Exercise as Primary Prevention}

\section{i. Introduction}

In patients with type 2 diabetes, physical activity/exercise improves glycemic control and reduces risk factors for cardiovascular disease. Such exercise includes aerobic exercise, resistance exercise, and their combination. In patients with type 2 diabetes, aerobic exercise and resistance exercise are independently effective for glycemic control and their effectiveness increases when used together.

\section{ii. Effectiveness of Exercise Therapy}

Physical activity/exercise for type 2 diabetes improves glycemic control ${ }^{87-92}$ and reduces cardiovascular disease risk factors, which are obesity, ${ }^{\mathbf{9}}$ accumulation of visceral fat, ${ }^{, 4,95}$ IR, ${ }^{96}$ dyslipidemia, ${ }^{94,97-101}$ hypertension,,${ }^{93,99,100,102}$ and chronic inflammation. ${ }^{101,103}$ The level of glycemic improvement differs according to intervention duration, intensity, frequency, and type of exercise. When a metaanalysis study was performed on physical activity/exercise of at least 8 weeks (average 3.4 times/week for 18 weeks), significant weight loss was not observed but $\mathrm{HbAlc}$ was significantly improved $(-0.66 \%){ }^{88}$

In another meta-analysis study, the effects of physical activity/exercise on cardiopulmonary function in patients with type 2 diabetes were examined. Maximal oxygen consumption significantly increased $(11.8 \%)$, when individuals performed exercise with average characteristics of approximately $50 \mathrm{~min} / \mathrm{session}, 3-4$ sessions/week for 20 weeks. The exercise intensity range was $50-75 \%$ of maximal oxygen consumption. ${ }^{104}$

The usefulness of high-intensity interval training is beginning to be shown. A meta-analysis study examined the effectiveness of 2-16-week, high-intensity interval training ${ }^{105}$ against metabolic syndrome and type 2 diabetes. The training better improved fasting plasma glucose and HbAlc levels in patients with such disease than in the control group. However, these levels did not significantly improve in the 
high-intensity interval training patients compared with patients performing continuous exercise training. The effects of shorter period of high-intensity interval training on longer term glycemic control and safety are unknown, and there is insufficient evidence to clinically implement this therapy.

At present, moderate- to high-intensity aerobic exercise is recommended for at least $150 \mathrm{~min} /$ week (at least 3 days/ week with no more than 2 consecutive days between exercise). High-intensity or interval training exercise might be able to produce similar effects within a shorter time ( $75 \mathrm{~min} /$ week) for young individuals or patients with high cardiopulmonary function..$^{\mathbf{1 0 6}, 107}$

Evidence has been accumulating on the effectiveness of resistance exercise, which increases muscle mass and strength, and improves IR and glycemic control. ${ }^{87,88,91,92,94}$ In general, it is recommended that the individual begins with 8-10 types of resistance exercise, involving major muscle groups, with $10-15$ repetitions ( $1 \mathrm{set}$ ) performed $2-3$ days per week. It is also recommended that the individual gradually increases the intensity or number of sets. ${ }^{106} \mathrm{~A}$ study has compared aerobic exercise, resistance exercise, and their combination and showed that the combination had a more enhanced effect on $\mathrm{HbA} 1 \mathrm{c}$ reduction. ${ }^{\mathbf{9 7}, 108}$ Resistance exercise has also been shown to have a noninferior effect on $\mathrm{HbA1c}$ reduction compared with aerobic exercise. ${ }^{109,110}$ Thus, resistance exercise can be an option for patients such as the elderly, who have difficulty with aerobic exercise. There is evidence of its effectiveness in the elderly, ${ }^{\mathbf{1 1 1}}$ and its more proactive implementation is anticipated.

It has been indicated that weight loss and prognostic improvement can be promoted by not only exercise but also increasing routine daily physical activities (non-exercise activities). There is a large difference in non-exercise activity thermogenesis (NEAT) between obese individuals and individuals with ideal body weight, and this difference has been suggested to have a great effect on the development of obesity. In addition, mortality rate and cardiovascular disease have been indicated to increase with increasing duration of being seated in daily living. ${ }^{\mathbf{1 1 2}}$ When patients with type 2 diabetes perform light exercise once every $30 \mathrm{~min}$, their postprandial hyperglycemia improves compared with when they remain seated. ${ }^{113}$ Individuals are recommended to stand up and engage in light exercise after $30 \mathrm{~min}$ in a seated position. Epidemiologically, it has been shown that when patients with diabetes have a higher level of physical activity, including exercise and daily physical activities (non-exercise activities), both the onset of cardiovascular disease onset and all-cause death are lower.114

\section{iii. Medical Evaluation Before Beginning Physical Activity/ Exercise (Medical Checkup)}

Before patients start physical activity/exercise, it is important to examine the necessity of restrictions on physical activity/exercise based on their physical condition, including orthopedic disorders and complications such as retinopathy, nephropathy, and neuropathy. ${ }^{107}$

Screening for cardiovascular disease is generally unnecessary if patients are asymptomatic and the exercises are of low to moderate intensity (within the extent of non-exercise activities, such as brisk walking). If they are performing exercise of a higher intensity than routine activity or at high-risk of cardiovascular disease, then their primary care physicians should consider screening and exercise stress testing as needed. ${ }^{115}$

If patients have diabetic retinopathy that is or more severe than pre-proliferative retinopathy, they should refrain from activities that involve jumping, have a high impact on their bodies, lowering of the head, and straining and stopping of breath (e.g., Valsalva maneuver). ${ }^{107}$ In patients with microalbuminuria, urinary protein levels can transiently increase after exercise but the progression of nephropathy is thought to be unaffected. Instead it has been suggested that a certain level of physical activity can




inhibit the onset and progression of nephropathy. Patient guidance to increase physical activities is generally recommended, even in patients with a condition more severe than overt nephropathy. The aim of such guidance is to improve physical function and QOL with exercise, but implementation is based on consideration of each individual. In patients with peripheral neuropathy, caution is required regarding the development of foot ulcer due to physical activities, and proper foot care is needed. Patients with autonomic neuropathy commonly have exercise-induced adverse events for reasons such as reduced circulatory response to exercise stress, orthostatic hypotension, impaired thermoregulation, and impaired vision. Cardiovascular autonomic neuropathy is an independent risk factor of cardiovascular death and silent myocardial infarction, and the implementation of physical activity/exercise depends on its severity. ${ }^{107}$ If patients have bone or joint disease, there should be coordination with an orthopedic department for appropriate exercises that include flexibility and resistance exercise for affected joints and do not place excessive load. ${ }^{107}$

\section{iv. Specific Types of Physical Activity/Exercise}

Physical activity/exercise is divided into aerobic exercise and resistance exercise. Each type of exercise is effective in improving IR and glycemic control. When both types of exercise are performed, glycemic control is expected to further improve. Aerobic exercise is expected to improve endurance, and resistance exercise is expected to increase muscle strength and skeletal muscle mass. Thus, it is advisable to perform both types of exercises (Figure 7). ${ }^{106}$

The recommended aerobic exercise is moderate intensity, and the amount is at least $150 \mathrm{~min} /$ week and at least 3 days/ week with no more than 2 consecutive days between exercise. The recommended amount of resistance exercise is 2-3 times/week with no consecutive days of exercise. Patients are advised to perform both exercises unless contraindicated, to avoid being routinely in a prolonged seated position, and to engage in light activity at 30 -min breaks. ${ }^{106,107}$

\section{(1) Aerobic Exercise}

The recommended target intensity of aerobic exercise is moderate (40-60\% of maximal oxygen consumption) based on risk and effectiveness. The common indices of exercise intensity are heart rate and rating of perceived exertion (RPE), which is represented by a Borg index score (Table 3). It is advisable to first implement low-intensity physical activity/exercise and gradually increase the intensity over time. For example, if patients are newly implementing aerobic exercise, they should aim for less intense exercise even within moderate-intensity exercise (50-60\% of maximal heart rate; Borg index of 11-12 (approximate intensity= fairly light)). HbAlc is expected to become lower with increasing intensity of exercise. ${ }^{116}$ Therefore, as patients become accustomed to the exercises, a slight increase in intensity can be considered ( $60-70 \%$ of maximal heart rate; Borg index of 12-13 (approximate intensity=somewhat hard); approximately 4-6 metabolic equivalents (METs)) (Table 4). However, it is difficult to determine the appropriate exercise intensity using pulse rates in some patients such as those with autonomic neuropathy, the elderly, and patients using an antihypertensive drug ( $\beta$-blocker).

A meta-analysis of supervised aerobic exercise training showed that HbAlc was reduced more in the group doing at least $150 \mathrm{~min} /$ week of exercise compared with the group doing less exercise. ${ }^{87}$ Thus, $150 \mathrm{~min} /$ week is used as a standard minimum goal for the duration of aerobic exercise. Because insulin sensitivity is increased not only during exercise but for approximately $24-48 \mathrm{~h}$ after exercise, the exercise frequency should be at least 3 times per week with no more than 2 consecutive days between exercise. It is desirable to perform exercises for at least $10 \mathrm{~min} / \mathrm{session}$ but to eventually increase to approximately $10-30 \mathrm{~min}$ or more.

Postprandial hyperglycemia has been reported to improve when light aerobic exercise (walking) of $3 \mathrm{~min}$ is performed every $30 \mathrm{~min}$ after a meal. ${ }^{113}$ In addition to incorporating aerobic exercise, patients are advised to minimize as much as possible being seated, to engage in light activity at least once every $30 \mathrm{~min}$, and to increase daily physical activities (non-exercise activities).

(2) Resistance Exercise

Generally, a resistance exercise program is first implemented

\begin{tabular}{|c|c|c|}
\hline \multicolumn{3}{|c|}{ Table 3. Borg Index and Rating of Perceived Exertion (RPE) } \\
\hline $\begin{array}{c}\text { Index } \\
\text { (scale) }\end{array}$ & RPE & Exercise intensity \\
\hline 20 & Maximal exertion & 100 \\
\hline 19 & Very very hard & 95 \\
\hline 18 & & \\
\hline 17 & Very hard & 85 \\
\hline 16 & & 70 \\
\hline 15 & Hard & \\
\hline 14 & & \\
\hline 13 & Somewhat hard & 55 (corresponds to AT) \\
\hline 12 & & \\
\hline 11 & Fairly light & \\
\hline 10 & & \\
\hline 9 & Very light & \\
\hline 8 & & \\
\hline 7 & Very very light & \\
\hline 6 & & \\
\hline
\end{tabular}

AT, anaerobic threshold.

\begin{tabular}{|l|l|c|l|l|}
\hline \multicolumn{3}{|c|}{ Table 4. Physical Activities Equivalent to 1 Exercise Unit (Ex) } \\
\hline \multicolumn{2}{|c|}{ Exercise } & Intensity & \multicolumn{2}{|c|}{ Daily activities (non-exercise) } \\
\hline Light weight lifting: 20 min & Playing volleyball: 20 min & $3 \mathrm{METs}$ & Walking: 20 min \\
\hline Golfing: $15 \mathrm{~min}$ & Brisk walking: $15 \mathrm{~min}$ & $4 \mathrm{METs}$ & Bicycling: 15 min & $\begin{array}{l}\text { Playing with a } \\
\text { child: } 15 \mathrm{~min}\end{array}$ \\
\hline Light jogging: $10 \mathrm{~min}$ & Aerobic exercising: 10 min & $6 \mathrm{METs}$ & Walking up and down the stairs: 10 min \\
\hline Running: 7-8 min & Swimming: 7-8 min & $8 \mathrm{METs}$ & Moving a heavy load: 7-8 min \\
\hline
\end{tabular}


with a frequency of 2-3 non-consecutive days per week and 8-10 types of exercise that involve muscles of the upper and lower body. The patients begin with 1 set with a load permitting $10-15$ repetitions. The load is gradually increased thereafter and the target is $1-3$ sets with a load permitting 8-12 repetitions per set.

\section{(3) Practical Physical Activity/Exercise Prescription}

Physical activity/exercise is prescribed according to each individual's physical fitness level (endurance and muscle strength), age, complications, and lifestyle. Walking is the most commonly performed aerobic exercise, and a metaanalysis has shown that walking exercise alone improves glycemic control. ${ }^{93}$ A pulse rate of $100-120$ pulses/min is used as a reference for exercise intensity in individuals aged less than 50 years and less than 100 pulses/min in individuals aged 50 years or older. The perceived intensity should be at the level of "fairly light" when the therapy is first implemented. When a patient becomes used to the exercise, a physician should consider increasing the intensity to the level of "somewhat hard" depending on the patient's condition. The first and last $5 \mathrm{~min}$ of the exercise program are warm-up and cool-down periods during which the load is gradually increased and decreased, respectively.

Aerobic exercise is performed with a goal of approximately $150 \mathrm{~min} /$ week. A recent study has compared patients who underwent a supervised exercise program using time as a goal and patients who self-managed using pedometerbased steps as a goal. The study showed that physical activity/exercise adherence and plasma glucose reduction were superior in the latter patients. ${ }^{117}$ A meta-analysis study also showed that the use of a pedometer and an activity tracker was effective in increasing the amount of activity. ${ }^{118}$ If the number of steps is used as an index, approximately 15,000 walking steps are equivalent to $150 \mathrm{~min}$ of aerobic exercise/week. If the number of steps is equally distributed per day, then the rate of 2,000+ steps/day can be used a goal. Eventually, patients should use a daily total of approximately 8,000 steps as a reference. ${ }^{119}$

Caution is required in patients using pharmacotherapy, such as insulin or SU, because they are prone to hypoglycemia if they exercise while fasting. Patients are instructed to take a snack for nutritional supplementation if their blood glucose is low before exercising.

For resistance exercise, patients are recommended to use weight machines, free weights, elastic resistance bands (rubber and silicone), or body weight based on their goals. ${ }^{107}$ Elderly patients with diabetes are more susceptible to muscle mass loss than patients without diabetes. ${ }^{120}$ Thus, resistance exercise is likely be emphasized in aging societies in the future.

\section{(b) Exercise Therapy as Secondary Prevention}

\section{i. What Is Cardiac Rehabilitation?}

Cardiac rehabilitation is a comprehensive activity program performed with the goals of helping heart disease patients recover their physical fitness, regain their confidence, return to comfortable family and social lives, and prevent



Figure 8. Cardiac rehabilitation team. 




Figure 9. Flowchart for exercise therapy prescription. Reproduced from The Japanese Circulation Society guidelines for rehabilitation in patients with cardiovascular disease. 2012 revised edn (in Japanese). p. 23 (figure 1). http://www.j-circ.or.jp/ guideline/pdf/JCS2012_nohara_h.pdf (accessed Jan. 27, 2020).

recurrence and rehospitalization. The program includes exercise therapy, educational activities, lifestyle guidance, and counseling. When patients have/had HF, myocardial infarction, angina pectoris, or heart surgery, the patients' cardiac function has been reduced, or their exercise capacity and their body's regulatory function are decreased due to prolonged rest. They are, therefore, unable to engage in intense activities soon after hospital discharge and can be apprehensive about the safe level of activity.

It is useful to implement appropriate exercise therapy through cardiac rehabilitation to address the aforementioned issues. Cardiac rehabilitation also aims to prevent the progression of atherosclerosis, which causes heart disease, through dietary counseling and smoking cessation intervention. In cardiac rehabilitation, multidisciplinary health professionals are involved, such as physicians with specialized knowledge, physical therapists, nurses, pharmacists, clinical psychologists, medical technologists, occupational therapists, and health fitness instructors. These professionals plan and implement an effective rehabilitation program for an individual patient depending on his/her condition (Figure 8).

\section{ii. Evidence for the Effectiveness of Cardiac Rehabilitation} Many reports have shown that cardiac rehabilitation, focusing on exercise therapy, is effective for secondary prevention of ischemic heart disease.121,122 In 1982, May et al published a meta-analysis of 6 large-scale randomized trials and reported that cardiac rehabilitation can be expected to reduce the mortality rate by $21-32 \%{ }^{\mathbf{1 2 3}}$ In 2011 , Heran et al published a systematic review on secondary prevention of CAD, involving 10,794 subjects from 47 studies in the Cochrane database. ${ }^{\mathbf{1 2 4}}$ Cardiac rehabilitation with exercise as the core component reduced all-cause death by $18 \%$ in 6-12 months and by $13 \%$ in 1 year or more. Cardiac rehabilitation also reduced cardiovascular death by $26 \%$ in 1 year or more and rehospitalization by $31 \%$ within 12 months. ${ }^{\mathbf{1 2 4}}$ After treatment for acute coronary syndrome had greatly advanced, van Halewijn et al125 performed a meta-analysis of 18 randomized controlled trials on cardiovascular prevention and rehabilitation, involving 7,691 individuals and published between 2010 and 2015. Although all-cause death was not reduced, cardiovascular death was reduced by $58 \%$, myocardial infarction by $30 \%$, and cerebrovascular disease by $60 \%$. All-cause death was reduced by $37 \%$ in patients who underwent comprehensive cardiac rehabilitation, which included the management of at least 6 risk factors. ${ }^{\mathbf{1 2 5}}$ Dibben et al performed a meta-analysis of 40 randomized controlled trials and reported that cardiac rehabilitation increased physical activity. ${ }^{126}$ Therefore, comprehensive cardiac rehabilitation is considered essential to prolong the healthy lifespan of patients with heart disease.

Comprehensive cardiac rehabilitation, which improves various coronary risk factors, is particularly effective as secondary prevention in patients with type 2 diabetes. Exercise therapy has been reported to improve IR, IGT, and postprandial hypoglycemia. ${ }^{\mathbf{1 2 7 - 1 2 9}}$ A retrospective study of PCI from 1994 to 2010 in Olmsted County (Minnesota) in the USA with a median follow-up of 8.1 years showed that via cardiac rehabilitation patients with diabetes were able to reduce all-cause death by $44 \%$ and the composite endpoint of death, myocardial infarction, or revascularization by $23 \%$. The patients without diabetes were able to 
reduce all-cause death by $33 \%$ and cardiac death by $33 \%$ via cardiac rehabilitation. ${ }^{130}$ Therefore, patients with diabetes can expect a reduction in mortality rate similar to that of patients without diabetes. However, in that study there was a significantly lower percentage of patients with diabetes who participated in cardiac rehabilitation $(38 \%)$ compared with patients without diabetes $(45 \%){ }^{130}$ Cardiac rehabilitation is said to be less prevalent in Japan than in Europe or the USA. Thus, in Japan, it is necessary to increase its prevalence to improve vital prognosis and QOL of patients with diabetes and heart disease.

\section{iii. Practical Cardiac Rehabilitation}

In Japan, the "Guidelines for rehabilitation in patients with cardiovascular disease" were first developed in 2012 and they include basic strategies and outline their implementation. ${ }^{122}$ The Japanese Association of Cardiac Rehabilitation has released on its website a standard program for myocardial infarction in the acute and recovery phases (2013), and one for HF (2017) to maintain the quality of care in cardiac rehabilitation. Each institution is encouraged to refer to the guidelines and implement standard programs to promote cardiac rehabilitation.

Figure 9 is a flowchart of implementing exercise therapy after evaluation of its indications, contraindications, and risks in healthy individuals and patients with cardiovascular disease. For specific exercise prescriptions, the "Exercise Standards for Health Promotion 2006" were developed by the Study Group for the Formulation of Recommended Exercise Allowance and Exercise Guide funded by the Japanese Ministry of Health, Labour and Welfare. The "Exercise Guidelines for Health Promotion 2006" promote the widespread use of such exercises. The Exercise Guide 2006 established a unit for the amount of exercise, "exercise: Ex (METs $\times$ exercise duration)". In the guide, the goal is to perform exercise of at least 23 Ex per week to prevent lifestyle-related disease. At least 4 Ex should be active exercising, such as playing sports. Table 4 shows the amount of exercise equivalent to 1 Ex.

It is generally necessary to have an exercise prescription for exercise therapy in heart disease patients. The 5 components of an exercise prescription are (1) exercise type, (2) exercise intensity, (3) exercise duration, (4) exercise frequency, and (5) repeat prescription based on increased physical activity level. ${ }^{121}$ Training comprises warm-up, endurance exercise, resistance training, additional exercises such as recreational activities, and cool-down. It is recommended that endurance training be performed 3-5 times/ week and complementary resistance training be performed 2-3 times/week. ${ }^{\text {122,131 }}$

Exercise prescription is based on the results of a symptomlimited, multistage stress test using a treadmill or bicycle ergometer. It is also useful to measure anaerobic threshold (AT) and maximal oxygen consumption assessed by expiratory gas analysis as well as ECG, heart rate, blood pressure response. ${ }^{\mathbf{1 2 1}}$ The exercise intensity used for aerobic exercise is at the AT or less and 50-70\% of maximal oxygen consumption (equivalent to $40-60 \%$ of maximal heart rate). ${ }^{\mathbf{1 3 2}}$ In Japan, an exercise stress test with expiratory gas analysis (cardiopulmonary stress test) is widely used, and exercise prescription is commonly based on the heart rate when the AT is reached (AT prescription). ${ }^{121}$ Exercise intensity equivalent to a Borg index of $11-13$ is recommended in prescriptions that are not based on heart rate (Table 3). ${ }^{121,122}$ Recently, the effectiveness of resistance training in addition to aerobic exercise has attracted attention. Muscle training is safe and effective when performed repeatedly using $60-80 \%$ of the maximum muscle strength. Exercise therapy is recommended in which resistance training is added to aerobic exercise and is performed as a part of comprehensive cardiac rehabilitation. ${ }^{\mathbf{1 2 1}, \mathbf{1 2 2}}$

\subsubsection{Smoking Cessation and Nutritional, Dietary, and Weight Management \\ (a) Smoking Cessation}

Many epidemiological studies have shown the causal relationship between smoking and macroangiopathies. Many studies in Japan and other countries have indicated their causal relationship in patients with diabetes alone. ${ }^{133,134}$ A recent meta-analysis study ${ }^{135}$ of prospective cohort studies showed that smoking is a risk factor for cardiovascular disease even when based only on patients with diabetes. The relative risk was particularly high in patients with PAD (relative risk for total cardiovascular diseases: 1.44, 95\% confidence interval (CI): 1.34-1.54; for CAD: 1.51 , 95\% CI: 1.41-1.62; PAD: 2.15, 95\% CI: 1.62-2.85). Many cohort studies and their meta-analyses have indicated that smoking cessation subsequently lowers the cardiovascular risk. ${ }^{136,137}$ Past smokers have been shown to have a higher risk of CAD. However, the point estimate of hazard ratio did not change after adjusting for weight change before and after smoking cessation in individuals who recently stopped smoking (within the past 4 years). Thus, even if individuals temporarily gain weight due to smoking cessation, it does not mean that this weight gain causes an increase in the risk of CAD. ${ }^{137}$ Smoking cessation should be prioritized despite the temporary weight-gain risk.

A meta-analysis of Japanese epidemiological studies showed that smoking is associated with an increased risk of type 2 diabetes. ${ }^{138}$ Patients with prediabetes are strongly recommended to avoid smoking also from the standpoint of preventing the macroangiopathy risk increased by diabetes onset.

Although there is no clear evidence on the hazard of e-cigarettes (including heated tobacco), their use is not recommended, at least in non-smokers.

\section{(b) Nutrition and Diet}

Diabetes and prediabetes are both risk factors for macroangiopathy. The Diabetes Prevention Program (DPP) studies have shown that a program focusing on weight loss reduced the risk of diabetes in individuals with prediabetes. ${ }^{15,139}$ In the Look AHEAD (Action for Health in Diabetes) study, glycemic control improved in patients with diabetes who underwent an intervention focusing on weight loss. ${ }^{\mathbf{1 4 0}}$ Based on these results, patients with diabetes and prediabetes are recommended to practice proper weight management via exercise and diet. Specifically, for obese patients in Japan, a 3\% loss from the current weight is thought to be appropriate as the target weight loss. In the aforementioned Look AHEAD study, a weight-loss focused intervention was performed in adult patients with type 2 diabetes who were overweight or obese (intervention group). However, the intervention group and the control group did not differ in the rate of cardiovascular events (cardiovascular death, nonfatal myocardial infarction, nonfatal stroke, and hospitalization for angina). This trial was stopped at the interim analysis (hazard ratio: $0.95,95 \% \mathrm{CI}$ : 0.83-1.09). ${ }^{\mathbf{1 4 0}}$ One of the reported reasons for the lack of difference was that the intervention group had poor adherence to weight 
management.

The Steno-2 $2^{\mathbf{1 4 1}}$ trial and the Japan Diabetes Complications Study ${ }^{\mathbf{1 4 2}}$ were randomized controlled trials in patients with type 2 diabetes that compared comprehensive therapeutic intervention and conventional therapy on modifiable risk factors for cardiovascular disease. They found that in the comprehensive therapeutic intervention group the incidence of cardiovascular events was lowered compared with the conventional therapy group. However, in the Japan Diabetes Optimal Integrated Treatment study for 3 major risk factors of cardiovascular diseases (J-DOIT3), patients with type 2 diabetes and conventional therapy and those with comprehensive therapeutic intervention showed no significant difference in the frequency of the primary outcome (myocardial infarction, stroke, revascularization, or all-cause death) (hazard ratio: 0.81, 95\% CI: 0.63-1.04, $\mathrm{P}=0.094) .{ }^{143}$ The comprehensive intervention group had significantly more smokers than the conventional therapy group at baseline. When analysis was performed adjusting for predetermined factors, including smoking, the comprehensive intervention group had a significantly lower frequency of the primary outcome (hazard ratio: $0.76,95 \%$ CI: $0.59-0.99, \mathrm{P}=0.042$ ). Another reason for the insignificant difference in the primary analysis could have been a statistical power that was lower than expected. There has been a yearly decline in complication frequencies among patients with diabetes as a whole, which could have resulted in the lower statistical power.

A significant relationship has been reported between reduction of cardiovascular events and several dietary patterns, including the Dietary Approaches to Stop Hypertension (DASH) diet $^{144}$ and the Mediterranean diet. ${ }^{145}$ Although these diets were not designed as antidiabetic measures, their effectiveness has been reported in patients with pre-diabetes ${ }^{\mathbf{1 4 6}}$ and diabetes. ${ }^{147}$ However, there has been no agreement of opinion on the recommended percentages of macronutrients in patients with diabetes. In particular, there is conflicting information on the effectiveness of a low carbohydrate diet. Although a low carbohydrate diet is thought to improve glycemic control, at least in the short term, this diet might not be beneficial in the long term. A recent study has shown that a low carbohydrate diet is associated with increased mortality, an association similar to that of a high carbohydrate diet. ${ }^{\mathbf{1 4 8}}$

Intakes of fats and saturated fatty acids are lower in Japan than in Europe or the USA. The Dietary Reference Intakes for Japanese (2020 edn $)^{\mathbf{1 4 9}}$ has established a total fat intake of 20-30 energy percent as appropriate in adults, which is lower than that in the US dietary guidelines (2535 energy percent). ${ }^{150}$ There is insufficient basis for a stricter intake level in patients with diabetes. As with other nutrients, the intake level of fats should be based on the individual's pathological condition and preferences. However, one should be mindful about the quality of fats when increasing the percentage of dietary fat. The target intake of saturated fatty acids is recommended to be $\leq 7$ energy percent. There is insufficient evidence that a large intake of n-3 fatty acids (such as EPA and DHA) reduces the risk of diabetes or the risk of cardiovascular disease in patients with diabetes. Thus, a target intake has not been established for n-3 fatty acids.

In elderly patients with diabetes, sarcopenia prevention needs to be considered when their nutritional intake is examined. Sarcopenia is defined by the loss of skeletal muscle mass related to advancing age and either loss of muscle strength or decline in physical function. ${ }^{151}$ Studies have suggested an association between cardiovascular disease and sarcopenia. In the UK, it has been reported that sarcopenia, particularly sarcopenia obesity (sarcopenia combined with obesity or high body fat), increased the risk of death from cardiovascular disease and the risk of allcause death. ${ }^{\mathbf{1 5 2}}$ A cross-sectional study in South Korea has shown relationships between a high Framingham risk score and sarcopenia, and between a high score and sarcopenia obesity. ${ }^{153}$ For prevention and inhibition of sarcopenia development, the "Guidelines for the Management of Sarcopenia 2017" recommended, in addition to exercise, appropriate nutritional intakes - in particular, a daily protein intake of at least $1.0 \mathrm{~g} / 1 \mathrm{~kg}$ (ideal body weight). This intake amount has been indicated to be potentially effective for sarcopenia prevention. ${ }^{\mathbf{1 5 1}}$ If patients also have kidney disease, then the aforementioned intake obviously conflicts with management recommendations for kidney disease. Thus, the individual patient's condition should be considered when setting priorities.

Evidence from the Japan Diabetes Complications Study indicated that excessive intake of dietary sodium increases the risk for cardiovascular disease in patients with diabetes, particularly those with poor glycemic control, ${ }^{154}$ but another study had a contradictory result. ${ }^{155}$ Therefore, there is no clear basis to establish a special reference for dietary sodium intake for patients with diabetes. The target sodium intakes in the Dietary Reference Intakes for Japanese are used: $<7.5 \mathrm{~g} /$ day for men, $<6.5 \mathrm{~g} /$ day for women, and $<6.0 \mathrm{~g} /$ day for patients with hypertension or with nephropathy more severe than overt nephropathy.

Guidelines are being revised based on new findings, including those mentioned above. The "Japanese clinical practice guidelines for diabetes 2019" includes revised methods for establishing total energy intake, macronutrient intake amounts, and percentages of energy from macronutrient intakes. For long-term sustainable and effective dietary therapy, it is necessary to flexibly establish total energy intake and the percentage of energy from each macronutrient intake and to change them as needed. Such an approach can be based on the patient's physical activity level, pathological condition, and complications, or based on test results, body weight/composition changes, and the patient's preferences.

\section{(c) Summary}

This chapter outlined lifestyle management to prevent macroangiopathies in patients with impaired glucose metabolism. Such lifestyle management includes smoking cessation and nutritional, dietary, and weight management. Table 5 presents a summary.

\section{I.2 Pharmacotherapies}

\subsubsection{Antidyslipidemic, Antihypertensive, and Antiplatelet Drugs (a) Pharmacotherapy for Hypertension}

Hypertension is more frequently seen in patients with diabetes than patients without diabetes. When patients with diabetes also have hypertension, the risks of macroangiopathy and death have been shown to increase. ${ }^{156}$ In addition, the risk of diabetic microangiopathy increases with hypertension. ${ }^{157}$ Therefore, management and treatment of hypertension are very important in patients with diabetes. Treatment of hypertension is begun at blood pressures of 


\begin{tabular}{|c|c|c|}
\hline \multicolumn{2}{|l|}{ Smoking } & $\begin{array}{l}\text { - Smoking cessation is strongly recommended. } \\
\text { - New use of e-cigarettes (including heated tobacco) is not recommended, at least in non-smokers. }\end{array}$ \\
\hline \multirow[t]{4}{*}{ Dietary therapy } & Body weight & $\begin{array}{l}\text { - In obese patients, the immediate target weight loss is } 3 \% \text { of the current weight, which is achieved } \\
\text { through exercise and diet. } \\
\text { - Caution is required for sarcopenia and sarcopenia obesity. } \\
\text { - Target weight and total energy intake are established with consideration of various factors, including } \\
\text { age, obesity level, physical activity level, and pathological condition. }\end{array}$ \\
\hline & Dietary pattern & $\begin{array}{l}\text { - DASH diet and Mediterranean diet have been reported to be effective in patients with diabetes. } \\
\text { - There is no conclusion on the recommended percent energy intakes from macronutrients. }\end{array}$ \\
\hline & Fats & $\begin{array}{l}\text { - Although there is insufficient evidence, the following can be used as a reference: } \\
\text { - Percent energy intake from fat: } 20-30 \% \\
\text { - From saturated fatty acids: } \leq 7 \% \\
\text { - If the percent energy intake from fat exceeds } 25 \% \text {, then consideration is made about the fatty acid } \\
\text { composition. }\end{array}$ \\
\hline & Dietary salt & $\begin{array}{l}\text { - Patients with hypertension and patients with nephropathy more severe than overt nephropathy: } \\
<6.0 \mathrm{~g} / \text { day } \\
\text { - Other patients: }<7.5 \mathrm{~g} / \text { day for men and }<6.5 \mathrm{~g} / \text { day for women. }\end{array}$ \\
\hline
\end{tabular}



Figure 10. Treatment algorithm for patients with diabetes and hypertension. ACE, angiotensin-converting enzyme inhibitor; ARB, angiotensin-receptor blocker. 




Figure 11. Treatment algorithm for patients with diabetes and dyslipidemia (hyper-low-density lipoprotein cholesterolemia). LDL-C, low-density lipoprotein cholesterol.

$\geq 130 / 80 \mathrm{mmHg}$ in patients with diabetes. Hypertension is initially addressed by weight control through nutritional and dietary counseling, exercise therapy focusing on aerobic exercise, sodium intake reduction to $6 \mathrm{~g} / \mathrm{day}$, and improvement of lifestyle habits such as smoking cessation. If the target blood pressure of less than $130 / 80 \mathrm{mmHg}$ is not achieved after 1 month, then pharmacotherapy is considered. There is a higher risk for stroke in Japan than Europe or the USA. Thus, the target systolic blood pressure of less than $130 \mathrm{mmHg}$ has been established, based on the results of the ACCORD-BP trial. ${ }^{158}$

Patients with diabetes are first tested for microalbuminuria $(\geq 30 \mathrm{mg} / \mathrm{g} \mathrm{Cr}$ ) or proteinuria before the selection of the antihypertensive drug. If present, an angiotensin-converting enzyme (ACE) inhibitor (which is a renin-angiotensin system (RAS) inhibitor) or angiotensin-receptor blocker (ARB) is first considered. If absent, then a RAS inhibitor, calcium-channel blocker (CCB), or low-dose thiazide diuretic is considered as monotherapy. RAS inhibitors have been demonstrated in many studies to have not only an antihypertensive effect, but also a renoprotective effect, insulin-sensitizing effect, and inhibitory effect on new-onset diabetes ${ }^{\mathbf{1 5 9}-162}$ (Figure 10). If the antihypertensive effect of these first-line drugs is insufficient, dual therapy is used, consisting of a RAS inhibitor, CCB, and/or low-dose thiazide diuretic. ${ }^{163-165}$ If there is still inadequate blood pressure control, triple therapy is used. If the patient has renal dysfunction, there is the option of RAS monotherapy with an increased dose. However, hypertension is insufficiently controlled by antihypertensive monotherapy in many patients with diabetes and hypertension. A combination of ACE inhibitor and ARB is not recommended because it does not reduce cardiovascular events compared with an ACE inhibitor or ARB alone. Instead, this combination therapy increases adverse events such as hypotension and hyperkalemia. ${ }^{\mathbf{1 6 6}}$ Aliskiren, a direct renin inhibitor, causes excessive hypotension, hyperkalemia, and renal dysfunction. Therefore, it is contraindicated in patients with diabetes currently using an ACE inhibitor or ARB. ${ }^{167}$ Organ protective effects are not as clear with $\alpha$-blockers as 
with other drugs, and $\beta$-blockers increase IR and elevate triglycerides. These agents are not first-line drugs for patients with diabetes, except in special cases where they also have tachycardia or $\mathrm{HF}$.

\section{(b) Pharmacotherapy for Dyslipidemia}

Patients with diabetes are prone to dyslipidemia, such as hyper-LDL-cholesterolemia, hypo-HDL-cholesterolemia, and hypertriglyceridemia. ${ }^{168}$ LDL-C is the strongest risk factor for macrovascular diseases in patients with diabetes. ${ }^{\mathbf{1 6 9 , 1 7 0}}$ When Japanese patients with type 2 diabetes without a history of cardiovascular disease were analyzed in the Japan Diabetes Complications Study, LDL-C was the strongest risk factor for CAD. ${ }^{170}$ Others have examined the relationship between cardiovascular disease onset and HDL-C and between the onset and triglycerides, reporting that hypo-HDL-cholesterolemia and hypertriglyceridemia increased the onset of macroangiopathy. ${ }^{171}$ These results, however, are not in agreement with other results, ${ }^{169}$ and there is no consensus. Hypertriglyceridemia and hypo-HDLcholesterolemia can be risk factors for microvascular diseases, including retinopathy, nephropathy, and neuropathy. ${ }^{172,173}$

The "Japan Atherosclerosis Society guidelines for prevention of atherosclerotic cardiovascular diseases 2017" have established therapeutic target levels for lipid control in patients with diabetes based on the presence/absence of a history of CAD (Figure 11). Such patients receive lifestyle guidance, including dietary guidance, exercise therapy, and smoking cessation guidance, after which pharmacotherapy is considered. ${ }^{174}$ If individuals are primary prevention patients with diabetes but without a history of CAD, they are considered high-risk and their therapeutic target of LDL-C is $<120 \mathrm{mg} / \mathrm{dL}$. On the other hand, if individuals are secondary prevention patients with a history of CAD, their target of LDL-C is $<100 \mathrm{mg} / \mathrm{dL}$. However, the target of LDL-C can be $<70 \mathrm{mg} / \mathrm{dL}$, if the individual has familial hypercholesterolemia, has had onset of acute coronary syndrome or has diabetes and a high-risk condition such as noncardiogenic stroke, PAD, CKD, metabolic syndrome, overlapping (multiple) major risk factors, and smoking.

The standard treatment is a statin. ${ }^{\mathbf{1 7 5}}$ The meta-analysis in the CTT Collaboration study showed that statin administration for dyslipidemia reduced LDL-C by $39 \mathrm{mg} / \mathrm{dL}$, resulting in s reduction of major cardiovascular events by $21 \% .{ }^{176}$ The LDL-C reduction via statin resulted in a significant risk reduction of CAD even in patients with diabetes without high LDL-C. ${ }^{177}$ When statin therapy is used for dyslipidemia in patients with diabetes, it is effective in reducing the risk of cardiovascular disease and improving vital prognosis regardless of age, CAD history, and type of diabetes (1 or 2). Therefore, statins are recommended as the first-line drug for such patients. The FIELD trial was conducted with patients with type 2 diabetes and showed that fenofibrate administration significantly reduced nonfatal myocardial infarction by $24 \% .{ }^{178}$ In addition, fenofibrate was associated with significantly less progression of diabetic retinopathy and diabetic nephropathy. In a meta-analysis, fibrates were associated with a significant $16 \%$ reduction of cardiovascular events. ${ }^{179}$ In the SHARP trial, ezetimibe was administered to patients who had renal dysfunction and were using statins. It found that cardiovascular events were reduced regardless of whether or not the patients had diabetes. ${ }^{180}$ In the IMPROVE-IT trial, ezetimibe was added to simvastatin therapy in high-risk patients, including those with diabetes, and major cardiovascular events were reduced by approximately $6.4 \%$. These events were reduced by $14.4 \%$ in the subanalysis of patients with diabetes. ${ }^{181}$ In a high-risk group with target LDL-C level $<70 \mathrm{mg} / \mathrm{dL}$, PCSK9 inhibitors should be used to aggressively reduce LDL-C. This high-risk group includes patients with diabetes and familial hypercholesterolemia. ${ }^{182}$ In such cases, it is necessary to prescribe the maximum tolerated dose of statin beforehand, except when contraindicated. It should be noted that PCSK9 inhibitors have recently been found to exacerbate diabetes. ${ }^{\mathbf{1 8 2}}$



Figure 12. Algorithm for antiplatelet administration for patients with diabetes. ADP, adenosine diphosphate; PCl, percutaneous coronary intervention. 


\section{(c) Antiplatelet Drugs}

Low-dose aspirin reduces cardiovascular events by $20-30 \%$ in patients at high risk for cardiovascular disease. ${ }^{183}$ In Japan, low-dose aspirin has also been shown to reduce CAD in a secondary prevention trial of CAD. ${ }^{184}$ Antiplatelet therapy, including low-dose aspirin therapy, has been established as effective in secondary prevention of CAD in patients with type 2 diabetes. For primary prevention, however, it has not been shown to be effective for significant risk reduction of cardiovascular events based on the results of large-scale clinical trials and their meta-analysis. ${ }^{185}$ The Japanese Primary Prevention of Atherosclerosis with Aspirin for Diabetes (JPAD) trial found that cardiovascular death was significantly reduced in a group with low-dose aspirin use than without, but low-dose aspirin did not significantly reduce the risk of other cardiovascular events. ${ }^{186}$ The group with low-dose aspirin use also tended to have a higher occurrence of serious bleeding events. Thus, low-dose aspirin use has not been recommended for patients with type 2 diabetes without a history of cardiovascular disease. However, it can be useful for primary prevention of cardiovascular events in a subgroup of patients with type 2 diabetes ${ }^{186-188}$ (Figure 12).

It has been reported that clopidogrel is more effective in secondary prevention of cardiovascular events in patients with type 2 diabetes compared with low-dose aspirin. ${ }^{189}$ However, future studies are necessary to establish the maintenance dose. Cilostazol has been reported to significantly increase the walking distance in patients with diabetes and PAD, and to be effective in secondary prevention of stroke in Japanese patients with type 2 diabetes. ${ }^{190,191}$

\section{1.2.2 Antidiabetic Drugs}

Microangiopathy incidence is reduced by decreased blood glucose (HbA1c), but there is no consensus on the relationship between the reduction in macroangiopathy incidence and blood glucose (HbAlc) reduction.,192-195 There is consensus on avoiding hypoglycemia and implementing long-term, comprehensive therapeutic interventions for prevention of macroangiopathies in patients with impaired glucose metabolism. ${ }^{2,196-198}$ When physicians examine the options for antidiabetic therapy for primary and secondary prevention of macroangiopathies, they should evaluate the patient's age, duration of diabetes, comorbidities, and complications. In addition, they should carefully consider the drug's pharmacological characteristics and cardiovascular effects, as well as the results of clinical trials (Table 6).

This section will describe the evaluation indices for intervention effectiveness, focusing on the prevention of hard endpoints (noted as 3P-MACE or cardiovascular events). These endpoints consist of cardiovascular death, stroke, and myocardial infarction.

\section{(a) Biguanide}

In Europe and the USA, biguanide (metformin) is recognized as a first-line drug to treat diabetes. One reason is that it is medically economical. Metformin can be expected to reduce macroangiopathy risk in obese patients with diabetes. It is important to note that results for metformin are from trials in Europe and the USA, where the pathophysiology of diabetes and metformin doses differ from those in Japan.

In recent years, several cardiovascular outcome trials have been conducted for antidiabetic drugs and have demonstrated that the addition of some novel antidiabetic drugs to metformin therapy is effective in the high-risk group for cardiovascular events. However, it is unknown whether metformin monotherapy is more effective in the reduction of macroangiopathy risk compared with novel antidiabetic drugs. A meta-analysis study has been conducted on past clinical trials from which subgroups of metformin and placebo (or non-pharmacotherapy) groups were extracted. There tended to be reduced risks of cardiovascular outcomes (all-cause death, cardiovascular death, myocardial infarction, and PAD), excluding stroke. However, no significant difference in risk reduction was observed between the metformin and placebo groups. ${ }^{199}$

\section{(b) Thiazolidinediones}

There is certain evidence that pioglitazone prevents macroangiopathies in patients with impaired glucose metabolism who also have high IR and a high cardiovascular risk. When pioglitazone and SU were compared, pioglitazone showed a significantly higher rate of regression and a significantly lower rate of progression of surrogate markers for arteriosclerosis, such as coronary artery plaque and carotid IMT. ${ }^{200,201}$ Pioglitazone is thought to be an antidiabetic drug with an anti-arteriosclerotic effect, but caution is required as it can exacerbate HF.

\section{(c) Alpha-Glucosidase Inhibitors}

Alpha-glucosidase inhibitors regulate postprandial hyperglycemia, and are useful in the prevention of macroangiopathies, including myocardial infarction, in patients with IGT (mainly in the primary prevention of cardiovascular disease group). However, in patients with type 2 diabetes, no evidence has been established that $\alpha$-glucosidase inhibitors reduce macroangiopathies, improve vital prognosis, ${ }^{\mathbf{2 0 2 , 2 0 3}}$ are effective in a secondary prevention of cardiovascular disease, or have a class effect.

\section{(d) DPP-4 Inhibitors}

At present, DPP-4 inhibitors have not been demonstrated to reduce the macroangiopathy risk in patients with type 2 diabetes and a high-risk for cardiovascular disease, but because their safety has been shown, they can be useful for early intervention for long-term prevention of macroangiopathy in the primary prevention group.

\section{(e) GLP-1 Receptor Agonists}

Cardiovascular outcome trials of GLP-1 receptor agonists have had differences in study design, such as drug characteristic differences (e.g., short-acting vs. long-acting and once a day vs. once a week). Thus, GLP-1 receptor agonists have not shown consistent results, including by individual outcome type (Table 6). When meta-analysis results are examined, including results as of June 2019, ${ }^{\mathbf{2 0 4}, 205}$ GLP-1 receptor agonists can be useful in the reduction of $3 \mathrm{P}$ MACE in high-risk patients with type 2 diabetes for cardiovascular disease (particularly patients with previous cardiovascular disease) and in the reduction of individual types of cardiovascular outcomes (cardiovascular death, myocardial infarction, and stroke).

\section{(f) SGLT2 Inhibitors}

It has been suggested that SGLT2 inhibitors can be useful to prevent 3P-MACE in patients with type 2 diabetes and a high-risk for cardiovascular disease (particularly patients with previous cardiovascular disease). 
Table 6. Comparion of Recent CV Outcomes Trials With Antidiabetic Drugs vs. Placebo

\begin{tabular}{|c|c|c|c|c|c|c|c|c|c|c|c|}
\hline & \multirow{2}{*}{\multicolumn{2}{|c|}{$a-G I$}} & \multirow{2}{*}{\multicolumn{2}{|c|}{ Thiazolidinedione }} & \multirow{2}{*}{\multicolumn{4}{|c|}{ DPP-4 inhibitor }} & \multirow{2}{*}{\multicolumn{3}{|c|}{$\begin{array}{l}\text { GLP-1RA } \\
\text { Once-daily }\end{array}$}} \\
\hline & & & & & & & & & & & \\
\hline & $\begin{array}{l}\text { STOP- } \\
\text { NIDDM } \\
\text { (Acar- } \\
\text { bose) }\end{array}$ & $\begin{array}{l}\text { ACE } \\
\text { (Acar- } \\
\text { bose) }\end{array}$ & $\begin{array}{c}\text { PROactive } \\
\text { (Piogli- } \\
\text { tazone) }\end{array}$ & $\begin{array}{c}\text { IRIS } \\
\text { (Piogli- } \\
\text { tazone) }\end{array}$ & $\begin{array}{l}\text { SAVOR- } \\
\text { TIMI 53 } \\
\text { (Saxa- } \\
\text { gliptin) }\end{array}$ & $\begin{array}{l}\text { EXAMINE } \\
\text { (Alogliptin) }\end{array}$ & $\begin{array}{l}\text { TECOS } \\
\text { (Sita- } \\
\text { gliptin) }\end{array}$ & $\begin{array}{c}\text { CARME- } \\
\text { LINA } \\
\text { (Lina- } \\
\text { gliptin) }\end{array}$ & $\begin{array}{c}\text { ELIXA } \\
\text { (Lixisena- } \\
\text { tide) }\end{array}$ & $\begin{array}{l}\text { LEADER } \\
\text { (Liraglu- } \\
\text { tide) }\end{array}$ & $\begin{array}{c}\text { PIONEER } \\
6 \text { (Oral } \\
\text { Semaglu- } \\
\text { tide }^{\star} \text { ) }\end{array}$ \\
\hline No. of patients & 1,429 & 6,522 & 5,238 & 3,876 & 16,492 & 5,380 & 14,671 & 6,979 & 6,068 & 9,340 & 3,183 \\
\hline $\begin{array}{l}\text { Median follow-up } \\
\text { duration, years }\end{array}$ & $\begin{array}{c}3.3 \\
\text { (mean) }\end{array}$ & 5.0 & 2.9 (mean) & 4.8 & 2.1 & 1.5 & 3.0 & 2.2 & 2.1 & 3.8 & 1.3 \\
\hline Key eligibility & IGT & $\begin{array}{l}\text { IGT and } \\
\text { CAD }\end{array}$ & $\begin{array}{l}\text { T2D with } \\
\text { previous } \\
\text { CVD }\end{array}$ & $\begin{array}{c}\mathrm{IR} \text { and } \\
\text { recent } \\
\text { stroke/TIA }\end{array}$ & $\begin{array}{l}\text { T2D with } \\
\text { high-risk } \\
\text { for CVD }\end{array}$ & $\begin{array}{l}\text { T2D with } \\
\text { recent } \\
\text { ACS }\end{array}$ & $\begin{array}{l}\text { T2D with } \\
\text { previous } \\
\text { CVD }\end{array}$ & \begin{tabular}{|c|} 
T2D with \\
high-risk \\
for CVD \\
and kidney \\
events
\end{tabular} & $\begin{array}{l}\text { T2D with } \\
\text { recent } \\
\text { ACS }\end{array}$ & $\begin{array}{l}\text { T2D with } \\
\text { high-risk } \\
\text { for CVD }\end{array}$ & $\begin{array}{l}\text { T2D with } \\
\text { high-risk } \\
\text { for CVD }\end{array}$ \\
\hline Mean age, years & 55 & 64 & 62 & 64 & 65 & $\begin{array}{c}61 \\
\text { (median) }\end{array}$ & 66 & 66 & 60 & 64 & 66 \\
\hline Prior CVD, \% & 5 & 100 & 100 & 100 & 79 & 100 & 100 & 57 & 100 & 81 & 85 \\
\hline $\begin{array}{l}\text { Prior heart } \\
\text { failure, \% }\end{array}$ & - & 4 & - & - & 13 & 28 & 18 & 27 & 22 & 14 & 12 \\
\hline $\begin{array}{l}\text { Mean eGFR, } \\
\mathrm{mL} / \mathrm{min} / 1.73 \mathrm{~m}^{2}\end{array}$ & - & $\begin{array}{c}88 \\
\text { (median) }\end{array}$ & - & - & $\begin{array}{c}73 \\
(\mathrm{~mL} / \mathrm{min}) \\
\end{array}$ & $\begin{array}{c}71 \\
\text { (median) }\end{array}$ & 75 & 55 & 76 & 80 & 74 \\
\hline $\begin{array}{l}\text { Mean baseline } \\
\mathrm{HbA1c}, \%\end{array}$ & - & 5.9 & 7.8 & 5.8 & 8.0 & 8.0 & 7.2 & 7.9 & 7.7 & 8.7 & 8.2 \\
\hline Insulin use, \% & 0 & 0 & 34 & - & 41 & 30 & 23 & 58 & 39 & 45 & 61 \\
\hline $\begin{array}{l}\text { Metformin use, } \\
\%\end{array}$ & 0 & 0 & 62 & - & 70 & 66 & 82 & 55 & 66 & 76 & 77 \\
\hline Statin use, \% & - & 93 & 45 & 82 & 78 & 90 & 80 & 72 & 93 & 72 & - \\
\hline $\begin{array}{l}\text { RAAS inhibitor } \\
\text { use, } \%\end{array}$ & - & 59 & - & 55 & $\begin{array}{l}54 \text { (ACEi) } \\
28 \text { (ARB) }\end{array}$ & 82 & 79 & 81 & 85 & 83 & - \\
\hline \multicolumn{12}{|l|}{$\begin{array}{l}\text { Outcomes } \\
\text { (HR [95\%Cl]) }\end{array}$} \\
\hline MACE $^{\star *}$ & $\begin{array}{c}0.51 \\
{[0.28-} \\
0.95]\end{array}$ & $\begin{array}{c}0.95 \\
{[0.81-} \\
1.19] \\
\end{array}$ & $\begin{array}{c}0.84 \\
{[0.72-} \\
0.98]\end{array}$ & $\begin{array}{c}0.76 \\
{[0.62-} \\
0.93]\end{array}$ & $\begin{array}{c}1.00 \\
{[0.89-} \\
1.12]\end{array}$ & $\begin{array}{c}0.96 \\
{[1.16]^{\dagger+}}\end{array}$ & $\begin{array}{c}0.99 \\
{[0.89-} \\
1.11]\end{array}$ & $\begin{array}{c}1.02 \\
{[0.89-} \\
1.17] \\
\end{array}$ & $\begin{array}{c}1.02 \\
{[0.89-} \\
1.17] \\
\end{array}$ & $\begin{array}{c}0.87 \\
{[0.78-} \\
0.97]\end{array}$ & $\begin{array}{c}0.79 \\
{[0.57-} \\
1.11]\end{array}$ \\
\hline CV death & $\begin{array}{c}0.55 \\
{[0.05-} \\
6.11]\end{array}$ & $\begin{array}{c}0.89 \\
{[0.71-} \\
1.11]\end{array}$ & - & - & $\begin{array}{c}1.03 \\
{[0.87-} \\
1.22]\end{array}$ & $\begin{array}{c}0.85 \\
{[0.66-} \\
1.10]\end{array}$ & $\begin{array}{c}1.03 \\
{[0.89-} \\
1.19]\end{array}$ & $\begin{array}{c}0.96 \\
{[0.81-} \\
1.14]\end{array}$ & $\begin{array}{c}0.98 \\
{[0.78-} \\
1.22]\end{array}$ & $\begin{array}{c}0.78 \\
{[0.66-} \\
0.93]\end{array}$ & $\begin{array}{c}0.49 \\
{[0.27-} \\
0.92]\end{array}$ \\
\hline $\begin{array}{l}\text { Myocardial } \\
\text { infarction }\end{array}$ & $\begin{array}{c}0.09 \\
{[0.01-} \\
0.72]\end{array}$ & $\begin{array}{c}1.12 \\
{[0.87-} \\
1.46]\end{array}$ & $\begin{array}{c}0.83 \\
{[0.65-} \\
1.06]\end{array}$ & $\begin{array}{c}0.75 \\
{[0.52-} \\
1.07]^{\ddagger \ddagger}\end{array}$ & $\begin{array}{c}0.95 \\
{[0.80-} \\
1.12]\end{array}$ & $\begin{array}{c}1.08 \\
{[0.88-} \\
1.33]\end{array}$ & $\begin{array}{c}0.95 \\
{[0.81-} \\
1.11]\end{array}$ & $\begin{array}{c}1.12 \\
{[0.90-} \\
1.40]\end{array}$ & $\begin{array}{c}1.03 \\
{[0.87-} \\
1.22]\end{array}$ & $\begin{array}{c}0.86 \\
{[0.73-} \\
1.00] \\
\end{array}$ & $\begin{array}{c}1.18 \\
{[0.73-} \\
1.90]\end{array}$ \\
\hline Stroke & $\begin{array}{c}0.56 \\
{[0.10-} \\
3.07]\end{array}$ & $\begin{array}{c}0.97 \\
{[0.70-} \\
1.33]\end{array}$ & $\begin{array}{c}0.81 \\
{[0.61-} \\
1.07]\end{array}$ & $\begin{array}{c}0.82 \\
{[0.61-} \\
1.10] \\
\end{array}$ & $\begin{array}{c}1.11 \\
{[0.88-} \\
1.39]\end{array}$ & $\begin{array}{c}0.91 \\
{[0.55-} \\
1.50]\end{array}$ & $\begin{array}{c}0.97 \\
{[0.79-} \\
1.19]\end{array}$ & $\begin{array}{c}0.91 \\
{[0.67-} \\
1.23]\end{array}$ & $\begin{array}{c}1.12 \\
{[0.79-} \\
1.58]\end{array}$ & $\begin{array}{c}0.86 \\
{[0.71-} \\
1.06]\end{array}$ & $\begin{array}{c}0.74 \\
{[0.35-} \\
1.57]\end{array}$ \\
\hline $\begin{array}{l}\text { All-cause } \\
\text { death }\end{array}$ & - & $\begin{array}{c}0.98 \\
{[0.81-} \\
1.19]\end{array}$ & $\begin{array}{c}0.96 \\
{[0.78-} \\
1.18]\end{array}$ & $\begin{array}{c}0.93 \\
{[0.73-} \\
1.17]\end{array}$ & $\begin{array}{c}1.11 \\
{[0.96-} \\
1.27]\end{array}$ & $\begin{array}{c}0.88 \\
{[0.71-} \\
1.09]\end{array}$ & $\begin{array}{c}1.01 \\
{[0.90-} \\
1.14]\end{array}$ & $\begin{array}{c}0.98 \\
{[0.84-} \\
1.13]\end{array}$ & $\begin{array}{c}0.94 \\
{[0.78-} \\
1.13]\end{array}$ & $\begin{array}{c}0.85 \\
{[0.74-} \\
0.97]\end{array}$ & $\begin{array}{c}0.51 \\
{[0.31-} \\
0.84]\end{array}$ \\
\hline $\begin{array}{l}\text { Hospitalization } \\
\text { for heart } \\
\text { failure }\end{array}$ & - & $\begin{array}{c}0.89 \\
{[0.63-} \\
1.24]\end{array}$ & $\begin{array}{c}1.41 \\
{[1.10-} \\
1.80]^{\S \S}\end{array}$ & -IIIII & $\begin{array}{c}1.27 \\
{[1.07-} \\
1.51]\end{array}$ & $\begin{array}{c}1.07 \\
{[0.79-} \\
1.46]\end{array}$ & $\begin{array}{c}1.00 \\
{[0.83-} \\
1.20]\end{array}$ & $\begin{array}{c}0.90 \\
{[0.74-} \\
1.08]\end{array}$ & $\begin{array}{c}0.96 \\
{[0.75-} \\
1.23]\end{array}$ & $\begin{array}{c}0.87 \\
{[0.73-} \\
1.05]\end{array}$ & $\begin{array}{c}0.86 \\
{[0.48-} \\
1.55]\end{array}$ \\
\hline $\begin{array}{l}\text { Composite } \\
\text { renal } \\
\text { endpoints }\end{array}$ & - & $\begin{array}{c}0.81 \\
{[0.54-} \\
1.23]\end{array}$ & - & - & $\begin{array}{c}1.08 \\
{[0.88-} \\
1.32]\end{array}$ & - & - & $\begin{array}{c}0.98 \\
{[0.82-} \\
1.18]\end{array}$ & - & $\begin{array}{c}0.78 \\
{[0.67-} \\
0.92]\end{array}$ & - \\
\hline
\end{tabular}

*Unapproved in Japan as of June 2019. †Pooled data from CANVAS and CANVAS-R. ${ }^{\ddagger}$ eGFR $30-90 \mathrm{~mL} / \mathrm{min} / 1.73 \mathrm{~m}^{2}$ and UACR $300-5,000 \mathrm{mg} / \mathrm{g}$. \$ $\$$ schemic etiology for heart failure. "Statin or ezetimibe. IIncluding sacubitril/valsartan. ${ }^{* *}$ Composite (CAD, CV death, heart failure, cerebrovascular event, and peripheral vascular disease) in STOP-NIDDM, stroke or myocardial infaction in IRIS, 4-point MACE in


unstable angina. \$\&Serious heart failure including hospitalization for heart failure. IIIISerious heart failure including hospitalization for heart


heart failure or urgent visit. ACEi, angiotensin converting enzyme inhibitor; ACS, acute coronary syndrome; ARB, angiotensin II receptor blocker; $\mathrm{Cl}$, confidence interval; CAD coronary artery disease; CVD, cardiovascular disease; DPP-4, dipeptidyl peptidase-4; eGFR, estimated glomerular filtration rate; GI, glucosidase inhibitor; GLP-1RA, glucagon-like peptide-1 receptor agonist; IR, insulin resistance; HFrEF, heart failure with reduced ejection fraction; HR, hazard ratio; MACE, major adverse cardiovascular events; NT-proBNP, NT N-terminal pro-B-type natriuretic peptide; RAAS, renin-angiotensin-aldosterone system; SGLT2, sodium-glucose cotransporter 2; TIA, transient ischemic attack; T2D, type 2 diabetes; UACR, urine albumin-to-creatinine ratio. 


\begin{tabular}{|c|c|c|c|c|c|c|c|c|c|}
\hline \multicolumn{5}{|c|}{ GLP-1RA } & \multirow{2}{*}{\multicolumn{5}{|c|}{ SGLT2 inhibitor }} \\
\hline & \multicolumn{4}{|c|}{ Once-weekly } & & & & & \\
\hline & $\begin{array}{c}\text { SUSTAIN-6 } \\
\text { (Semaglu- } \\
\text { tide }^{\star} \text { ) }\end{array}$ & $\begin{array}{c}\text { EXSCEL } \\
\text { (Exenatide) }\end{array}$ & $\begin{array}{l}\text { HARMONY } \\
\text { (Albiglu- } \\
\text { tide }^{\star} \text { ) }\end{array}$ & $\begin{array}{c}\text { REWIND } \\
\text { (Dulaglutide) }\end{array}$ & \begin{tabular}{|c|} 
EMPA-REG \\
OUTCOME \\
(Empa- \\
gliflozin) \\
\end{tabular} & $\begin{array}{l}\text { CANVAS } \\
\text { Programt } \\
\text { (Cana- } \\
\text { gliflozin) }\end{array}$ & \begin{tabular}{|l} 
DECLARE- \\
TIMI 58 \\
(Dapa- \\
gliflozin) \\
\end{tabular} & $\begin{array}{l}\text { CREDENCE } \\
\text { (Cana- } \\
\text { gliflozin) }\end{array}$ & $\begin{array}{l}\text { DAPA-HF } \\
\text { (Dapa- } \\
\text { gliflozin) }\end{array}$ \\
\hline No. of patients & 3,297 & 14,752 & 9,463 & 9,901 & 7,020 & 10,142 & 17,160 & 4,401 & 4,774 \\
\hline $\begin{array}{l}\text { Median follow-up } \\
\text { duration, years }\end{array}$ & 2.1 & 3.2 & 1.6 & 5.4 & 3.1 & 2.4 & 4.2 & 2.6 & 1.5 \\
\hline Key eligibility & $\begin{array}{l}\text { T2D with } \\
\text { high-risk for } \\
\text { CVD }\end{array}$ & $\begin{array}{c}\text { T2D with } \\
\text { high-risk for } \\
\text { CVD }\end{array}$ & $\begin{array}{l}\text { T2D with } \\
\text { previous } \\
\text { CVD }\end{array}$ & $\begin{array}{l}\text { T2D with } \\
\text { high-risk for } \\
\text { CVD }\end{array}$ & $\begin{array}{l}\text { T2D with } \\
\text { previous } \\
\text { CVD }\end{array}$ & $\begin{array}{l}\text { T2D with } \\
\text { high-risk for } \\
\text { CVD }\end{array}$ & $\begin{array}{l}\text { T2D with } \\
\text { high-risk for } \\
\text { CVD }\end{array}$ & $\begin{array}{l}\text { T2D with } \\
\text { CKD } \neq\end{array}$ & $\begin{array}{l}\text { HFrEF with } \\
\text { elevated } \\
\text { NT-proBNP }\end{array}$ \\
\hline Mean age, years & 65 & $\begin{array}{c}62 \\
\text { (median) }\end{array}$ & 64 & 66 & 63 & 63 & 64 & 63 & 66 \\
\hline Prior CVD, \% & 83 & 73 & 100 & 31 & 99 & 66 & 41 & 50 & $56 \S$ \\
\hline $\begin{array}{l}\text { Prior heart } \\
\text { failure, } \%\end{array}$ & 24 & 16 & 20 & 9 & 10 & 14 & 10 & 15 & 100 \\
\hline $\begin{array}{l}\text { Mean eGFR, } \\
\mathrm{mL} / \mathrm{min} / 1.73 \mathrm{~m}^{2}\end{array}$ & 71 & $\begin{array}{c}76 \\
\text { (median) } \\
\end{array}$ & 79 & $\begin{array}{c}75 \\
\text { (median) } \\
\end{array}$ & 74 & 77 & 85 & 56 & 66 \\
\hline $\begin{array}{l}\text { Mean baseline } \\
\mathrm{HbA} 1 \mathrm{c}, \%\end{array}$ & 8.7 & 8.0 & 8.7 & 7.3 & 8.1 & 8.2 & 8.3 & 8.3 & - \\
\hline Insulin use, \% & 58 & 46 & 59 & 24 & 48 & 50 & 41 & 66 & - \\
\hline $\begin{array}{l}\text { Metformin use, } \\
\%\end{array}$ & 73 & 77 & 74 & 81 & 74 & 77 & 82 & 58 & - \\
\hline Statin use, \% & 73 & 74 & 84 & 66 & 77 & 75 & $75^{\|}$ & 69 & - \\
\hline $\begin{array}{l}\text { RAAS inhibitor } \\
\text { use, } \%\end{array}$ & 84 & 80 & $\begin{array}{l}49 \text { (ACEi) } \\
33 \text { (ARB) }\end{array}$ & 81 & 81 & 80 & 81 & $>99$ & 941 \\
\hline $\begin{array}{l}\text { Outcomes } \\
\text { (HR [95\%Cl]) }\end{array}$ & & & & & & & & & \\
\hline MACE ${ }^{\star *}$ & $\begin{array}{c}0.74 \\
{[0.58-} \\
0.95]\end{array}$ & $\begin{array}{c}0.91 \\
{[0.83-} \\
1.00]\end{array}$ & $\begin{array}{c}0.78 \\
{[0.68-} \\
0.90]\end{array}$ & $\begin{array}{c}0.88 \\
{[0.79-} \\
0.99]\end{array}$ & $\begin{array}{c}0.86 \\
{[0.74-} \\
0.99]\end{array}$ & $\begin{array}{c}0.86 \\
{[0.75-} \\
0.97]\end{array}$ & $\begin{array}{c}0.93 \\
{[0.84-} \\
1.03]\end{array}$ & $\begin{array}{c}0.80 \\
{[0.67-} \\
0.95]\end{array}$ & - \\
\hline CV death & $\begin{array}{c}0.98 \\
{[0.65-} \\
1.48]\end{array}$ & $\begin{array}{c}0.88 \\
{[0.76-} \\
1.02]\end{array}$ & $\begin{array}{c}0.93 \\
{[0.73-} \\
1.19]\end{array}$ & $\begin{array}{c}0.91 \\
{[0.78-} \\
1.06]\end{array}$ & $\begin{array}{c}0.62 \\
{[0.49-} \\
0.77]\end{array}$ & $\begin{array}{c}0.87 \\
{[0.72-} \\
1.06]\end{array}$ & $\begin{array}{c}0.98 \\
{[0.82-} \\
1.17]\end{array}$ & $\begin{array}{c}0.78 \\
{[0.61-} \\
1.00]\end{array}$ & $\begin{array}{c}0.82 \\
{[0.69-} \\
0.98]\end{array}$ \\
\hline $\begin{array}{l}\text { Myocardial } \\
\text { infarction }\end{array}$ & $\begin{array}{c}0.74 \\
{[0.51-} \\
1.08]\end{array}$ & $\begin{array}{c}0.97 \\
{[0.85-} \\
1.10]\end{array}$ & $\begin{array}{c}0.75 \\
{[0.61-} \\
0.90]\end{array}$ & $\begin{array}{c}0.96 \\
{[0.79-} \\
1.15]\end{array}$ & $\begin{array}{c}0.87 \\
{[0.70-} \\
1.09]\end{array}$ & $\begin{array}{c}0.85 \\
{[0.69-} \\
1.05]\end{array}$ & $\begin{array}{c}0.89 \\
{[0.77-} \\
1.01]\end{array}$ & - & - \\
\hline Stroke & $\begin{array}{c}0.61 \\
{[0.38-} \\
0.99]\end{array}$ & $\begin{array}{c}0.85 \\
{[0.70-} \\
1.03]\end{array}$ & $\begin{array}{c}0.86 \\
{[0.66-} \\
1.14]\end{array}$ & $\begin{array}{c}0.76 \\
{[0.62-} \\
0.94]\end{array}$ & $\begin{array}{c}1.18 \\
{[0.89-} \\
1.56]\end{array}$ & $\begin{array}{c}0.90 \\
{[0.71-} \\
1.15]\end{array}$ & $\begin{array}{c}1.01 \\
{[0.84-} \\
1.21]\end{array}$ & - & - \\
\hline $\begin{array}{l}\text { All-cause } \\
\text { death }\end{array}$ & $\begin{array}{c}1.05 \\
{[0.74-} \\
1.50] \\
\end{array}$ & $\begin{array}{c}0.86 \\
{[0.77-} \\
0.97] \\
\end{array}$ & $\begin{array}{c}0.95 \\
{[0.79-} \\
1.16] \\
\end{array}$ & $\begin{array}{c}0.90 \\
{[0.80-} \\
1.01] \\
\end{array}$ & $\begin{array}{c}0.68 \\
{[0.57-} \\
0.82] \\
\end{array}$ & $\begin{array}{c}0.87 \\
{[0.74-} \\
1.01] \\
\end{array}$ & $\begin{array}{c}0.93 \\
{[0.82-} \\
1.04] \\
\end{array}$ & $\begin{array}{c}0.83 \\
{[0.68-} \\
1.02] \\
\end{array}$ & $\begin{array}{c}0.83 \\
{[0.71-} \\
0.97] \\
\end{array}$ \\
\hline $\begin{array}{l}\text { Hospitalization } \\
\text { for heart } \\
\text { failure }\end{array}$ & $\begin{array}{c}1.11 \\
{[0.77-} \\
1.61]\end{array}$ & $\begin{array}{c}0.94 \\
{[0.78-} \\
1.13]\end{array}$ & $\begin{array}{l}0.85 \\
{[0.70-} \\
1.04]^{111}\end{array}$ & $\begin{array}{c}0.93 \\
{[0.77-} \\
1.12]^{\star \star \star}\end{array}$ & $\begin{array}{c}0.65 \\
{[0.50-} \\
0.85]\end{array}$ & $\begin{array}{c}0.67 \\
{[0.52-} \\
0.87]\end{array}$ & $\begin{array}{c}0.73 \\
{[0.61-} \\
0.88]\end{array}$ & $\begin{array}{c}0.61 \\
{[0.47-} \\
0.80]\end{array}$ & $\begin{array}{c}0.70 \\
{[0.59-} \\
0.83]\end{array}$ \\
\hline $\begin{array}{l}\text { Composite } \\
\text { renal } \\
\text { endpoints }\end{array}$ & $\begin{array}{c}0.64 \\
{[0.46-} \\
0.88]\end{array}$ & - & - & $\begin{array}{c}0.85 \\
{[0.77-} \\
0.93]\end{array}$ & $\begin{array}{c}0.61 \\
{[0.53-} \\
0.70]\end{array}$ & $\begin{array}{c}0.60 \\
{[0.47-} \\
0.77]\end{array}$ & $\begin{array}{c}0.53 \\
{[0.43-} \\
0.66]\end{array}$ & $\begin{array}{c}0.66 \\
{[0.53-} \\
0.81]\end{array}$ & $\begin{array}{c}0.71 \\
{[0.44-} \\
1.16]\end{array}$ \\
\hline
\end{tabular}




\section{(g) Summary}

When selecting an antidiabetic drug, physicians need to examine the results accumulated from clinical trials to determine whether the drug's action is appropriate for an individual patient's pathophysiology, and to carefully consider the risk of hypoglycemia and the evidence on prevention of complications.

In recent years, based on the results of cardiovascular outcome trials, GLP-1 receptor agonists and SGLT2 inhibitors have become second-line drugs after metformin in patients with diabetes at high risk for arteriosclerotic cardiovascular disease in the USA. ${ }^{206}$ In Europe, these drugs are also recommended in the aforementioned high-risk patients as second-line drugs after metformin and as firstline drugs in patients naïve to any antidiabetic drugs. ${ }^{207}$ Because there are racial and pathophysiological differences between Japanese patients and European or American patients, there is insufficient evidence on the effects of these drugs on cardiovascular events in Japanese patients. Thus, no conclusion has been reached on whether these 2 drugs should be similarly recommended in Japan. Further evidence needs to be accumulated to determine which antidiabetic drug should be selected in which type of patient and with what timing, and whether they are effective in preventing cardiovascular events in Japanese patients.

\section{I1.3 Coronary Revascularization}

Approximately two-thirds of patients with CAD also have impaired glucose metabolism. In the CREDO-Kyoto study in Japan, ${ }^{208}$ diabetes was found in over $40 \%$ of the patients who underwent PCI. The mortality rate is high in patients with diabetes and CAD.

In the Finnish 7-year follow-up study, ${ }^{15}$ the incidence of myocardial infarction was approximately $3.5 \%$ and $18.8 \%$, respectively, in patients without and with diabetes, without previous myocardial infarction. The incidence of myocardial infarction was approximately $20.2 \%$ and $45.0 \%$, respectively, in patients without and with diabetes, with previous myocardial infarction. The shocking result in that study was that coronary death occurred in approximately half of the patients with diabetes and previous myocardial infarction during the 7-year period. A subsequent 18-year follow-up study showed a similar trend. ${ }^{209}$ In Japan, there are not many observational studies of prognosis after PCI. However, one follow-up study examined the clinical outcomes after PCI for an average of 12 years. ${ }^{210}$ Cardiovascular death occurred in $4.2 \%$ and $9.4 \%$ of patients without and with diabetes, respectively. When an analysis was performed with corrections involving inclusion of other risk factors, the difference was still significant at $\mathrm{P}=0.016$. When another study examined patients with and without diabetes after $\mathrm{CABG}$, the odds ratio for operative and 30-day mortality was 1.19 (95\% CI: $1.03-1.3)$ in patients with diabetes compared with patients without diabetes. ${ }^{211}$

As described above, prognosis is poor in patients with diabetes who undergo coronary revascularization. Some possible explanations are: patients with diabetes have other risk factors such as hypertension, dyslipidemia, and CKD, and that they often have vascular disease other than CAD. In patients with diabetes, common coexisting coronary lesions are diffuse lesions and calcified lesions, based on their characteristics, and comprise left main CAD and multivessel disease based on the affected vessel(s). Thus, difficulty in treatment is thought to be another factor for poor prognosis.

\section{1.3.1 Coronary Revascularization in Patients With Stable Angina: PCI vs. CABG}

As mentioned earlier, the characteristics of patients with diabetes vary and the lesions are often complex. Thus, caution is required when selecting the method of revascularization. Special consideration is necessary because many patients also have $\mathrm{CKD}$, lifestyle disease, and/or low cardiac function.

It is appropriate to first consider PCI for 1- or 2-vessel disease without the involvement of the proximal left anterior descending artery. However, CABG has been shown to be useful for 3-vessel disease, left main CAD, and multivessel disease with involvement of the proximal left anterior descending artery.

The BARI study, ${ }^{212}$ a 10 -year follow-up study, was conducted during the bare metal stent era and examined the 10-year survival after coronary revascularization for multivessel disease. In patients without diabetes, the postPCI and post-CABG survival did not differ, at slightly less than $80 \%$. In patients with diabetes, the post-PCI and postCABG survival was approximately $46 \%$ and $58 \%$, respectively. This study made evident that patients with coexisting diabetes have worse prognoses when PCI is performed. The subgroup analysis results of the BARI study indicated that the aforementioned trend is marked in patients using insulin. ${ }^{213}$

The FREEDOM study ${ }^{214}$ compared coronary revascularization via CABG and that via PCI with a drug-eluting stent (DES) in 1,900 patients with diabetes and multivessel disease. The incidence of the composite endpoint of allcause death, myocardial infarction, or stroke was $26.6 \%$ and $18.7 \%$ for the PCI group and CABG group, respectively, over a 5-year period (average follow-up: 3.8 years). Thus, CABG yielded a significantly better result. At the 2018 annual meeting, the American Heart Association presented the results of a long-term (8-year) follow-up of the FREEDOM study. ${ }^{215}$ The aforementioned trend remained unchanged. When subgroup analysis was performed by age with 63.3 years as the cut off (young and advanced age subgroups), there was a significant difference between PCI and $\mathrm{CABG}$, indicating that the young subgroup was more likely to benefit from CABG over PCI.

The SYNTAX trial ${ }^{216}$ compared CABG and PCI using the first-generation paclitaxel DES in patients with 3-vessel disease or left main CAD. Compared with the patients who underwent PCI, the patients who had CABG had significantly (i) reduced all-cause death; (ii) reduced major adverse cardiac and cerebrovascular events, which is a composite of all-cause death, myocardial infarction, and cerebrovascular disease; and (iii) reduced repeat revascularization during a 1-year follow-up. A subgroup analysis ${ }^{217}$ was subsequently performed on patients with diabetes in the SYNTAX trial. There was no significant difference in deaths between the PCI and CABG groups at 1 year after revascularization when the SYNTAX score was $\leq 32$ (lowand moderate-score groups). However, the PCI group had significantly higher mortality compared with the CABG group when the SYNTAX score was $\geq 33$ (high score group), which indicated the presence of complex lesions.

In 2018, the European Society of Cardiology and the European Association for Cardio-Thoracic Surgery published their "Guidelines on myocardial revascularization". ${ }^{218}$ These indicated the following for patients with 




Figure 13. Flowchart for coronary revascularization in patients with diabetes. CABG, coronary artery bypass grafting; PCI, percutaneous coronary intervention.

diabetes and multivessel disease based on the aforementioned studies and based on comparison between CABG and stenting with everolimus DES.

(1) Patients with a SYNTAX score of 0-22: CABG with a Class I recommendation (evidence level A), PCI with a Class IIb recommendation (evidence level A)

(2) Patients with a SYNTAX score $>22$ : CABG with a Class I recommendation (evidence level A), PCI with a Class III recommendation (evidence level A). It should be noted that, in their 2014 guidelines, the recommendation for PCI was Class IIa in patients with a SYNTAX score of $0-22$, indicating a downgrading of PCI in the current guidelines.

PCI has long been established as a localized treatment of lesion sites and thought to be ineffective in preventing progression of lesions other than the treated lesion. In contrast, $\mathrm{CABG}$ connects a bypass to the distal portion of the normal coronary artery. Therefore, if the bypass can maintain its patency long term, myocardium supplied by that coronary artery should not be prone to progression of myocardial ischemia, even if postoperative progression of stenosis or occlusion occurs in the proximal coronary artery. On the other hand, perioperative complications of $\mathrm{CABG}$ have been considered to contribute to worsening of prognosis and it has been thought important to pay particular attention to these complications.

The incidence of cardiovascular events has declined in the current era because of (i) innovation in PCI, including stents, and innovation in CABG; (ii) prevalent use of optimal pharmacotherapy; (iii) use of aggressive lipid-lowering treatment such as with statins, ezetimibe, and PCSK9 inhibitors; and (iv) use of antidiabetic drugs such as pioglitazone, SGLT2 inhibitors, and GLP-1 receptor agonists. However, there still remain issues that need to be examined, including what type of repeat revascularization should be performed on what type of patients and on what type of lesions. In particular, thorough discussion is necessary in cardiac teams, centering around cardiac surgery and cardiology departments (Figure 13).

\subsubsection{Points of Caution Regarding PCI in Patients With Diabetes}

Patients with diabetes are more likely to have unstable plaques compared with patients without diabetes, ${ }^{219}$ and lipid-rich plaques (portending unstable plaques) have been associated with IR. ${ }^{220}$ These results indicate that these patients are more prone to not only acute coronary syndrome but also adverse events such as perioperative myocardial damage in elective cases. ${ }^{221}$

Many patients with diabetes have coexisting CKD, and prevention of contrast-induced nephropathy is important. When patients are using a biguanide antidiabetic drug, discontinuance of this drug should be considered if a contrast agent is to be used.

\section{1.3.3 Points of Caution When Performing PCI in Acute Coronary Syndrome Patients With Hyperglycemia at Hospitalization}

In acute coronary syndrome, early revascularization of the target vessel(s) is important even for multivessel disease. It is important to note that prognosis has been shown to be negatively affected by hyperglycemia at admission. ${ }^{222} \mathrm{~A}$ 
point of caution is that such prognostic decline is seen in not only patients with diabetes but also patients without diabetes. The mechanism is thought to involve abolishment of ischemic preconditioning by hyperglycemia. ${ }^{223}$ Prognosis has been shown to improve with nicorandil administration, resulting in K-ATP channel opening, which is considered to cause ischemic preconditioning. ${ }^{224}$

\section{Prevention and Treatment of Heart Failure in Patients With Impaired Glucose Metabolism}

\subsection{Lifestyle Intervention}

Obesity and diabetes are closely associated with the onset of $\mathrm{HF}$, and $\mathrm{HF}$ is one of the important factors in determining the vital prognosis in patients with impaired glucose metabolism. ${ }^{225-227}$ In general, the risk of HF is positively correlated with body mass index. ${ }^{228}$ This correlation is stronger for $\mathrm{HFpEF}$ than $\mathrm{HFrEF}^{229}$ and is more marked in women than men. ${ }^{230}$ Heart failure negatively correlates with the intensity of physical activity. ${ }^{231,232}$ Regardless of whether or not individuals have impaired glucose metabolism, preventive effects on HF can be expected from weight loss, exercise therapy, and improved lifestyle habits such as smoking cessation. The use of the "JCS 2017/JHFS 2017 Guideline on Diagnosis and Treatment of Acute and Chronic Heart Failure" 74 is appropriate as a reference for general HF prevention.

The Look AHEAD study examined the effects of intensive lifestyle intervention on cardiovascular events and death in obese patients with type 2 diabetes. This intensive lifestyle intervention aimed for weight loss through calorie intake restriction and increased physical activity. The incidence was not reduced for the composite primary endpoint (cardiovascular death, nonfatal myocardial infarction, nonfatal stroke, or hospitalization for angina), any of these cardiovascular events, or death. However, the hazard ratio for $\mathrm{HF}$ was 0.80 (95\% CI: 0.62-1.04, $\mathrm{P}=0.10)$ for patients with intensive lifestyle intervention compared with those with a conventional intervention. This result was the most improved one among all outcomes. ${ }^{140}$ In the same study, subgroup analysis was performed by change in weight and by change in fitness level from baseline to 1 year thereafter. Patients with $\geq 10 \%$ weight loss had a $21 \%$ reduced risk of the primary composite endpoint than patients with weight gain or stable weight. Examination was also performed of a secondary composite endpoint consisting of the composite primary endpoint plus CABG, carotid endarterectomy, PCI, hospitalization for congestive HF, PAD, or all-cause death. The patients with weight loss had a $24 \%$ reduced risk of the secondary outcome compared with patients with weight gain or stable weight. There was a significant association of increased fitness with risk reduction of the primary and secondary endpoints. In particular, patients whose fitness level improved by $\geq 2$ METs had a 23\% risk reduction of the secondary endpoint compared with patients whose fitness declined or was unchanged. ${ }^{\mathbf{2 3 3}}$

The Steno-2 trial examined the long-term effectiveness of an intensive multifactorial intervention on cardiovascular events and microvascular events in patients with type 2 diabetes and microalbuminuria. The intervention consisted of improvement of lifestyle habits and stepwise intensified pharmacotherapy for blood pressure, lipid, and blood glucose (HbA1c) control. The Steno-2 trial is a representative study that showed the importance of comprehensive intervention in patients with diabetes. ${ }^{\mathbf{1 4 1 , 2 3 4 , 2 3 5}}$ Until recently, the effectiveness of intensified multifactorial intervention had not been demonstrated for HF in patients with diabetes. In 2018, a report on the Steno-2 trial showed a $70 \%$ reduction in $\mathrm{HF}$ hospitalization in patients with type 2 diabetes and microalbuminuria who received an intensive multifactorial intervention for 7.8 years, compared with those who received conventional therapy, during an average follow-up of 21.2 years. ${ }^{236}$ The long-term risk for HF has also been shown to increase more with greater increase in the NT-proBNP level in the 2 years after the intervention began. Thus, the importance of biomarker measurement needs to be also emphasized from the standpoint of predicting HF. A clinical trial, J-DOIT3, 143 has been conducted on a similar intensive multifactorial intervention but its results did not show a significant difference in the HF incidence between patients with the intervention and those with conventional therapy.

In summary, appropriate weight loss, focusing on improved fitness level and portion control of food, is effective in the risk reduction of cardiovascular events in obese patients with type 2 diabetes. However, direct evidence has not yet been sufficiently established on the effectiveness of such interventions on HF prevention. For treatment of diabetes, a comprehensive intervention needs to be implemented which includes lifestyle intervention and pharmacotherapy for blood pressure, lipid, and blood glucose control. It is highly likely that such comprehensive interventions are also effective in HF prevention.

\subsection{Pharmacotherapies}

\subsubsection{Drugs for Heart Failure}

A clinical trial has not yet been reported with only patients with $\mathrm{HF}$ and diabetes as the subjects in whom the effectiveness was examined of evidence-based HF therapies using ACE inhibitors, ARBs, and $\beta$-blockers. In subgroup analyses of large-scale trials, however, ACE inhibitors and $A R B$ are reported to have similar effectiveness in patients with and without diabetes. ${ }^{237-239}$ Beta-blockers have also been reported to have similar effectiveness in patients with and without diabetes. ${ }^{\mathbf{2 4 0 , 2 4 1}}$ There are concerns that $\beta$-blockers negatively affect glucose metabolism and mask hypoglycemic symptoms. Because $\beta$-blockers reduce mortality effectively, they should not be discontinued as a treatment for symptomatic chronic HF (particularly with coexisting myocardial infarction) in patients with diabetes. In addition, the effect on glucose metabolism is not the same for all $\beta$-blockers. For example, hypertensive patients with carvedilol administration were reported to have more improved IR and reduced microalbuminuria than those with metoprolol tartrate administration. ${ }^{242}$ Thus, drugs that have a small effect on glucose metabolism should be appropriately selected. Such drugs include carvedilol and bisoprolol, which are currently widely used for HF treatment. ${ }^{243}$ Mineralocorticoid receptor antagonists have also been reported to be effective in patients with diabetes and those without. ${ }^{244,245}$ Collectively, there is currently no specific treatment for HF patients with diabetes that differs from the treatment given to those without diabetes. For HF patients with diabetes, drugs with the least effect on glucose metabolism are selected from among the general HF drugs. 


\section{2.2.2 Antidiabetic Drugs}

\section{(a) Therapeutic Goals for Diabetes}

There is still debate on whether or not strict glycemic control is effective for preventing/slowing the development/ worsening of HF. ${ }^{66,195,246,247}$ Hypoglycemia has been shown to negatively affect the cardiovascular system via various pathways, including inflammation and sympathetic nervous system activation. ${ }^{248}$ Therefore, it is appropriate to avoid hypoglycemia and to establish a target for HbAlc control for each drug based on evidence of the drug's effect on HF. In the USA, the target for HbAlc control has been established as $<7 \%$ in nonpregnant adults with diabetes and HF. ${ }^{249}$ This target is the same as in the "Management goals for prevention of complications in patients with diabetes" in the "Treatment guide for diabetes in Japan". ${ }^{14}$

\section{(b) Antidiabetic Drugs and Heart Failure}

There has been much attention on HF-related outcomes, focusing on hospitalization for $\mathrm{HF}$, in cardiovascular outcome trials using antidiabetic drugs. Described below are the major antidiabetic drugs for which a relationship with HF has been indicated, regardless of whether it be of risk or benefit; and opinions by class based mainly on the results of cardiovascular outcome trials (Table 6).

\section{i. Thiazolidinediones}

Thiazolidinediones are contraindicated in Stage-C symptomatic HF. The main reason is fluid retention due to increased sodium reabsorption in the kidneys, but there has been no report that thiazolidinediones have caused myocardial damage or deterioration of cardiac function. There is limited evidence to restrict the use of thiazolidinediones in Stage-A or B asymptomatic HF. However, their doses need to be adjusted according to fluid retention, including edema, and fluid management needs to be implemented, such as by sodium restriction and diuretic use. Reduction of HF risk can be expected when a thiazolidinedione is used in combination with a SGLT2 inhibitor, ${ }^{250}$ but further evaluation is necessary.

\section{ii. Biguanide}

Biguanide is contraindicated in patients with severe cardiovascular disorder or severely impaired pulmonary function because of a concern of lactic acidosis. In recent years, a study has shown that a biguanide significantly reduced $\mathrm{HF}$ hospitalization and all-cause death in patients with diabetes and HF. 251-255 Therefore, such contraindication has been rescinded in Europe and the USA, and biguanide is considered a first-line drug in patients with diabetes, chronic $\mathrm{HF}$, and stable renal function (eGFR $>30 \mathrm{~mL} / \mathrm{min} /$ $\left.1.73 \mathrm{~m}^{2}\right) .207$ However, it is contraindicated in $\mathrm{HF}$ with hemodynamic instability, such as acute HF. In Japan, biguanide is, in principle, contraindicated in HF patients because of limited evidence showing its effectiveness in such patients. Its primary prevention effect in HF is a topic for future studies in Japan.

\section{iii. Incretin Modulators}

The SAVOR-TIMI 53 trial was a cardiovascular outcome trial using a DDP-4 inhibitor, saxagliptin, and showed significantly more hospitalization for $\mathrm{HF}$ among patients with type 2 diabetes using saxagliptin than among those using placebo. ${ }^{256}$ The EXAMINE trial was conducted in patients with type 2 diabetes and recent acute coronary syndrome and found that more patients using alogliptin tended to be hospitalized for HF than in the placebo group. ${ }^{257}$ In contrast, the TECOS trial found no significant increase in HF hospitalization with sitagliptin use compared with placebo use. ${ }^{\mathbf{2 5 8}}$ The CARMELINA trial also showed that linagliptin did not increase the risk for HF hospitalization compared with a placebo, even in the patient group with high cardiovascular and renal risks, ${ }^{259}$ suggesting its safety in this patient population.

GLP-1 receptor agonists did not show a significant effect on HF hospitalization in cardiovascular outcome trials. ${ }^{\mathbf{2 6 0 - 2 6 6}}$ The FIGHT trial examined the use of liraglutide in acute HF patients with HFrEF, and it tended to increase the risk of another episode of $\mathrm{HF}$ compared with placebo in patients with coexisting diabetes. ${ }^{\mathbf{2 6 7}}$

Incretin modulators have little effect on HF, as described above. However, it should be noted that some of these drugs increase the HF risk depending on the patient's pathological conditions. Thus, the use of the drug needs to be examined on an individual basis.

\section{iv. SGLT2 Inhibitors}

Cardiovascular outcome trials showed the effectiveness of SGLT2 inhibitors (empagliflozin, canagliflozin, and dapagliflozin) for HF prevention in patients with diabetes and a high-risk for cardiovascular disease. ${ }^{205,268,269}$ However, $10-15 \%$ of the subjects had coexisting HF and there are still many unanswered questions, such as for which HF pathology and at what stage are SGLT2 inhibitors effective and what is their mechanism of action. 270,271

The DAPA-HF trial was conducted on patients with $\mathrm{HF}$ and reduced left ventricular ejection fraction regardless of type 2 diabetes. In the trial, dapagliflozin significantly reduced the worsening of $\mathrm{HF}$, including hospitalization, and cardiovascular death compared with placebo in both patients with and without diabetes. These results suggest the usefulness of SGLT2 inhibitors in HF patients. ${ }^{272}$

\section{v. Other Antidiabetic Drugs}

The effectiveness and adverse effects of insulin, SUs, glinides, and $\alpha$-glucosidase inhibitors have not been clearly shown for HF, and thus there are generally no clinical restrictions on their use.

\section{| 2.2.3 Summary}

Standard HF drugs are recommended to be used in HF patients with diabetes in a similar way to how they are used in patients without diabetes.

To prevent HF in patients with type 2 diabetes, the use of an SGLT2 inhibitor is recommended in the following cases in addition to comprehensive intervention to reduce risk factors and to improve lifestyle habits: patients with Stage-C or -D symptomatic HF and patients with Stage-B latent $\mathrm{HF}$ who have a high-risk for HF (e.g., elevated BNP or NT-proBNP, history of myocardial infarction, or CKD excluding eGFR $<30 \mathrm{~mL} / \mathrm{min} / 1.73 \mathrm{~m}^{2}$ ) (Figure 14). For concomitant use of diuretics, its dose should be adjusted to prevent dehydration. Based on the patient's pathological condition, physicians should select drugs with limited adverse effects on cardiac function and $\mathrm{HF}$ for patients with limited indications for SGLT2 inhibitors (due to severe renal dysfunction and concerns of adverse events), and for patients requiring the addition of an antidiabetic drug. 




Figure 14. Heart failure prevention in patients with diabetes. *High-risk for heart failure include BNP $\geq 100 \mathrm{pg} / \mathrm{mL}$ or NTproBNP $\geq 400 \mathrm{pg} / \mathrm{mL}$; history of myocardial infarction; and chronic kidney disease with estimated glomerular filtration rate $\geq 30 \mathrm{~mL} / \mathrm{min} / 1.73 \mathrm{~m}^{2}$. SGLT2, sodium-glucose cotransporter 2 .

\section{Treatment of Atrial Fibrillation in Patients With Impaired Glucose Metabolism}

At present, there is insufficient evidence of effective prevention and treatment of AF in patients with diabetes. Atrial fibrillation has been reported to coexist at a high rate in patients with type 2 diabetes. ${ }^{273}$ It can cause cardiogenic cerebral embolism and congestive HF, and its coexistence in patients with diabetes is thought to greatly affect both vital prognosis and QOL. Great advances in the treatment of AF have been made in recent years and efforts should be made in early detection AF in patients with diabetes and for implementation of proper treatment.

\subsection{Treatment Strategy Planning for Atrial Fibrillation}

The important point in AF treatment is to prioritize the improvement of correctable pathologies besides the arrhythmia. Such pathologies include hypertension, reduced cardiac function, and ischemia. Until the turn of this century, the goal of AF treatment had been maintenance of sinus rhythm. Since 2000, the results of large-scale clinical trials $^{274}$ have been successively published in Europe and the USA and indicated that sinus rhythm maintenance (rhythm control and recurrence prevention) using antiarrhythmic drugs is non-superior to rate control. 275

In the management of AF, coexistence of cerebral embolism (cardiogenic stroke) requires the most caution. First, determination needs to be made on the implementation of anticoagulant therapy to reduce the risk of cerebral embolism. If anticoagulant therapy is indicated and no contraindication exists, then the therapy can be initiated (Figure 15). ${ }^{275}$ Thereafter either rhythm or rate control is selected. Even if sinus rhythm is maintained in patients with AF, they will need to continue anticoagulant therapy for life if they have a high-risk for embolism. ${ }^{276}$

The use of rate control does not produce a noninferior prognosis to rhythm control. In fact, rate control is a safer treatment when the side effects of antiarrhythmic drugs are considered. In most cases, paroxysmal AF can change to a persistent or chronic condition, and many patients with



chronic AF achieve satisfactory QOL using only rate control and anticoagulant therapy. However, it is also a fact that there are patients who suffer from uncomfortable subjective symptoms with each recurrent attack of AF. ${ }^{275}$ In Japan, the J-RHYTHM study ${ }^{277}$ was conducted on patients with paroxysmal AF or persistent AF who were randomly assigned to a rhythm control group or a rate control group and followed up for 3 years. The primary endpoint was a composite of death, symptomatic stroke, systemic embolism, major bleeding, hospitalization for $\mathrm{HF}$, and physical/psychological disability requiring alteration of treatment strategy. Physical/psychological disability requiring alteration of treatment strategy was found to be the most important outcome measure in the treatment of paroxysmal AF, but there was no difference between the 2 groups for deaths and cardiovascular morbidity. ${ }^{277}$

There are serious side effects of the antiarrhythmic drugs used in rhythm control, limiting the long-term outlook of that strategy. Recently, the use of catheter ablation has become more prevalent. There are many specialized institutions in Japan that perform this procedure safely and effectively, due in part to improved tools and techniques. This procedure can be expected to achieve rhythm control not only in paroxysmal but also persistent $\mathrm{AF}$, and reduction of stroke risk and improvement of vital prognosis can be expected. ${ }^{278}$ If a diagnosis of AFis made, it is desirable to proactively consult a cardiologist on the indications for catheter ablation before cerebral embolism occurs or the left atrium enlarges.

\subsection{Indications for and Methods of Anticoagulant Therapy}

It is necessary to properly evaluate the risk for bleeding and stroke to determine the indications for and methods of anticoagulant therapy. ${ }^{275}$

\subsubsection{Evaluation of Risk for Stroke}

In nonvalvular AF patients, it is advisable to evaluate the 


\begin{tabular}{|c|l|c|}
\hline \multicolumn{1}{|c|}{ Table 7. CHADS 2 Score } & Score \\
\hline & \multicolumn{1}{|c|}{ Risk factor } & 1 \\
\hline C & Congestive heart failure/LV dysfunction & 1 \\
\hline H & Hypertension & 1 \\
\hline A & Age $\geq 75$ years & 1 \\
\hline D & Diabetes mellitus & 2 \\
\hline S2 & Stroke/TIA & $0-6$ \\
\hline & Total &
\end{tabular}

LV, left ventricular; TIA, transient ischemic attack. Reproduced from Gage et al. ${ }^{83}$

risk for stroke before the selection of antithrombotic therapy. $\mathrm{CHADS}_{2}$ scoring is commonly used in Japan to evaluate the risk for stroke. Valvular AF refers to AF in patients with rheumatic mitral valve disease (mainly stenosis) or an artificial valve (mechanical or bioprosthetic valve). Nonvalvular AF increases the incidence of stroke with the accumulation of stroke risk factors, and CHADS 2 scoring (0-6 points) was proposed for the estimation of the stroke risk (Table 7). ${ }^{83}$ The acronym for this scoring system comes from the first letters of congestive heart failure, hypertension, age $\geq 75$ years, diabetes mellitus, and stroke/transient ischemic attack (TIA) (double weight). One point is given for each of the first 4 conditions, which moderately increase the risk for subsequent stroke. The annual incidence of stroke in patients with 1 of these 4 conditions is $5-8 \%$. Two points are given for a history of stroke/TIA, which highly increases the risk for subsequent stroke. The annual incidence of stroke in patients with a history of stroke/TIA reaches $12 \%$. The $\mathrm{CHADS}_{2}$ score is the sum of the points of these 4 conditions.

This scoring system is simple and useful and should be used first to evaluate the risk for stroke. Half of the patients with nonvalvular AF have a score of 0 or 1 point, and the effectiveness of warfarin has not been established in patients with these scores. The incidence of stroke is lower for patients with 1 point or less than for patients with 2 points or more. However, because the absolute number of patients who score 1 point is large, the absolute incidence of stroke is considerable. This scoring system is good for extracting the high-risk group, but it has a low ability to extract the true low-risk patients. Thus, the problem with this system is that there is a non-negligible number of patients with a score of 0 or 1 point who will have a stroke. The $\mathrm{CHA}_{2} \mathrm{DS}_{2}-$ VASc scoring system was developed to extract the low-risk patients, but it is a complicated system and difficult to use. In clinical practice, it is more realistic to use the simpler $\mathrm{CHADS}_{2}$ score while using the $\mathrm{CHA}_{2} \mathrm{DS}_{2}$-VASc score as a complementary tool.

\section{3.2.2 Evaluation of Bleeding Risk During Anticoagulant Therapy and Measures for Risk Reduction}

The relatively simple HAS-BLED scoring system was proposed to predict bleeding based on various risk factors (Table 8). ${ }^{279}$ The HAS-BLED score ranges from 0 to 9 points: 0 points for low risk (1-year risk for major bleeding: $1 \%), 1-2$ points for moderate risk $(2-4 \%)$, and $\geq 3$ points for high risk $(4-6 \%){ }^{280}$

\section{3.2.3 Practical Anticoagulant Therapy}

With anticoagulant therapy, if the benefit of reducing stroke risk outweighs the bleeding risk, the therapy should

\begin{tabular}{|c|c|c|}
\hline & Clinical presentation & Points \\
\hline $\mathrm{H}$ & Hypertension*1 & 1 \\
\hline A & Abnormal renal//iver function (1 point each) $)^{\star 2}$ & 2 \\
\hline $\mathrm{S}$ & Stroke & 1 \\
\hline $\mathrm{B}$ & Bleeding ${ }^{\star 3}$ & 1 \\
\hline $\mathrm{L}$ & Labile INR $^{\star 4}$ & 1 \\
\hline $\mathrm{E}$ & Elderly (>65 years) & 1 \\
\hline \multirow[t]{2}{*}{$\mathrm{D}$} & Drugs/alcohol (1 point each) ${ }^{\star 5}$ & 2 \\
\hline & Total & 9 \\
\hline
\end{tabular}

${ }^{*}$ Systolic blood pressure $>160 \mathrm{mmHg}$.

${ }^{*}$ Abnormal renal function: chronic dialysis or renal transplant; serum creatinine $>200 \mu \mathrm{mol} / \mathrm{L}$ (or $>2.26 \mathrm{mg} / \mathrm{dL}$ ). Abnormal liver function: chronic liver disease (such as cirrhosis) or abnormal test results (bilirubin >twice normal upper limit, AST/ALT/ATP $>3$-fold normal upper limit).

${ }^{*}$ History of bleeding or predisposition to bleeding (such as hemorrhagic diathesis or anemia).

${ }^{*} 4$ Labile INR, high INR or time in therapeutic range (TTR) $<60 \%$. ${ }^{*}$ Concurrent use of antiplatelet or nonsteroidal anti-inflammatory drugs or alcohol dependence. INR, international normalized ratio. (Reproduced from Pisters et al. Chest 2010; 138: 1093-1100.279 Copyright (2010) American College of Chest Physicians, with permission from Elsevier.)

be aggressively used. ${ }^{275}$ Patients with diabetes score at least 1 point in the $\mathrm{CHADS}_{2}$ scoring system due to the presence of diabetes alone, and anticoagulant therapy is indicated in most cases. In clinical practice, some patients with $\mathrm{AF}$ are found using an antiplatelet drug, such as aspirin, instead of an anticoagulant. However, aspirin has no preventive effect on stroke in patients with AF and has been shown to increase serious bleeding complications. ${ }^{281}$ Antiplatelet drugs should not be used to prevent cerebral embolism in patients with AF.

\section{(a) Warfarin}

With warfarin therapy, it is recommended that the PT-INR is controlled in the range of 2.0-3.0 in patients aged $<70$ years and $1.6-2.6$ in patients aged $\geq 70$ years. ${ }^{275} \mathrm{~A}$ metaanalysis was performed on 6 randomized controlled clinical trials conducted in Europe and the USA, and showed that warfarin therapy reduced the incidence of stroke by $68 \%$ in patients with nonvalvular AF. ${ }^{282}$ If warfarin therapy is selected for patients with a CHADS 2 score of 0 or 1 point, the therapy cannot be considered appropriate because the stroke prevention benefit does not outweigh the bleeding complication risk. Therefore, warfarin therapy is limited to a "may be considered" category in patients with a CHADS 2 score of 1 point (Figure 16).

\section{(b) Direct Oral Anticoagulants (DOACs)}

Warfarin had been the only oral anticoagulant in use for nearly 50 years, but dabigatran, a DOAC, came on the market in 2011. There are presently 4 types of DOACs available (Table 9). All have shown noninferior safety and effectiveness to warfarin in multiregional phase III clinical trials. ${ }^{283-287}$ Because the anticoagulant effect of DOACs is through selective inhibition of thrombin or factor Xa, their effect is minimally or not affected by food. Compared with warfarin, the advantages of the novel DOACs are that they do not require a routine blood test to monitor the effect, do not require frequent dosing adjustment in some patients, have considerably lower rates of intracranial hemorrhage, 




Figure 16. Anticoagulant therapy for atrial fibrillation. The novel oral anticoagulants are preferable to warfarin if the indications are the same. ${ }^{*}$ History of myocardial infarction, aortic plaque, and peripheral artery disease. ${ }^{*}$ Includes mechanical and bioprosthetic valves. ${ }^{*}$ Indications not approved by Japanese health insurance as of December 2013. Reproduced from the Guidelines for pharmacotherapy of atrial fibrillation (2013 revised edn), p. 21 (Figure 7). Revised on March 2020 as "JCS/JHRS 2020 guideline on pharmacotherapy of cardiac arrhythmias", and not available now. INR, international normalized ratio; TIA, transient ischemic attack.

have fewer drug interactions, show faster effects, and do not require or require only short-term preoperative bridging with heparin due to their short half-lives. The disadvantages are that they cannot be administered in patients with severely reduced renal function, they rapidly lose their effect if a dose is missed, owing to their short half-lives, they have no fully established measures against major bleeding, and they cost more, placing a higher financial burden on patients. It is important to note that each DOAC has criteria for reduced doses. They are contraindicated in patients with reduced renal function (Table 9).

Dabigatran and apixaban are "recommended" even in patients with a $\mathrm{CHADS}_{2}$ score of 1 point because they have clearly resulted in lower rates of major bleeding and intracranial hemorrhage than warfarin (Figure 16). ${ }^{275,283,286}$ The ROCKET AF trial ${ }^{285}$ and J-ROCKET AF trial ${ }^{287}$ were conducted on rivaroxaban, and the ENGAGE AF-TIMI 48 trial $^{284}$ on edoxaban. Patients with a $\mathrm{CHADS}_{2}$ score of 1 were not enrolled in these trials and there are no data for them. Therefore, rivaroxaban and edoxaban "may be considered"275 in such patients.

\section{(c) Anticoagulant Therapy for Dental Extraction and Surgery}

The safety for dental extraction under continued antithrombotic therapy has been reported in randomized controlled trials and observational studies. ${ }^{288}$ In 2010, 3 Japanese dental societies jointly published the "Scientific EvidenceBased Guidelines for Dental Extraction in Patients with Antithrombotic Therapy". The guidelines recommended that the PT-INR be measured within $72 \mathrm{~h}$ before dental extraction and be confirmed to be $\leq 3.0$, with dental extraction subsequently performed under continued warfarin therapy. ${ }^{289}$ Although sufficient evidence has not been established for DOACs, it is advisable to perform dental extraction under their continued use following the aforementioned recommendation for warfarin. ${ }^{275}$

For superficial minor surgery, postoperative hemorrhage control is desirable similar to that in dental extraction if such control can be easily performed. Many ophthalmologists perform cataract surgery under continued antithrombotic therapy because a lens is avascular and a patient is not prone to bleeding. ${ }^{275}$

For major surgery, warfarin is discontinued after the patient is hospitalized, and heparin administration is started. ${ }^{275}$ The heparin dose is adjusted to an activated partial thromboplastin time (APTT) of 1.5-2.5-fold of the control. Heparin is discontinued 4-6h preoperatively, or protamine is used to reverse heparin's effect, which is confirmed preoperatively by APTT measurement. Heparin and warfarin are resumed as soon as possible after surgery, and heparin is subsequently discontinued when the PT-INR is in the therapeutic range. For dabigatran, its use is discontinued 1-2 days preoperatively in patients with creatinine clearance $(\mathrm{CCr})$ of at least $50 \mathrm{~mL} / \mathrm{min}$ and $2-4$ days preoperatively in those with $\mathrm{CCr} 30-49 \mathrm{~mL} / \mathrm{min}$. Preoperative bridging with heparin is used, as needed, $12 \mathrm{~h}$ after dabigatran discontinuation. Rivaroxaban and edoxaban are discontinued $24 \mathrm{~h}$ preoperatively and preoperative bridging with heparin is used, as needed. Apixaban is discontinued $24-48 \mathrm{~h}$ preoperatively, depending on the bleeding risk, and preoperative bridging with heparin is 


\begin{tabular}{|c|c|c|c|c|}
\hline Product name & Pradaxa & Xarelto & Eliquis & Lixiana \\
\hline Generic name & Dabigatran & Rivaroxaban & Apixaban & Edoxaban \\
\hline Target factor & Thrombin & Factor Xa & Factor $\mathrm{Xa}$ & Factor $\mathrm{Xa}$ \\
\hline Dosage forms & $75 \mathrm{mg} / 110 \mathrm{mg}$ & $10 \mathrm{mg} / 15 \mathrm{mg}$ & $2.5 \mathrm{mg} / 5 \mathrm{mg}$ & $15 \mathrm{mg} / 30 \mathrm{mg} / 60 \mathrm{mg}$ \\
\hline $\begin{array}{l}\text { Normal daily dose } \\
\text { (for nonvalvular atrial } \\
\text { fibrillation) }\end{array}$ & $300 \mathrm{mg}$ or $220 \mathrm{mg}$ & $15 \mathrm{mg}$ & $10 \mathrm{mg}$ & $60 \mathrm{mg}$ \\
\hline Dosing frequency & $\mathrm{BID}$ & OD & BID & OD \\
\hline $\begin{array}{l}\text { Criteria for reduced } \\
\text { dose }\end{array}$ & $\begin{array}{l}\text { As needed (careful } \\
\text { administration with } \\
\text { consideration for } \\
110 \mathrm{mg} / \text { day BID in the } \\
\text { following patients) } \\
\text { - } 30 \leq C \mathrm{Cr} \leq 50 \mathrm{~mL} / \mathrm{min} \\
\text { - Concomitant use of } \\
\text { P-glycoprotein inhibitor } \\
\text { - Age } \geq 70 \text { years } \\
\text { - History of gastrointestinal } \\
\text { bleeding }\end{array}$ & $\begin{array}{l}30 \leq \mathrm{CCr}<50 \mathrm{~mL} / \mathrm{min} \\
\text { (except careful } \\
\text { administration for patients } \\
\text { with } 15 \leq \mathrm{CCr}<30 \mathrm{~mL} / \mathrm{min} \text { ) }\end{array}$ & $\begin{array}{l}\geq 2 \text { of the following criteria } \\
\text { apply (age } \geq 80 \text { years, } \\
\text { weight } \leq 60 \mathrm{~kg} \text {, and } / \mathrm{or} \mathrm{CCr} \\
\geq 1.5 \mathrm{mg} / \mathrm{dL} \text { ) }\end{array}$ & $\begin{array}{l}\geq 1 \text { of the following criteria } \\
\text { apply (weight } \leq 60 \mathrm{~kg} \text {, } \\
30 \leq \mathrm{C} \mathrm{C}<50 \mathrm{~mL} / \mathrm{min} \text {, and } / \mathrm{or} \\
\text { concomitant use of } \\
\text { P-glycoprotein, except } \\
\text { careful administration for } \\
\text { patients with } \\
15 \leq C \mathrm{C} r 30 \mathrm{~mL} / \mathrm{min} \text { ) }\end{array}$ \\
\hline $\begin{array}{l}\text { Daily dose for } \\
\text { reduced dose }\end{array}$ & $220 \mathrm{mg}$ & $10 \mathrm{mg}$ & $5 \mathrm{mg}$ & $30 \mathrm{mg}$ \\
\hline Contraindications & $\mathrm{CCr}<30 \mathrm{~mL} / \mathrm{min}$ & $\mathrm{CCr}<15 \mathrm{~mL} / \mathrm{min}$ & $\mathrm{CCr}<15 \mathrm{~mL} / \mathrm{min}$ & $\mathrm{CCr}<15 \mathrm{~mL} / \mathrm{min}$ \\
\hline Other dosage form & & Granules & & OD tablets \\
\hline Antidote & Available & None & None & None \\
\hline
\end{tabular}

$\mathrm{CCr}$ (creatinine clearance) is calculated using the Cockcroft-Gault equation.

considered.

With discontinuance of an antithrombotic drug, bridging with heparin is frequently performed due to the short half-life of heparin. Thus, this bridging enables the antithrombotic drug to be continued as long as possible. The heparin dose is adjusted to an APTT of 1.5-2.5-fold of the control. The effectiveness has not been established for bridging with heparin, and dose management should be performed carefully if bridging with heparin. ${ }^{275}$

In 2012, the Japan Gastroenterological Endoscopy Society revised its "Guidelines for Gastroenterological Endoscopy in Patients Undergoing Antithrombotic Treatment".290 The revisions included the following 4 classifications of endoscopic practice by bleeding risk: (1) conventional gastroenterological endoscopy (observation), (2) endoscopic mucosal biopsy (excluding endoscopic ultrasound-guided fine needle aspiration), (3) gastroenterological endoscopy with a low-risk for bleeding (balloon endoscopy; marking; gastrointestinal, pancreatic, and biliary stenting; and endoscopic papillary balloon dilation); and (4) gastroenterological endoscopy with a high-risk for bleeding (including polypectomy and endoscopic mucosal resection). If patients are undergoing endoscopic mucosal biopsy or endoscopy with a low-risk for bleeding and if they are using an anticoagulant or antiplatelet drug, then cessation of the drug is not necessary for the procedure. In 2017, the "Guidelines for Gastroenterological Endoscopy in Patients Undergoing Antithrombotic Treatment: 2017 Appendix on Anticoagulants Including Direct Oral Anticoagulants (DOACs)"291 was published. For gastroenterological endoscopy with a high-risk for bleeding, the guidelines stated that DOAC users should continue the drug's use until the day before the procedure and then discontinue it on the morning of the procedure. The guidelines recommended that DOAC use be resumed the morning following the procedure.

If patients using warfarin are to undergo biopsy, PT-INR is measured to confirm that it is in the normal therapeutic range and then the biopsy is performed. If patients are using a combination of $\geq 2$ drugs, careful management is necessary depending on the patient, and bridging anticoagulation with heparin is used as a general rule. In gastroenterological endoscopy with a high-risk for bleeding, the drug is temporarily discontinued as for major surgery, and bridging with heparin is performed as needed.

\subsection{Indications for and Methods of Rate Control}

There is a concern of HF if AF with a high heart rate continues, even without organic heart disease. It is important to maintain a heart rate of $\leq 130$ beats/min during AF to prevent HF. For rate control, a $\beta$-blocker, non-dihydropyridine CCB (verapamil or diltiazem), or digitalis is selected. However, rate control using digitalis has been suggested to result in high mortality rates in various studies. Therefore, its use is thought to be limited to cases where the patient's heart rate cannot be controlled using other drugs. ${ }^{292}$ A combination of catheter ablation of the atrioventricular node and a pacemaker is selected to achieve rate control in rare cases, such as patients with unsatisfactory rate control using multiple drugs, or patients with unsatisfactory rhythm control using antiarrhythmic drugs or pulmonary vein isolation with catheter ablation. It is desirable to consult a cardiologist on the indications for the combination of catheter ablation of the atrioventricular node and a pacemaker.

\subsection{Rhythm Control Using Drugs}

Sinus rhythm is preferable to AF because discomfort caused by irregular heartbeat and abnormal tachycardia can be avoided in the former and because a booster effect of atrial contraction on cardiac pumping function can be expected. ${ }^{275}$ Its major advantage is that it prevents intra-atrial thrombus formation. However, serious life-threatening side effects can 
occur when preventing its recurrence using simple chemical defibrillation, electrical defibrillation, or antiarrhythmic drugs. Thus, a careful examination is necessary. ${ }^{277}$ If rhythm control is desirable, it is appropriate to consult a cardiologist and determine the long-term treatment strategy (Figure 15). The success rate of catheter ablation for AF has improved and its safety has increased over the years. Therefore, it is thought important to proactively recommend catheter ablation to improve long-term prognosis.

\subsection{Catheter Ablation}

The success rate of catheter ablation has improved for paroxysmal and persistent AF, and this procedure is rapidly becoming widely used. The "Guidelines for pharmacotherapy of atrial fibrillation (2013 revised edition)" were published by the Japanese Circulation Society. In the guidelines, catheter ablation for paroxysmal AF is given a Class I recommendation in certain patients when the procedure is done at institutions performing at least 50 cases/year of AF ablation. These patients are those with symptoms, AF that is uncontrollable by antiarrhythmic drugs, preserved left ventricular function, left atrial dimension of $\leq 45 \mathrm{~mm}$, no left intra-atrial thrombus, and aged $\leq 75$ years. ${ }^{275}$ Today, a satisfactory outcome can be expected using catheter ablation not only in patients with paroxysmal AF but also those with a certain level of left atrial enlargement and those with persistent AF. ${ }^{278}$ A randomized controlled trial has not yet been conducted that compares catheter ablation and pharmacotherapy alone. However, a number of non-randomized trials have reported that catheter ablation reduced death and stroke. ${ }^{293}$ If AF occurs in a patient with diabetes, appropriate anticoagulant therapy should be started and then a timely consultation with a cardiologist on the indications of catheter ablation is desirable.

\subsection{Points of Caution on Treatment in Patients With Diabetes and AF}

Caution is required for the use of cibenzoline among the antiarrhythmic drugs because it can induce a serious hypoglycemic attack. Caution is also required for SU, biguanide, and $\alpha$-glucosidase inhibitor, among the antidiabetic drugs, because they have been reported to potentiate the effect of warfarin. P-glycoprotein inhibitors, associated with the DOAC dose reduction criteria, are not included among the antidiabetic drugs. For rate control, a $\beta$-blocker, such as carvedilol or bisoprolol, is selected because it will have a small effect on glucose metabolism.

\section{Criteria for Patient Referral}

\section{Criteria for Patient Referral From a Diabetologist to a Cardiologist}

\section{I1.1 Criteria for Referral of Asymptomatic Patients}

(a) Depending on the patient's age and the duration of diabetes, evaluate the coronary risk factors (e.g., smoking, hypertension, dyslipidemia, CKD, family history, and history of atherosclerotic cardiovascular disease); and, to the extent they are available at the institution, perform tests such as chest X-ray, ECG, BNP or NT-proBNP measurement, vascular function test, carotid duplex, echocardiography, and unenhanced MDCT (evaluation of coronary artery calcification). Then comprehensively determine whether to refer the patient to a cardiologist using the results or changes over time as a reference. In this process, use as a reference the diagnostic criteria flowcharts for various cardiovascular diseases in this consensus statement. In particular, because patients with diabetes are highly likely to have silent myocardial ischemia, proactively consider a detailed examination by a cardiologist, especially for patients with a long history of diabetes and patients with an accumulation of coronary risk factors.

(b) Consider a referral to a cardiologist if the aforementioned tests are difficult to perform or unavailable at the institution or the results are difficult to interpret.

\section{I1.2 Referral of Symptomatic Patients}

(a) Patients with hypertension who have difficulty achieving the target blood pressure (b) Patients with ECG changes or chest symptoms suspicious of CAD

(c) Patients with AF (including asymptomatic) or other arrhythmia (frequent premature ventricular contractions)

(d) Patients with HF symptoms such as dyspnea and pedal edema; increased cardiothoracic ratio on chest X-ray or pulmonary congestion; or elevated $\mathrm{BNP}(\geq 100 \mathrm{pg} / \mathrm{mL})$ or NT-proBNP $(\geq 400 \mathrm{pg} / \mathrm{mL})$

(e) Patients with lower limb ischemic symptoms suspicious of arteriosclerosis obliterans or decreased ABI $(<0.9)$

Using the aforementioned criteria as a reference, determine flexibly whether to refer a patient to a cardiologist after considering the patient's characteristics/circumstances, including institutional or regional medical care, and social resource and support systems. After referral, the patient is cotreated by the cardiologist and diabetologist based on the diagnostic results and will continue to undergo treatment for cardiovascular disease and diabetes. If the patient requires a reverse referral from a cardiologist to a diabetologist based on subsequent treatment progress, the cardiologist provides information on relevant cardiovascular disease, including information on necessary subsequent measures.

\section{Criteria for Patient Referral From a Cardiologist to a Diabetologist}

I 2.1 Criteria for Referral of Patients Who Newly Develop Diabetes (Cotreat After Referral or Consider Continuing Diabetes Treatment With a Cardiologist After a Certain Time Period)

(a) Patients with markedly poor glycemic control (e.g., 
patients with symptoms such as thirst, polyuria, or weight loss; fasting blood glucose $\geq 250 \mathrm{mg} / \mathrm{dL}$; or casual blood glucose $\geq 350 \mathrm{mg} / \mathrm{dL}$ ); or a suspicion of type 1 diabetes (using measures for type 1 diabetes onset such as being positive for urinary ketone bodies; being positive for anti-GAD antibodies; and fasting blood C-peptide $\leq 0.5 \mathrm{ng} / \mathrm{mL}$ )

(b) Patients who require education on diabetes (information on basic disease concept of diabetes and on other complications of diabetes (nephropathy, retinopathy, and neuropathy))

(c) Other: test and treatment strategies are unknown

\subsection{Criteria for Referral of Patients in Whom Substantial Changes in Diabetes Treatment Are Desirable (Cotreat After Referral or Consider Continuing Diabetes Treatment With a Cardiologist After a Certain Time Period)}

(a) Patients in whom poor glycemic control continues for a certain time period (reference values are $\mathrm{HbAlc}$ $\geq 8.0 \%$ in the nonelderly and $\mathrm{HbA} 1 \mathrm{c} \geq 8.5 \%$ in the elderly for at least 3 months)

(b) Patients requiring re-evaluation of diabetes treatment (such as when considering beginning the use of a drug (SU or insulin) with a risk for severe hypoglycemia)

(c) Patients with acute exacerbation of diabetes or acute complications (steroid use, pancreatic disease/conditions (pancreatic cancer or post-pancreatectomy), rapid exacerbation of blood glucose level due to infection, or acute metabolic failure such as lactic acidosis, hyperosmolar hyperglycemic state, and diabetic ketoacidosis*)

(d) Patients who require glycemic control peri- or preoperatively

(e) Patients who require re-education on diabetes (i.e., basic disease concept of diabetes and other complications of diabetes (nephropathy, retinopathy, and neuropathy)) *Caution is required in patients using an SGLT2 inhibitor, because even if their blood glucose level is near normal, they can have ketoacidosis (euglycemic ketoacidosis).

\section{2.3 Criteria for Referral of Patients in Whom Continued Diabetes Management by a Diabetologist is Desirable (Also With Consideration of Continued Cotreatment by Both Specialists)}

Patients who might have severely depleted endogenous insulin secretion (patients with type 1 diabetes; frequently repeated hypoglycemic episodes; brittle diabetes (marked blood glucose fluctuations); or fasting blood C-peptide $\leq 0.5 \mathrm{ng} / \mathrm{mL}$; or post-pancreatectomy patients).

Using the aforementioned criteria as a reference, determine flexibly whether to refer a patient to a diabetologist after considering the patient's characteristics/circumstances, institutional and regional medical care, and social resource and support systems.

\section{Acknowledgments}

We appreciate the special assistance given by Mr. Takashi Itakiyo and Ms. Koko Okuda, as well as the office staff of the Japanese Circulation Society and the Japan Diabetes Society in support of this work.

\section{Sources of Funding}

\section{Disclosures}

H. Ito., T.M., I.K., K.N. are members of the Circulation Journal's Editorial Team.

Disclosure of individual potential conflicts of interest

(1) Compensation (officers and advisors) 1 million yen or more

(2) Stock profit 1 million yen or more or holding $5 \%$ or more

(3) Patent fee 1 million yen or more

(4) Lecturer's fee 500,000 yen or more

(5) Manuscript fee 500,000 yen or more

(6) Research expenses and grants 1 million yen or more

(7) Scholarship (encouragement) donation 1 million yen or more

(8) Endowed course 1 million yen or more

(9) Travel expenses, gifts 50,000 yen or more

B. Spouse of Declarer

Eiichi Araki: (4), AstraZeneca K.K., MSD K.K., ONO PHARMACEUTICAL CO., LTD., Kowa Company, Ltd., Sanofi K.K., Sumitomo Dainippon Pharma Co., Ltd., Mitsubishi Tanabe Pharma Corporation, NOVO NORDISK PHARMA LTD. (7), Astellas Pharma Inc., MSD K.K., ONO PHARMACEUTICAL CO., LTD., Sanofi K.K, DAIICHI SANKYO CO., LTD, TAISHO PHARMACEUTICAL CO., LTD., Sumitomo Dainippon Pharma Co., Ltd., TAKEDA PHARMACEUTICAL COMPANY LIMITED, Mitsubishi Tanabe Pharma Corporation, NIPPON BOEHRINGER INGELHEIM CO., LTD., NOVARTIS PHARMA K.K., NOVO NORDISK PHARMA LTD., BAYER YAKUHIN, LTD., PFIZER JAPAN INC. (8), MSD K.K., ONO PHARMACEUTICAL CO., LTD., Terumo Corporation.

Hideki Ishii: (4), Astellas Pharma Inc., AstraZeneca K.K., MSD K.K., DAIICHI SANKYO CO., LTD, CHUGAI PHARMACEUTICAL CO., LTD., BAYER YAKUHIN, LTD., PFIZER JAPAN INC., Bristol-Myers Squibb K.K.

Hiroshi Ito: (4), Astellas Pharma Inc., AstraZeneca K.K., MSD K.K., DAIICHI SANKYO CO., LTD, CHUGAI PHARMACEUTICAL CO., LTD., BAYER YAKUHIN, LTD., PFIZER JAPAN INC., Bristol-Myers Squibb K.K. (6), Kowa Company, Ltd., NOVARTIS PHARMA K.K. (7), Astellas Pharma Inc., MSD K.K., ONO PHARMACEUTICAL CO., LTD., Kowa Company, Ltd., Sanofi K.K., DAIICHI SANKYO CO, LTD, TAISHO PHARMACEUTICAL CO., LTD., Sumitomo Dainippon Pharma Co., Ltd., TAKEDA PHARMACEUTICAL COMPANY LIMITED, Mitsubishi Tanabe Pharma Corporation, NIPPON BOEHRINGER INGELHEIM CO., LTD., MOCHIDA PHARMACEUTICAL CO., LTD. (8), Medtronic Japan Co., Ltd.

Nobuya Inagaki: (4), Astellas Pharma Inc., MSD K.K., ONO PHARMACEUTICAL CO., LTD., Kowa Company, Ltd., TAKEDA PHARMACEUTICAL COMPANY LIMITED, Mitsubishi Tanabe Pharma Corporation, NIPPON BOEHRINGER INGELHEIM CO., LTD., NOVO NORDISK PHARMA LTD. (6), DAIICHI SANKYO CO., LTD, Terumo Corporation, Drawbridge Inc. (7), Astellas Pharma Inc., MSD K.K., ONO PHARMACEUTICAL CO., LTD., KISSEI PHARMACEUTICAL CO., LTD., Kyowa Kirin Co., Ltd., Sanofi K.K, SANWA KAGAKU KENKYUSHO CO., LTD., DAIICHI SANKYO CO., LTD, Sumitomo Dainippon Pharma Co., Ltd., TAKEDA PHARMACEUTICAL COMPANY LIMITED, Mitsubishi Tanabe Pharma Corporation, TEIJIN PHARMA Limited, ELI LILLY JAPAN K.K., Japan Tobacco Inc., NIPPON BOEHRINGER INGELHEIM CO., LTD., NOVARTIS PHARMA K.K., NOVO NORDISK PHARMA LTD., Life Scan Japan.

Kenjiro Imai: None to disclose.

Kohjiro Ueki: (4), Astellas Pharma Inc., AstraZeneca K.K., MSD K.K., ONO PHARMACEUTICAL CO., LTD., Sanofi K.K, DAIICHI SANKYO CO., LTD, Sumitomo Dainippon Pharma Co., Ltd., TAKEDA PHARMACEUTICAL COMPANY LIMITED, Mitsubishi Tanabe Pharma Corporation, NIPPON BOEHRINGER INGELHEIM CO., LTD., NOVO NORDISK PHARMA LTD. (6), Astellas Pharma Inc., Abbott Japan LLC., MSD K.K., ELI LILLY JAPAN K.K., NIPPON BOEHRINGER INGELHEIM CO., LTD., NOVO NORDISK PHARMA LTD. (7), Astellas Pharma Inc., MSD K.K., ONO PHARMACEUTICAL CO., LTD., Kyowa Kirin Co., Ltd., Sumitomo Dainippon Pharma Co., Ltd., TAKEDA 
PHARMACEUTICAL COMPANY LIMITED, Mitsubishi Tanabe Pharma Corporation, NIPPON BOEHRINGER INGELHEIM CO., LTD., NOVO NORDISK PHARMA LTD.

Takashi Kadowaki: (4), MSD Corporation, Daiichi Sankyo Co., Ltd., Takeda Pharmaceutical Co., Ltd., Mitsubishi Tanabe Pharma Corporation, Kowa Pharmaceutical Co., Ltd., Astellas Pharma Inc., Ono Pharmaceutical Co., Ltd., AstraZeneca K.K., Sumitomo Dainippon Pharma Co., Ltd., Sanofi K.K., Eli Lilly Japan K.K., Nippon Boehringer Ingelheim Co., Ltd., Sanwa Kagaku Kenkyusho Co., Ltd., Kyowa Hakko Kirin Co., Ltd., Taisho Pharmaceutical Co., Ltd., Novo Nordisk Pharma Ltd. (6), MSD Corporation, Daiichi Sankyo Co., Ltd., Novo Nordisk Pharma Ltd., Sanofi K.K., Takeda Pharmaceutical Co., Ltd. (8), Asahi Mutual Life Insurance Company, Takeda Pharmaceutical Co., Ltd., TERUMO Corporation, MSD Corporation, Novo Nordisk Pharma Ltd., Nippon Boehringer Ingelheim Co., Ltd.

Issei Komuro: (4), Astellas Pharma Inc., MSD K.K., Amgen Astellas BioPharma K.K., AstraZeneca K.K., Pfizer Japan Inc., ONO PHARMACEUTICAL CO. LTD., DAIICHI SANK YO COMPANY, LIMITED., Takeda Pharmaceutical Company Limited., Mitsubishi Tanabe Pharma Corporation, BAYER YAKUHIN, LTD, BristolMyers Squibb Company, Nippon Boehringer Ingelheim Co. Ltd., Actelion Pharmaceuticals Japan Ltd. (6), QVIA Services Japan, ONO PHARMACEUTICAL CO. LTD. (7), Dainippon Sumitomo Pharma Co. Ltd., Terumo Corporation, DAIICHI SANKYO COMPANY, LIMITED, Takeda Pharmaceutical Company Limited, Mitsubishi Tanabe Pharma Corporation, TEIJIN PHARMA LIMITED.

Masataka Sata: (4), Amgen Astellas BioPharma K.K., Astellas Pharma Inc., MSD K.K., KOWA PHARMACEUTICAL COMPANY LTD., DAIICHI SANKYO CO., LTD, TAKEDA PHARMACEUTICAL COMPANY LIMITED, Mitsubishi Tanabe Pharma Corporation, NIPPON BOEHRINGER INGELHEIM CO., LTD., BAYER YAKUHIN, LTD., Bristol-Myers Squibb K.K. (6), DAIICHI SANKYO CO., LTD, NIPPON BOEHRINGER INGELHEIM CO., LTD., BAYER YAKUHIN, LTD. (7), Astellas Pharma Inc., MSD K.K., DAIICHI SANKYO CO., LTD, TAKEDA PHARMACEUTICAL COMPANY LIMITED, Mitsubishi Tanabe Pharma Corporation. (8), NIPPON BOEHRINGER INGELHEIM CO., LTD.

Takehiro Sugiyama: (8), JMDC.

Atsushi Tanaka: (6), GlaxoSmithKline K.K.

Koichi Node: (4), Astellas Pharma Inc., AstraZeneca K.K., MSD K.K., OTSUKA PHARMACEUTICAL Co., Ltd., ONO PHARMACEUTICAL CO., LTD., KOWA PHARMACEUTICAL COMPANY LTD., DAIICHI SANKYO CO., LTD, TAKEDA PHARMACEUTICAL COMPANY LIMITED, Mitsubishi Tanabe Pharma Corporation, ELI LILLY JAPAN K.K., NIPPON BOEHRINGER INGELHEIM CO., LTD., BAYER YAKUHIN, LTD. (6), Asahi Kasei Corp., Astellas Pharma Inc., Mitsubishi Tanabe Pharma Corporation, TEIJIN PHARMA Limited, Terumo Corporation, NIPPON BOEHRINGER INGELHEIM CO., LTD., BAYER YAKUHIN, LTD., Eli Lilly and Company (USA). (7), Astellas Pharma Inc., ONO PHARMACEUTICAL CO., LTD., DAIICHI SANKYO CO., LTD, TAKEDA PHARMACEUTICAL COMPANY LIMITED, TEIJIN PHARMA Limited, ELI LILLY JAPAN K.K., NIPPON BOEHRINGER INGELHEIM CO., LTD., NOVARTIS PHARMA K.K., BAYER YAKUHIN, LTD., PFIZER JAPAN INC., Bristol-Myers Squibb K.K., Sanofi K.K.

Toyoaki Murohara: (4), Actelion Pharmaceuticals Japan Ltd., Amgen Astellas BioPharma K.K., AstraZeneca K.K., MSD K.K., Kowa Company, Ltd., DAIICHI SANKYO CO., LTD, TAKEDA PHARMACEUTICAL COMPANY LIMITED, Mitsubishi Tanabe Pharma Corporation, NIPPON BOEHRINGER INGELHEIM CO., LTD., BAYER YAKUHIN, LTD. (7), Astellas Pharma Inc., OTSUKA PHARMACEUTICAL Co., Ltd., DAIICHI SANKYO CO., LTD, TAKEDA PHARMACEUTICAL COMPANY LIMITED, TEIJIN PHARMA Limited, BAYER YAKUHIN, LTD.

Shunsuke Yamane: (7), Mitsubishi Tanabe Pharma Corporation.

Disclosure of Potential Conflicts of Interest as Organization

Companies that funded the activities of the Japanese Circulation
Society from January 1, 2017 to December 31, 2019

\section{Co-Sponsored Seminar}

Actelion Pharmaceuticals Japan Ltd., Asahi Kasei ZOLL Medical Corporation., Amgen Astellas BioPharma K.K., Astellas Pharma Inc., AstraZeneca K.K., Abbott Japan LLC., Abbott Vascular Japan Co., Ltd., Abbott Medical Japan LLC, Alere Medical Co.,Ltd., Alnylam Japan, AnGes, Inc., EA Pharma Co.,Ltd., A\&D Company, Limited., Eisai Co., Ltd., AEGERION PHARMACEUTICALS K.K. Edwards Lifesciences Corporation., MSD K.K., LSI Medience Corporation, OTSUKA PHARMACEUTICAL Co., Ltd., ONO PHARMACEUTICAL CO., LTD., Japanese Coronary Spasm Association, CANON MEDICAL SYSTEMS CORPORATION, Kyowa Medex Co., Ltd, Cuorips Inc., GlaxoSmithKline K.K., KOWA PHARMACEUTICAL COMPANY LTD., Kotobuki pharmaceutical Co., Ltd., Sanofi K.K, Sawai Pharmaceutical Co., Ltd., Sun Medical Technology Research Corp., SANWA KAGAKU KENKYUSHO CO., LTD., CSL Behring K.K., Siemens Healthcare Diagnostics K.K., JCR Pharmaceuticals Co., Ltd., SHIONOGI \& CO., LTD., CMIC HOLDINGS Co., Ltd., SUZUKEN CO.,LTD., SEKISUI MEDICAL CO., LTD., Century Medical, Inc., St. Jude Medical Japan Co., Ltd., DAIICHI SANKYO CO., LTD, TAISHO PHARMACEUTICAL CO., LTD., Sumitomo Dainippon Pharma Co., Ltd., TAKEDA PHARMACEUTICAL COMPANY LIMITED, Mitsubishi Tanabe Pharma Corporation, CHUGAI PHARMACEUTICAL CO., LTD., TSUMURA \& CO., DS Pharma Biomedical Co.,Ltd., Teijin Home Healthcare Limited, TEIJIN PHARMA Limited, Terumo Corporation, DENSO CORPORATION, TOSHIBA MEDICAL SYSTEMS CORPORATION, Tosoh Corporation., Toray Industries, Inc., TOA EIYO LTD., Nipro Corporation, Abiomed Japan K.K., ELI LILLY JAPAN K.K., Japanese Organization for Medical Device Development, Inc., The Japanese Society of Nuclear Medicine, Nippon Kayaku Co.,Ltd., W. L. Gore \& Associates G.K., The Japanese Society of Nuclear Cardiology., Nippon Shinyaku Co., Ltd., NIPPON BOEHRINGER INGELHEIM CO., LTD., Nihon Medi-Physics Co.,Ltd., Medtronic Japan Co., Ltd., Japan Lifeline Co.,Ltd., NOVO NORDISK PHARMA LTD., BAYER YAKUHIN, LTD., BIOTRONIK Japan, Inc., PFIZER JAPAN INC., Philips Respironics GK, FUKUDA LIFE TECH K.K., FUKUDA DENSHI CO., LTD., FUJIFILM RI Pharma Co.,Ltd., FUJIFILM Medical Co., Ltd, FUJIFILM Toyama Chemical Co., Ltd., FUJIYAKUHIN Co., Ltd., FUJIREBIO Inc., Bristol-Myers Squibb K.K, Boston Scientific Japan KK, Volcano Japan Co., Ltd., MYLAN EPD G.K., MOCHIDA PHARMACEUTICAL CO., LTD., ResMed.KK

\section{Supporting Member}

Astellas Pharma Inc., AstraZeneca K.K., IGAKU-SHOIN Ltd., Ueda Japan Radio Co., Ltd., Eisai Co., Ltd., MSD K.K., ElementHRC, OTSUKA PHARMACEUTICAL Co., Ltd., Omura Printing Co., Ltd., OMRON HEALTHCARE Co., Ltd., Kaito, Gakuju Shoin, KK, KAKEN PHARMACEUTICAL CO., LTD., Kyoto Pharmaceutical Industries, Ltd., KYOWA KIKAKU Ltd, Goodman Co.,LTD, Kawakita Printing Co., Ltd., KOWA PHARMACEUTICAL COMPANY LTD., Congrès Inc, Sanofi K.K, GE Healthcare Japan Corp., Siemens Healthcare K.K., JTB corp. Western Japan MICE division, SHIMADZU CORPORATION Medical project planning department, St. Jude Medical Japan Co., Ltd., Sompo Japan Insurance Inc., DAIICHI SANKYO CO., LTD Marketing Department, TAISHO PHARMACEUTICAL CO., LTD., Sumitomo Dainippon Pharma Co., Ltd., Mitsubishi Tanabe Pharma Corporation, TEIJIN PHARMA Limited, Tokyo Planning Center KK., Toray Medical Co.,Ltd., TOA EIYO LTD., TORII PHARMACEUTICAL CO., LTD., Nankodo Co., Ltd., Nissen Techno Comms, Nipro Corporation, Japan Convention Services, Inc., Zeon Corporation, NIPPON BOEHRINGER INGELHEIM CO., LTD., Nihon Medi-Physics Co.,Ltd., Medtronic Japan Co., Ltd., BAYER YAKUHIN, LTD., BIOTRONIK Japan, Inc., Hitachi Aloka Medical, Ltd, PFIZER JAPAN INC., FUKUDA COLIN Co.,Ltd., Fukuda AD Agency, FUKUDA DENSHI CO., LTD., Bristol-Myers Squibb K.K., Proactive.Inc, HEIWA BUSSAN CO.,LTD, MEDICAL VIEW CO.,LTD., Medical Review Co., Ltd., MOCHIDA PHARMACEUTICAL CO., LTD., YOSHIDA PRINTING GROUP., Radiometer K.K., Roche Diagnostics K.K.

\section{Research Grant \\ None}

Honoring Program

Japan Heart Foundation 
Companies that funded the activities of the Japan Diabetes Society from January 1, 2017 to December 31, 2019

\section{Co-Sponsored Seminar}

ARKRAY, Inc., ARKRAY Marketing, Inc., Asahi Kasei Pharma Corporation., Ajinomoto Co., Inc., ASKA Pharmaceutical Co.,Ltd., Astellas Pharma Inc., AstraZeneca K.K., Abbott Japan LLC., Abbott Vascular Japan Co., Ltd., Alere Medical Co.,Ltd., InBody Japan Inc., Welbe, Inc., ARBROWN CO.,LTD., EIKEN CHEMICAL CO.,LTD., Eisai Co., Ltd., AEGERION PHARMACEUTICALS K.K., SRL, Inc., MSD K.K., LSI Medience Corporation, OTSUKA PHARMACEUTICAL Co., Ltd., ONO PHARMACEUTICAL CO., LTD., KAKEN PHARMACEUTICAL CO., LTD., KISSEI PHARMACEUTICAL CO., LTD., Kyowa Kirin Co., Ltd., Kyowa Medex Co., Ltd, Gilead Sciences, Inc., Kracie Pharmaceutical, Ltd., Covidien Japan Inc., Kowa Company, Ltd., Cosmic Corporation Co., Ltd., Kotobuki pharmaceutical Co., Ltd., Sanofi K.K, SANWA KAGAKU KENKYUSHO CO., LTD., Santen Pharmaceutical Co., Ltd., Johnson \& Johnson K.K., DAIICHI SANKYO CO., LTD, TAISHO PHARMACEUTICAL CO., LTD., TAISHO PHARMACEUTICAL CO., LTD., Sumitomo Dainippon Pharma Co., Ltd., Mitsubishi Tanabe Pharma Corporation, TAKEDA PHARMACEUTICAL COMPANY LIMITED, Terumo Corporation, Nikkiso Co., Ltd., Nipro Corporation, ELI LILLY JAPAN K.K., NIPPON BOEHRINGER INGELHEIM CO., LTD., Nippon Becton Dickinson Company, Ltd., Medtronic Japan Co., Ltd., NOVARTIS PHARMA K.K., NOVO NORDISK PHARMA LTD., BAYER YAKUHIN, LTD., Hakubaku Co.,Ltd., PFIZER JAPAN INC., FUKUDA COLIN Co.,Ltd., FUKUDA DENSHI CO., LTD., FUJIFILM Pharma Co., Ltd., FUJIFILM Toyama Chemical Co., Ltd., Healthy Network, HORIBA, Ltd., MYLAN EPD G.K., MOCHIDA PHARMACEUTICAL CO., LTD., UNEX corporation, LifeScan Japan, RIZAP GROUP, Inc., Roche DC Japan K.K.

\section{Supporting Member}

ARKRAY Marketing, Inc., Astellas Pharma Inc., AstraZeneca K.K., Abbott Japan LLC., EA Pharma Co.,Ltd., Eisai Co., Ltd., H+B Life Science Co.,Ltd., SRL, Inc., MSD K.K., ONO PHARMACEUTICAL CO., LTD., KAKEN PHARMACEUTICAL CO., LTD., KISSEI PHARMACEUTICAL CO., LTD., Kyowa Kirin Co., Ltd., Kowa Company, Ltd., Sanofi K.K, SANWA KAGAKU KENKYUSHO CO., LTD., SHIONOGI \& CO., LTD., SYSMEX CORPORATION, Johnson \& Johnson K.K., SEKISUI MEDICAL CO., LTD., DAIICHI SANKYO CO., LTD, TAISHO PHARMACEUTICAL CO., LTD., TAISHO PHARMACEUTICAL CO., LTD., Sumitomo Dainippon Pharma Co., Ltd., TAKEDA PHARMACEUTICAL COMPANY LIMITED, Mitsubishi Tanabe Pharma Corporation, CHUGAI PHARMACEUTICAL CO., LTD., Terumo Corporation, Tosoh Corporation., Nipro Corporation, ELI LILLY JAPAN K.K., Japan Tobacco Inc., NIPPON BOEHRINGER INGELHEIM CO., LTD., Medtronic Japan Co., Ltd., NOVO NORDISK PHARMA LTD., Panasonic Healthcare Co., Ltd., PHC Holdings Corporation, Bunkodo Co., Ltd., HORIBA, Ltd., LifeScan Japan, Roche DC Japan K.K.

\section{Research Grant}

Abbott Japan LLC., MSD K.K., Sanofi K.K, TAKEDA PHARMACEUTICAL COMPANY LIMITED, ELI LILLY JAPAN K.K., NIPPON BOEHRINGER INGELHEIM CO., LTD., NOVO NORDISK PHARMA LTD.

Honoring Program

Sanofi K.K, ELI LILLY JAPAN K.K., NOVO NORDISK PHARMA LTD.

(The company name is as of December 2019.)

\section{Ethical Statement}

This article does not contain any studies with human or animal subjects performed by any of the authors.

\section{References}

1. Stratton IM, Adler AI, Neil HA, Matthews DR, Manley SE, Cull CA, et al. Association of glycaemia with macrovascular and microvascular complications of type 2 diabetes (UKPDS 35): Prospective observational study. BMJ 2000; 321: 405-412. PMID: 10938048

2. Holman RR, Paul SK, Bethel MA, Matthews DR, Neil HA. 10 -year follow-up of intensive glucose control in type 2 diabetes.
N Engl J Med 2008; 359: 1577-1589. PMID: 18784090

3. Writing Group for the DCCT/EDIC Research Group, Orchard TJ, Nathan DM, Zinman B, Cleary P, Brillon D, et al. Association between 7 years of intensive treatment of type 1 diabetes and long-term mortality. JAMA 2015; 313: 45-53. PMID: 25562265

4. Ray KK, Seshasai SR, Wijesuriya S, Sivakumaran R, Nethercott S, Preiss D, et al. Effect of intensive control of glucose on cardiovascular outcomes and death in patients with diabetes mellitus: A meta-analysis of randomised controlled trials. Lancet 2009; 373: 1765-1772. PMID: 19465231

5. Hemmingsen B, Lund SS, Gluud C, Vaag A, Almdal TP, Hemmingsen $\mathrm{C}$, et al. Targeting intensive glycaemic control versus targeting conventional glycaemic control for type 2 diabetes mellitus. Cochrane Database Syst Rev 2013; CD008143. PMID: 24214280

6. Kähler P, Grevstad B, Almdal T, Gluud C, Wetterslev J, Lund $\mathrm{SS}$, et al. Targeting intensive versus conventional glycaemic control for type 1 diabetes mellitus: Systematic review with meta-analyses and trial sequential analyses of randomised clinical trials. BMJ Open 2014; 4: e004806. PMID: 25138801

7. Fullerton B, Jeitler K, Seitz M, Horvath K, Berghold A, Siebenhofer A. Intensive glucose control versus conventional glucose control for type 1 diabetes mellitus. Cochrane Database Syst Rev 2014; CD009122. PMID: 24526393

8. DECODE Study Group, the European Diabetes Epidemiology Group. Glucose tolerance and cardiovascular mortality: Comparison of fasting and 2-hour diagnostic criteria. Arch Intern Med 2001; 161:397-405. PMID: 11176766

9. Nakagami T, DECODA Study Group. Hyperglycaemia and mortality from all causes and from cardiovascular disease in five populations of Asian origin. Diabetologia 2004; 47: 385-394. PMID: 14985967

10. Tominaga M, Eguchi H, Manaka H, Igarashi K, Kato T, Sekikawa A. Impaired glucose tolerance is a risk factor for cardiovascular disease, but not impaired fasting glucose: The Funagata Diabetes Study. Diabetes Care 1999; 22: 920-924. PMID: 10372242

11. Chiasson JL, Josse RG, Gomis R, Hanefeld M, Karasik A, Laakso M, STOP-NIDDM Trial Research Group. Acarbose treatment and the risk of cardiovascular disease and hypertension in patients with impaired glucose tolerance: The STOP-NIDDM trial. JAMA 2003; 290: 486-494. PMID: 12876091

12. Oka R, Aizawa T, Miyamoto S, Yoneda T, Yamagishi M. One-hour plasma glucose as a predictor of the development of Type 2 diabetes in Japanese adults. Diabet Med 2016; 33: 1399-1405. PMID: 26482027

13. Alyass A, Almgren P, Akerlund M, Dushoff J, Isomaa B, Nilsson $\mathrm{P}$, et al. Modelling of OGTT curve identifies $1 \mathrm{~h}$ plasma glucose level as a strong predictor of incident type 2 diabetes: Results from two prospective cohorts. Diabetologia 2015; 58: 87-97. PMID: 25292440

14. Japan Diabetes Society. Treatment guide for diabetes 20182019. Tokyo: Bunkodo, 2018 [in Japanese].

15. Haffner SM, Lehto S, Rönnemaa T, Pyörälä K, Laakso M Mortality from coronary heart disease in subjects with type 2 diabetes and in nondiabetic subjects with and without prior myocardial infarction. $N$ Engl J Med 1998; 339: 229-234. PMID: 9673301

16. Emerging Risk Factors Collaboration, Sarwar N, Gao P, Seshasai SR, Gobin R, Kaptoge S, et al. Diabetes mellitus, fasting blood glucose concentration, and risk of vascular disease: A collaborative meta-analysis of 102 prospective studies. Lancet 2010; 375: 2215-2222. PMID: 20609967

17. Ambrose JA, Tannenbaum MA, Alexopoulos D, HjemdahlMonsen CE, Leavy J, Weiss M, et al. Angiographic progression of coronary artery disease and the development of myocardial infarction. J Am Coll Cardiol 1988; 12: 56-62. PMID: 3379219

18. Alpert JS. Myocardial infarction with angiographically normal coronary arteries. Arch Intern Med 1994; 154: 265-269. PMID: 8297192

19. Gerstein HC, Miller ME, Byington RP, Goff DC Jr, Bigger JT, et al, Action to Control Cardiovascular Risk in Diabetes Study Group. Effects of intensive glucose lowering in type 2 diabetes. N Engl J Med 2008; 358: 2545-2559. PMID: 18539917

20. Mahmoodi BK, Matsushita K, Woodward M, Blankestijn PJ, Cirillo M, Ohkubo T, et al, Chronic Kidney Disease Prognosis Consortium. Associations of kidney disease measures with mortality and end-stage renal disease in individuals with and without hypertension: A meta-analysis. Lancet 2012; 380: 1649-1661. PMID: 23013600 
21. Perk J, De Backer G, Gohlke H, Graham I, Reiner Z, Verschuren M, et al. European Guidelines on cardiovascular disease prevention in clinical practice (version 2012): The Fifth Joint Task Force of the European Society of Cardiology and Other Societies on Cardiovascular Disease Prevention in Clinical Practice (constituted by representatives of nine societies and by invited experts). Eur Heart $J$ 2012; 33: 1635-1701. PMID: 22555213

22. D'Agostino RB Sr, Vasan RS, Pencina MJ, Wolf PA, Cobain M, Massaro JM, et al. General cardiovascular risk profile for use in primary care: The Framingham Heart Study. Circulation 2008; 117: 743-753. PMID: 18212285

23. Goff DC Jr, Lloyd-Jones DM, Bennett G, Coady S, D'Agostino RB, Gibbons R, et al. 2013 ACC/AHA guideline on the assessment of cardiovascular risk: A report of the American College of Cardiology/American Heart Association Task Force on Practice Guidelines. Circulation 2014; 129 Suppl: S49-S73. PMID: 24222018

24. Kengne AP, Batty GD, Hamer M, Stamatakis E, Czernichow $\mathrm{S}$. Association of C-reactive protein with cardiovascular disease mortality according to diabetes status: Pooled analyses of 25,979 participants from four U.K. prospective cohort studies. Diabetes Care 2012; 35: 396-403. PMID: 22210562

25. Ridker PM. A test in context: High-sensitivity C-reactive protein $J$ Am Coll Cardiol 2016; 67: 712-723. PMID: 26868696

26. Djaberi R, Beishuizen ED, Pereira AM, Rabelink TJ, Smit JW, Tamsma JT, et al. Non-invasive cardiac imaging techniques and vascular tools for the assessment of cardiovascular disease in type 2 diabetes mellitus. Diabetologia 2008; 51: 1581-1593. PMID: 18607561

27. Joannides R, Haefeli WE, Linder L, Richard V, Bakkali EH, Thuillez C, et al. Nitric oxide is responsible for flow-dependent dilatation of human peripheral conduit arteries in vivo. Circulation 1995; 91: 1314-1319. PMID: 7867167

28. Gokce N, Keaney JF Jr, Hunter LM, Watkins MT, Nedeljkovic ZS, Menzoian JO, et al. Predictive value of noninvasively determined endothelial dysfunction for long-term cardiovascular events in patients with peripheral vascular disease. $J$ Am Coll Cardiol 2003; 41: 1769-1775. PMID: 12767663

29. Lee CD, Folsom AR, Pankow JS, Brancati FL, Atherosclerosis Risk in Communities (ARIC) Study Investigators. Cardiovascular events in diabetic and nondiabetic adults with or without history of myocardial infarction. Circulation 2004; 109: 855-860. PMID: 14757692

30. Bots ML, Hoes AW, Koudstaal PJ, Hofman A, Grobbee DE Common carotid intima-media thickness and risk of stroke and myocardial infarction: The Rotterdam Study. Circulation 1997; 96: $1432-1437$. PMID: 9315528

31. Cuspidi C, Lonati L, Macca G, Sampieri L, Fusi V, Severgnini B, et al. Cardiovascular risk stratification in hypertensive patients: Impact of echocardiography and carotid ultrasonography. $J$ Hypertens 2001; 19: 375-380. PMID: 11288806

32. Greenland P, Abrams J, Aurigemma GP, Bond MG, Clark LT, Criqui $\mathrm{MH}$, et al. Prevention Conference V: Beyond secondary prevention: Identifying the high-risk patient for primary prevention: Noninvasive tests of atherosclerotic burden: Writing Group III. Circulation 2000; 101: E16-E22. PMID: 10618318

33. Perez HA, Garcia NH, Spence JD, Armando LJ. Adding carotid total plaque area to the Framingham risk score improves cardiovascular risk classification. Arch Med Sci 2016; 12: 513-520. PMID: 27279842

34. Stary HC, Chandler AB, Dinsmore RE, Fuster V, Glagov S, Insull $\mathrm{W} \mathrm{Jr}$, et al. A definition of advanced types of atherosclerotic lesions and a histological classification of atherosclerosis: A report from the Committee on Vascular Lesions of the Council on Arteriosclerosis, American Heart Association. Circulation 1995; 92: 1355-1374. PMID: 7648691

35. Agatston AS, Janowitz WR, Hildner FJ, Zusmer NR, Viamonte M Jr, Detrano R. Quantification of coronary artery calcium using ultrafast computed tomography. J Am Coll Cardiol 1990; 15: $827-832$. PMID: 2407762

36. Hoff JA, Quinn L, Sevrukov A, Lipton RB, Daviglus M, Garside DB, et al. The prevalence of coronary artery calcium among diabetic individuals without known coronary artery disease. J Am Coll Cardiol 2003; 41: 1008-1012. PMID: 12651050

37. Yeboah J, McClelland RL, Polonsky TS, Burke GL, Sibley CT, O'Leary D, et al. Comparison of novel risk markers for improvement in cardiovascular risk assessment in intermediate- risk individuals. JAMA 2012; 308: 788-795. PMID: 22910756

38. Elkeles RS, Godsland IF, Feher MD, Rubens MB, Roughton M, Nugara F, et al, PREDICT Study Group. Coronary calcium measurement improves prediction of cardiovascular events in asymptomatic patients with type 2 diabetes: The PREDICT study. Eur Heart J 2008; 29: 2244-2251. PMID: 18573867

39. Anand DV, Lim E, Hopkins D, Corder R, Shaw LJ, Sharp P, et al. Risk stratification in uncomplicated type 2 diabetes: Prospective evaluation of the combined use of coronary artery calcium imaging and selective myocardial perfusion scintigraphy. Eur Heart J 2006; 27: 713-721. PMID: 16497686

40. Raggi P, Shaw LJ, Berman DS, Callister TQ. Prognostic value of coronary artery calcium screening in subjects with and without diabetes. J Am Coll Cardiol 2004; 43: 1663-1669. PMID: 15120828

41. Standards of Medical Care in Diabetes-2016: Summary of revisions. Diabetes Care 2016; 39(Suppl): S4-S5. PMID: 26696680

42. Raggi P, Callister TQ, Shaw LJ. Progression of coronary artery calcium and risk of first myocardial infarction in patients receiving cholesterol-lowering therapy. Arterioscler Thromb Vasc Biol 2004; 24: 1272-1277. PMID: 15059806

43. Arad Y, Goodman KJ, Roth M, Newstein D, Guerci AD. Coronary calcification, coronary disease risk factors, C-reactive protein, and atherosclerotic cardiovascular disease events: The St. Francis Heart Study. J Am Coll Cardiol 2005; 46: 158-165. PMID: 15992651

44. Lakatta EG, Levy D. Arterial and cardiac aging: Major shareholders in cardiovascular disease enterprises. Part I: Aging arteries: A "set up" for vascular disease. Circulation 2003; 107: 139-146. PMID: 12515756

45. Simons PC, Algra A, Bots ML, Grobbee DE, van der Graaf Y. Common carotid intima-media thickness and arterial stiffness: Indicators of cardiovascular risk in high-risk patients. The SMART Study (Second Manifestations of ARTerial disease) Circulation 1999; 100: 951-957. PMID: 10468526

46. Störk S, van den Beld AW, von Schacky C, Angermann CE, Lamberts SW, Grobbee DE, et al. Carotid artery plaque burden, stiffness, and mortality risk in elderly men: A prospective, population-based cohort study. Circulation 2004; 110: 344-348. PMID: 15238459

47. Willum-Hansen T, Staessen JA, Torp-Pedersen C, Rasmussen $\mathrm{S}$, Thijs L, Ibsen $\mathrm{H}$, et al. Prognostic value of aortic pulse wave velocity as index of arterial stiffness in the general population. Circulation 2006; 113: 664-670. PMID: 16461839

48. Gerhard-Herman MD, Gornik HL, Barrett C, Barshes NR, Corriere MA, Drachman DE, et al. 2016 AHA/ACC guideline on the management of patients with lower extremity peripheral artery disease: Executive summary: A report of the American College of Cardiology/American Heart Association Task Force on Clinical Practice Guidelines. Circulation 2017; 135: e686-e725. PMID: 27840332

49. Resnick HE, Lindsay RS, McDermott MM, Devereux RB, Jones KL, Fabsitz RR, et al. Relationship of high and low ankle brachial index to all-cause and cardiovascular disease mortality: The Strong Heart Study. Circulation 2004; 109: 733-739. PMID: 14970108

50. Criqui MH, McClelland RL, McDermott MM, Allison MA, Blumenthal RS, Aboyans V, et al. The ankle-brachial index and incident cardiovascular events in the MESA (Multi-Ethnic Study of Atherosclerosis). J Am Coll Cardiol 2010; 56: 1506-1512. PMID: 20951328

51. Doobay AV, Anand SS. Sensitivity and specificity of the ankle-brachial index to predict future cardiovascular outcomes: A systematic review. Arterioscler Thromb Vasc Biol 2005; 25: 1463-1469. PMID: 15879302

52. Stone NJ, Robinson JG, Lichtenstein AH, Bairey Merz CN, Blum CB, Eckel RH, et al. 2013 ACC/AHA guideline on the treatment of blood cholesterol to reduce atherosclerotic cardiovascular risk in adults: A report of the American College of Cardiology/American Heart Association Task Force on Practice Guidelines. Circulation 2014; 12(Suppl): S1-S45. PMID: 24222016

53. Paillole C, Ruiz J, Juliard JM, Leblanc H, Gourgon R, Passa P. Detection of coronary artery disease in diabetic patients. Diabetologia 1995; 38: 726-731. PMID: 7672497

54. Elhendy A, van Domburg RT, Poldermans D, Bax JJ, Nierop PR, Geleijnse ML, et al. Safety and feasibility of dobutamine-atropine stress echocardiography for the diagnosis of coronary artery disease in diabetic patients unable to perform an exercise stress test. Diabetes Care 1998; 21: 1797-1802. PMID: 9802723

55. Japan Diabetes Society. Japanese clinical practice guideline for 
diabetes 2019. Tokyo: Nankodo, 2019 [in Japanese].

56. Piepoli MF, Hoes AW, Agewall S, Albus C, Brotons C, Catapano AL, et al. 2016 European Guidelines on cardiovascular disease prevention in clinical practice: The Sixth Joint Task Force of the European Society of Cardiology and Other Societies on Cardiovascular Disease Prevention in Clinical Practice (constituted by representatives of 10 societies and by invited experts). Developed with the special contribution of the European Association for Cardiovascular Prevention \& Rehabilitation (EACPR). Eur Heart J 2016; 37: 2315 -2381. PMID: 27222591

57. Raff GL, Gallagher MJ, O'Neill WW, Goldstein JA. Diagnostic accuracy of noninvasive coronary angiography using 64-slice spiral computed tomography. J Am Coll Cardiol 2005; 46: 552-557. PMID: 16053973

58. Mollet NR, Cademartiri F, van Mieghem CA, Runza G, McFadden EP, Baks T, et al. High-resolution spiral computed tomography coronary angiography in patients referred for diagnostic conventional coronary angiography. Circulation 2005; 112: 2318-2323. PMID: 16203914

59. Hoffmann U, Moselewski F, Nieman K, Jang IK, Ferencik M, Rahman AM, et al. Noninvasive assessment of plaque morphology and composition in culprit and stable lesions in acute coronary syndrome and stable lesions in stable angina by multidetector computed tomography. J Am Coll Cardiol 2006; 47: $1655-1662$. PMID: 16631006

60. Kannel WB, Hjortland M, Castelli WP. Role of diabetes in congestive heart failure: The Framingham study. Am J Cardiol 1974; 34: 29-34. PMID: 4835750

61. Nichols GA, Hillier TA, Erbey JR, Brown JB. Congestive heart failure in type 2 diabetes: Prevalence, incidence, and risk factors. Diabetes Care 2001; 24: 1614-1619. PMID: 11522708

62. Thrainsdottir IS, Aspelund T, Hardarson T, Malmberg K, Sigurdsson G, Thorgeirsson G, et al. Glucose abnormalities and heart failure predict poor prognosis in the population-based Reykjavík Study. Eur J Cardiovasc Prev Rehabil 2005; 12: 465-471. PMID: 16210933

63. Thrainsdottir IS, Aspelund T, Thorgeirsson G, Gudnason V, Hardarson T, Malmberg K, et al. The association between glucose abnormalities and heart failure in the population-based Reykjavik study. Diabetes Care 2005; 28: 612-616. PMID: 15735197

64. Shah AD, Langenberg C, Rapsomaniki E, Denaxas S, PujadesRodriguez M, Gale CP, et al. Type 2 diabetes and incidence of cardiovascular diseases: A cohort study in 1.9 million people. Lancet Diabetes Endocrinol 2015; 3: 105-113. PMID: 25466521

65. Bertoni AG, Hundley WG, Massing MW, Bonds DE, Burke GL, Goff DC Jr. Heart failure prevalence, incidence, and mortality in the elderly with diabetes. Diabetes Care 2004; 27: 699-703. PMID: 14988288

66. Iribarren C, Karter AJ, Go AS, Ferrara A, Liu JY, Sidney S, et al. Glycemic control and heart failure among adult patients with diabetes. Circulation 2001; 103: 2668-2673. PMID: 11390335

67. Barzilay JI, Kronmal RA, Gottdiener JS, Smith NL, Burke GL, Tracy R, et al. The association of fasting glucose levels with congestive heart failure in diabetic adults $>$ or $=65$ years: The Cardiovascular Health Study. J Am Coll Cardiol 2004; 43: 2236-2241. PMID: 15193686

68. Metra M, Zacà V, Parati G, Agostoni P, Bonadies M, Ciccone M, et al, Heart Failure Study Group of the Italian Society of Cardiology. Cardiovascular and noncardiovascular comorbidities in patients with chronic heart failure. $J$ Cardiovasc Med (Hagerstown) 2011; 12: 76-84. PMID: 20962666

69. MacDonald MR, Petrie MC, Varyani F, Ostergren J, Michelson EL, Young JB, et al, CHARM Investigators. Impact of diabetes on outcomes in patients with low and preserved ejection fraction heart failure: An analysis of the Candesartan in Heart failure: Assessment of Reduction in Mortality and morbidity (CHARM) programme. Eur Heart J 2008; 29: 1377-1385. PMID: 18413309

70. Falcão-Pires I, Hamdani N, Borbély A, Gavina C, Schalkwijk CG, van der Velden J, et al. Diabetes mellitus worsens diastolic left ventricular dysfunction in aortic stenosis through altered myocardial structure and cardiomyocyte stiffness. Circulation 2011; 124: 1151-1159. PMID: 21844073

71. Wong TC, Piehler KM, Kang IA, Kadakkal A, Kellman P, Schwartzman DS, et al. Myocardial extracellular volume fraction quantified by cardiovascular magnetic resonance is increased in diabetes and associated with mortality and incident heart failure admission. Eur Heart J 2014; 35: 657-664. PMID: 23756336

72. Shimizu I, Minamino T, Toko H, Okada S, Ikeda H, Yasuda $\mathrm{N}$, et al. Excessive cardiac insulin signaling exacerbates systolic dysfunction induced by pressure overload in rodents. $J$ Clin Invest 2010; 120: 1506-1514. PMID: 20407209

73. Levelt E, Rodgers CT, Clarke WT, Mahmod M, Ariga R, Francis JM, et al. Cardiac energetics, oxygenation, and perfusion during increased workload in patients with type 2 diabetes mellitus. Eur Heart J 2016; 37: 3461 -3469. PMID: 26392437

74. Tsutsui $\mathrm{H}$, Isobe $\mathrm{M}$, Ito $\mathrm{H}$, Ito H, Okumura K, Ono M, et al, Japanese Circulation Society and the Japanese Heart Failure Society Joint Working Group. JCS 2017/JHFS 2017 guideline on diagnosis and treatment of acute and chronic heart failure: Digest version. Circ J 2019; 83: 2084-2184. PMID: 31511439

75. Movahed MR, Hashemzadeh M, Jamal MM. Diabetes mellitus is a strong, independent risk for atrial fibrillation and flutter in addition to other cardiovascular disease. Int J Cardiol 2005; 105: 315 -318. PMID: 16274775

76. Hofman A, van Duijn CM, Franco OH, Ikram MA, Janssen HL, Klaver CC, et al. The Rotterdam Study: 2012 objectives and design update. Eur J Epidemiol 2011; 26: 657-686. PMID: 21877163

77. Benjamin EJ, Levy D, Vaziri SM, D'Agostino RB, Belanger AJ, Wolf PA. Independent risk factors for atrial fibrillation in a population-based cohort: The Framingham Heart Study. JAMA 1994; 271: 840-844. PMID: 8114238

78. Iguchi Y, Kimura K, Aoki J, Kobayashi K, Terasawa Y, Sakai $\mathrm{K}$, et al. Prevalence of atrial fibrillation in community-dwelling Japanese aged 40 years or older in Japan: Analysis of 41,436 non-employee residents in Kurashiki-city. Circ J 2008; 72: 909-913. PMID: 18503215

79. Huxley RR, Filion KB, Konety S, Alonso A. Meta-analysis of cohort and case-control studies of type 2 diabetes mellitus and risk of atrial fibrillation. Am J Cardiol 2011; 108: 56-62. PMID: 21529739

80. Murphy NF, Simpson CR, Jhund PS, Stewart S, Kirkpatrick M, Chalmers J, et al. A national survey of the prevalence, incidence, primary care burden and treatment of atrial fibrillation in Scotland. Heart 2007; 93: 606-612. PMID: 17277353

81. Tayebjee MH, Lim HS, MacFadyen RJ, Lip GY. Matrix metalloproteinase- 9 and tissue inhibitor of metalloproteinase-1 and -2 in type 2 diabetes: Effect of 1 year's cardiovascular risk reduction therapy. Diabetes Care 2004; 27: 2049-2051. PMID: 15277439

82. Lim HS, MacFadyen RJ, Lip GY. Diabetes mellitus, the renin-angiotensin-aldosterone system, and the heart. Arch Intern Med 2004; 164: 1737-1748. PMID: 15364666

83. Gage BF, Waterman AD, Shannon W, Boechler M, Rich MW, Radford MJ. Validation of clinical classification schemes for predicting stroke: Results from the National Registry of Atrial Fibrillation. JAMA 2001; 285: 2864-2870. PMID: 11401607

84. Lip GY, Nieuwlaat R, Pisters R, Lane DA, Crijns HJ. Refining clinical risk stratification for predicting stroke and thromboembolism in atrial fibrillation using a novel risk factor-based approach: The Euro Heart Survey on Atrial Fibrillation. Chest 2010; 137: 263-272. PMID: 19762550

85. Chugh SS, Havmoeller R, Narayanan K, Singh D, Rienstra M, Benjamin EJ, et al. Worldwide epidemiology of atrial fibrillation: A Global Burden of Disease 2010 Study. Circulation 2014; 129: 837-847. PMID: 24345399

86. Marini C, De Santis F, Sacco S, Russo T, Olivieri L, Totaro R, et al. Contribution of atrial fibrillation to incidence and outcome of ischemic stroke: Results from a population-based study. Stroke 2005; 36: 1115-1119. PMID: 15879330

87. Umpierre D, Ribeiro PA, Kramer CK, Leitão CB, Zucatti AT, Azevedo MJ, et al. Physical activity advice only or structured exercise training and association with $\mathrm{HbAlc}$ levels in type 2 diabetes: A systematic review and meta-analysis. JAMA 2011; 305: 1790 -1799. PMID: 21540423

88. Boulé NG, Haddad E, Kenny GP, Wells GA, Sigal RJ. Effects of exercise on glycemic control and body mass in type 2 diabetes mellitus: A meta-analysis of controlled clinical trials. JAMA 2001; 286: 1218-1227. PMID: 11559268

89. Pai LW, Li TC, Hwu YJ, Chang SC, Chen LL, Chang PY. The effectiveness of regular leisure-time physical activities on long-term glycemic control in people with type 2 diabetes: A systematic review and meta-analysis. Diabetes Res Clin Pract 2016; 113: 77-85. PMID: 26822261

90. Boniol M, Dragomir M, Autier P, Boyle P. Physical activity and change in fasting glucose and HbAlc: A quantitative meta-analysis of randomized trials. Acta Diabetol 2017; 54: 983-991. PMID: 28840356

91. MacLeod SF, Terada T, Chahal BS, Boulé NG. Exercise lowers 
postprandial glucose but not fasting glucose in type 2 diabetes: A meta-analysis of studies using continuous glucose monitoring. Diabetes Metab Res Rev 2013; 29: 593-603. PMID: 24038928

92. Snowling NJ, Hopkins WG. Effects of different modes of exercise training on glucose control and risk factors for complications in type 2 diabetic patients: A meta-analysis. Diabetes Care 2006; 29: 2518-2527. PMID: 17065697

93. Qiu S, Cai X, Schumann U, Velders M, Sun Z, Steinacker JM. Impact of walking on glycemic control and other cardiovascular risk factors in type 2 diabetes: A meta-analysis. PLoS One 2014; 9: e109767. PMID: 25329391

94. Thomas DE, Elliott EJ, Naughton GA. Exercise for type 2 diabetes mellitus. Cochrane Database Syst Rev 2006; CD002968. PMID: 16855995

95. Sabag A, Way KL, Keating SE, Sultana RN, O'Connor HT, Baker MK, et al. Exercise and ectopic fat in type 2 diabetes: A systematic review and meta-analysis. Diabetes Metab 2017; 43: 195-210. PMID: 28162956

96. Way KL, Hackett DA, Baker MK, Johnson NA. The effect of regular exercise on insulin sensitivity in type 2 diabetes mellitus: A systematic review and meta-analysis. Diabetes Metab J 2016; 40: 253 -271. PMID: 27535644

97. Schwingshackl L, Missbach B, Dias S, König J, Hoffmann G. Impact of different training modalities on glycaemic control and blood lipids in patients with type 2 diabetes: A systematic review and network meta-analysis. Diabetologia 2014; 57: 1789-1797. PMID: 24996616

98. Kelley GA, Kelley KS. Effects of aerobic exercise on lipids and lipoproteins in adults with type 2 diabetes: A meta-analysis of randomized-controlled trials. Public Health 2007; 121: 643-655. PMID: 17544042

99. Hayashino Y, Jackson JL, Fukumori N, Nakamura F, Fukuhara S. Effects of supervised exercise on lipid profiles and blood pressure control in people with type 2 diabetes mellitus: A meta-analysis of randomized controlled trials. Diabetes Res Clin Pract 2012; 98: 349-360. PMID: 23116535

100. Chudyk A, Petrella RJ. Effects of exercise on cardiovascular risk factors in type 2 diabetes: A meta-analysis. Diabetes Care 2011; 34: 1228-1237. PMID: 21525503

101. Hayashino Y, Jackson JL, Hirata T, Fukumori N, Nakamura F, Fukuhara S, et al. Effects of exercise on C-reactive protein, inflammatory cytokine and adipokine in patients with type 2 diabetes: A meta-analysis of randomized controlled trials. Metabolism 2014; 63: 431-440. PMID: 24355625

102. Figueira FR, Umpierre D, Cureau FV, Zucatti AT, Dalzochio MB, Leitão CB, et al. Association between physical activity advice only or structured exercise training with blood pressure levels in patients with type 2 diabetes: A systematic review and meta-analysis. Sports Med 2014; 44: 1557-1572. PMID: 25047852

103. Melo LC, Dativo-Medeiros J, Menezes-Silva CE, Barbosa FT, de Sousa-Rodrigues CF, Rabelo LA. Physical exercise on inflammatory markers in type 2 diabetes patients: A systematic review of randomized controlled trials. Oxid Med Cell Longev 2017; 2017: 8523728. PMID: 28400914

104. Boulé NG, Kenny GP, Haddad E, Wells GA, Sigal RJ. Meta-analysis of the effect of structured exercise training on cardiorespiratory fitness in Type 2 diabetes mellitus. Diabetologia 2003; 46: 1071-1081. PMID: 12856082

105. Jelleyman C, Yates T, O'Donovan G, Gray LJ, King JA, Khunti K, et al. The effects of high-intensity interval training on glucose regulation and insulin resistance: A meta-analysis. Obes Rev 2015; 16: 942-961. PMID: 26481101

106. American Diabetes Association. 4: Lifestyle management: Standards of medical care in diabetes-2018. Diabetes Care 2018; 41(Suppl): S38-S50. PMID: 29222375

107. Colberg SR, Sigal RJ, Yardley JE, Riddell MC, Dunstan DW, Dempsey PC, et al. Physical activity/exercise and diabetes: A Position Statement of the American Diabetes Association. Diabetes Care 2016; 39: 2065-2079. PMID: 27926890

108. Oliveira C, Simões M, Carvalho J, Ribeiro J. Combined exercise for people with type 2 diabetes mellitus: A systematic review. Diabetes Res Clin Pract 2012; 98: 187-198. PMID: 22981711

109. Yang Z, Scott CA, Mao C, Tang J, Farmer AJ. Resistance exercise versus aerobic exercise for type 2 diabetes: A systematic review and meta-analysis. Sports Med 2014; 44: 487-499. PMID: 24297743

110. Nery C, Moraes SRA, Novaes KA, Bezerra MA, Silveira PVC, Lemos A. Effectiveness of resistance exercise compared to aerobic exercise without insulin therapy in patients with type 2 diabetes mellitus: A meta-analysis. Braz J Phys Ther 2017; 21: 400-415.
PMID: 28728958

111. Hovanec N, Sawant A, Overend TJ, Petrella RJ, Vandervoort AA. Resistance training and older adults with type 2 diabetes mellitus: Strength of the evidence. J Aging Res 2012; 2012: 284635. PMID: 22988507

112. Katzmarzyk PT, Church TS, Craig CL, Bouchard C. Sitting time and mortality from all causes, cardiovascular disease, and cancer. Med Sci Sports Exerc 2009; 41: 998-1005. PMID: 19346988

113. Dempsey PC, Larsen RN, Sethi P, Sacre JW, Straznicky NE, Cohen ND, et al. Benefits for type 2 diabetes of interrupting prolonged sitting with brief bouts of light walking or simple resistance activities. Diabetes Care 2016; 39: 964-972. PMID: 27208318

114. Kodama S, Tanaka S, Heianza Y, Fujihara K, Horikawa C, Shimano $\mathrm{H}$, et al. Association between physical activity and risk of all-cause mortality and cardiovascular disease in patients with diabetes: A meta-analysis. Diabetes Care 2013; 36: 471-479. PMID: 23349151

115. Colberg SR, Sigal RJ, Fernhall B, Regensteiner JG, Blissmer BJ, Rubin RR, et al. Exercise and type 2 diabetes: The American College of Sports Medicine and the American Diabetes Association: Joint position statement. Diabetes Care 2010; 33: e147-e167. PMID: 21115758

116. Liubaoerjijin Y, Terada T, Fletcher K, Boulé NG. Effect of aerobic exercise intensity on glycemic control in type 2 diabetes: A meta-analysis of head-to-head randomized trials. Acta Diabetol 2016; 53: 769-781. PMID: 27255501

117. Dasgupta K, Rosenberg E, Joseph L, Cooke AB, Trudeau L, Bacon SL, et al, SMARTER Trial Group. Physician Step prescription and Monitoring to improve ARTERial health (SMARTER): A randomized controlled trial in patients with type 2 diabetes and hypertension. Diabetes Obes Metab 2017; 19: 695-704. PMID: 28074635

118. Baskerville R, Ricci-Cabello I, Roberts N, Farmer A. Impact of accelerometer and pedometer use on physical activity and glycaemic control in people with Type 2 diabetes: A systematic review and meta-analysis. Diabet Med 2017; 34: 612-620. PMID: 28173623

119. Ministry of Health, Labour and Welfare. Japanese official physical activity references 2013 for health promotion [in Japanese]. https://www.mhlw.go.jp/stf/houdou/2r9852000002xple-att/ 2r9852000002xpqt.pdf [accessed November 1, 2019].

120. Park SW, Goodpaster BH, Lee JS, Kuller LH, Boudreau R, de Rekeneire N, et al. Health, Aging, and Body Composition Study: Excessive loss of skeletal muscle mass in older adults with type 2 diabetes. Diabetes Care 2009; 32: 1993-1997. PMID: 19549734

121. Ogawa $\mathrm{H}$, Adachi $\mathrm{H}$, Hayashi $\mathrm{T}$, Inoue $\mathrm{T}$, Ishihara $\mathrm{M}$, Ishii $\mathrm{H}$, et al, JCS Joint Working Group. Guidelines for secondary prevention of myocardial infarction (JCS 2011). Circ J 2013; 77: 231-248. PMID: 23165785

122. Nohara R, Adachi H, Goto Y, Hasegawa E, Ishihara S, Itoh H, et al, JCS Joint Working Group. Guidelines for rehabilitation in patients with cardiovascular disease (JCS 2012). Circ J 2014; 78: 2022-2093. PMID: 25047729

123. May GS, Eberlein KA, Furberg CD, Passamani ER, DeMets DL. Secondary prevention after myocardial infarction: A review of long-term trials. Prog Cardiovasc Dis 1982; 24: 331-352. PMID: 6119737

124. Heran BS, Chen JM, Ebrahim S, Moxham T, Oldridge N, Rees $\mathrm{K}$, et al. Exercise-based cardiac rehabilitation for coronary heart disease. Cochrane Database Syst Rev 2011; CD001800. PMID: 21735386

125. van Halewijn G, Deckers J, Tay HY, van Domburg R, Kotseva K, Wood D. Lessons from contemporary trials of cardiovascular prevention and rehabilitation: A systematic review and metaanalysis. Int J Cardiol 2017; 232: 294-303. PMID: 28094128

126. Dibben GO, Dalal HM, Taylor RS, Doherty P, Tang LH, Hillsdon M. Cardiac rehabilitation and physical activity: Systematic review and meta-analysis. Heart 2018; 104: 1394-1402. PMID: 29654095

127. Dylewicz P, Bienkowska S, Szczesniak L, Rychlewski T, Przywarska I, Wilk M, et al. Beneficial effect of short-term endurance training on glucose metabolism during rehabilitation after coronary bypass surgery. Chest 2000; 117: 47-51. PMID: 10631198

128. Eriksson KF, Lindgärde F. Prevention of type 2 (non-insulindependent) diabetes mellitus by diet and physical exercise: The 6-year Malmö feasibility study. Diabetologia 1991; 34: 891-898. PMID: 1778354 
129. Schneider SH, Khachadurian AK, Amorosa LF, Clemow L, Ruderman NB. Ten-year experience with an exercise-based outpatient life-style modification program in the treatment of diabetes mellitus. Diabetes Care 1992; 15: 1800-1810. PMID: 1468318

130. Jiménez-Navarro MF, Lopez-Jimenez F, Pérez-Belmonte LM, Lennon RJ, Diaz-Melean C, Rodriguez-Escudero JP, et al. Benefits of cardiac rehabilitation on cardiovascular outcomes in patients with diabetes mellitus after percutaneous coronary intervention. J Am Heart Assoc 2017; 6: e006404. PMID: 29021270

131. Thomas RJ, King M, Lui K, Oldridge N, Piña IL, Spertus J, et al. AACVPR. AACVPR/ACC/AHA 2007 performance measures on cardiac rehabilitation for referral to and delivery of cardiac rehabilitation/secondary prevention services endorsed by the American College of Chest Physicians, American College of Sports Medicine, American Physical Therapy Association, Canadian Association of Cardiac Rehabilitation, European Association for Cardiovascular Prevention and Rehabilitation, Inter-American Heart Foundation, National Association of Clinical Nurse Specialists, Preventive Cardiovascular Nurses Association, and the Society of Thoracic Surgeons. J Am Coll Cardiol 2007; 50: 1400-1433. PMID: 17903645

132. Fletcher GF, Balady GJ, Amsterdam EA, Chaitman B, Eckel $\mathrm{R}$, Fleg J, et al. Exercise standards for testing and training: A statement for healthcare professionals from the American Heart Association. Circulation 2001; 104: 1694-1740. PMID: 11581152

133. Zhu P, Pan XF, Sheng L, Chen H, Pan A. Cigarette smoking, diabetes, and diabetes complications: Call for urgent action. Curr Diab Rep 2017; 17: 78. PMID: 28766247

134. Diabetes Control and Complications Trial/Epidemiology of Diabetes Interventions and Complications (DCCT/EDIC) Research Group. Risk factors for cardiovascular disease in type 1 diabetes. Diabetes 2016; 65: 1370-1379. PMID: 26895792

135. Pan A, Wang Y, Talaei M, Hu FB. Relation of smoking with total mortality and cardiovascular events among patients with diabetes mellitus: A meta-analysis and systematic review. Circulation 2015; 132: 1795-1804. PMID: 26311724

136. Mons U, Müezzinler A, Gellert C, Schöttker B, Abnet CC, Bobak M, et al. Impact of smoking and smoking cessation on cardiovascular events and mortality among older adults: Meta-analysis of individual participant data from prospective cohort studies of the CHANCES consortium. BMJ 2015; 350: h1551. PMID: 25896935

137. Clair C, Rigotti NA, Porneala B, Fox CS, D'Agostino RB, Pencina MJ, et al. Association of smoking cessation and weight change with cardiovascular disease among adults with and without diabetes. JAMA 2013; 309: 1014-1021. PMID: 23483176

138. Akter S, Goto A, Mizoue T. Smoking and the risk of type 2 diabetes in Japan: A systematic review and meta-analysis. $J$ Epidemiol 2017; 27: 553-561. PMID: 28716381

139. Hamman RF, Wing RR, Edelstein SL, Lachin JM, Bray GA, Delahanty L, et al. Effect of weight loss with lifestyle intervention on risk of diabetes. Diabetes Care 2006; 29: 2102-2107. PMID: 16936160

140. Wing RR, Bolin P, Brancati FL, Bray GA, Clark JM, et al, Look AHEAD Research Group. Cardiovascular effects of intensive lifestyle intervention in type 2 diabetes. $N$ Engl $J$ Med 2013; 369: 145-154. PMID: 23796131

141. Gaede P, Vedel P, Larsen N, Jensen GV, Parving HH, Pedersen $O$. Multifactorial intervention and cardiovascular disease in patients with type 2 diabetes. $N$ Engl J Med 2003; 348: 383-393. PMID: 12556541

142. Sone H, Tanaka S, Iimuro S, Tanaka S, Oida K, Yamasaki Y, et al, Japan Diabetes Complications Study Group. Long-term lifestyle intervention lowers the incidence of stroke in Japanese patients with type 2 diabetes: A nationwide multicentre randomised controlled trial (the Japan Diabetes Complications Study). Diabetologia 2010; 53: 419-428. PMID: 20054522

143. Ueki K, Sasako T, Okazaki Y, Kato M, Okahata S, Katsuyama $\mathrm{H}$, et al, J-DOIT3 Study Group. Effect of an intensified multifactorial intervention on cardiovascular outcomes and mortality in type 2 diabetes (J-DOIT3): An open-label, randomised controlled trial. Lancet Diabetes Endocrinol 2017; 5: 951-964. PMID: 29079252

144. Salehi-Abargouei A, Maghsoudi Z, Shirani F, Azadbakht L. Effects of Dietary Approaches to Stop Hypertension (DASH)style diet on fatal or nonfatal cardiovascular diseases-incidence: A systematic review and meta-analysis on observational prospective studies. Nutrition 2013; 29: 611-618. PMID: 23466047
145. Sofi F, Macchi C, Abbate R, Gensini GF, Casini A. Mediterranean diet and health status: An updated meta-analysis and a proposal for a literature-based adherence score. Public Health Nutr 2014; 17: 2769-2782. PMID: 24476641

146. Filippatos TD, Panagiotakos DB, Georgousopoulou EN, Pitaraki E, Kouli GM, Chrysohoou C, et al, ATTICA Study Group. Mediterranean diet and 10-year (2002-2012) incidence of diabetes and cardiovascular disease in participants with prediabetes: The ATTICA study. Rev Diabet Stud 2016; 13: 226-235. PMID: 28278309

147. Campbell AP. DASH Eating Plan: An eating pattern for diabetes management. Diabetes Spectr 2017; 30: 76-81. PMID: 28588372

148. Seidelmann SB, Claggett B, Cheng S, Henglin M, Shah A, Steffen LM, et al. Dietary carbohydrate intake and mortality: A prospective cohort study and meta-analysis. Lancet Public Health 2018; 3: e419-e428. PMID: 30122560

149. Ministry of Health, Labour and Welfare. The dietary reference intakes for Japanese study group report. 2020 edn [in Japanese]. https://www.mhlw.go.jp/content/10904750/000586553.pdf [accessed January 31, 2020]

150. Department of Health and Human Services. Dietary guidelines for Americans 2015-2020. New York: Skyhorse Publishing Inc., 2017.

151. Development Committee for Guidelines for the Management of Sarcopenia. Guidelines for the management of sarcopenia 2017. Tokyo: Life Science Publishing Co., Ltd., 2017 [in Japanese].

152. Atkins JL, Whincup PH, Morris RW, Lennon LT, Papacosta O, Wannamethee SG. Sarcopenic obesity and risk of cardiovascular disease and mortality: A population-based cohort study of older men. J Am Geriatr Soc 2014; 62: 253-260. PMID: 24428349

153. Byeon CH, Kang KY, Kang SH, Bae EJ. Sarcopenia is associated with Framingham risk score in the Korean population: Korean National Health and Nutrition Examination Survey (KNHANES) 2010-2011. J Geriatr Cardiol 2015; 12: 366-372. PMID: 26346573

154. Horikawa C, Yoshimura Y, Kamada C, Tanaka S, Tanaka S, Hanyu O, et al, Japan Diabetes Complications Study Group. Dietary sodium intake and incidence of diabetes complications in Japanese patients with type 2 diabetes: Analysis of the Japan Diabetes Complications Study (JDCS). J Clin Endocrinol Metab 2014; 99: 3635-3643. PMID: 25050990

155. Ekinci EI, Clarke S, Thomas MC, Moran JL, Cheong K, MacIsaac RJ, et al. Dietary salt intake and mortality in patients with type 2 diabetes. Diabetes Care 2011; 34: 703-709. PMID: 21289228

156. Kengne AP, Patel A, Barzi F, Jamrozik K, Lam TH, et al, Asia Pacific Cohort Studies Collaboration. Systolic blood pressure, diabetes and the risk of cardiovascular diseases in the Asia-Pacific region. J Hypertens 2007; 25: 1205-1213. PMID: 17563533

157. Liu Y, Wang M, Morris AD, Doney AS, Leese GP, Pearson ER, et al. Glycemic exposure and blood pressure influencing progression and remission of diabetic retinopathy: A longitudinal cohort study in GoDARTS. Diabetes Care 2013; 36: 3979-3984. PMID: 24170761

158. Cushman WC, Evans GW, Byington RP, Goff DC Jr, Grimm $\mathrm{RH}$ Jr, et al, ACCORD Study Group. Effects of intensive blood-pressure control in type 2 diabetes mellitus. $N$ Engl J Med 2010; 362: 1575-1585. PMID: 20228401

159. Umemura S, Arima H, Arima S, Asayama K, Dohi Y, Hirooka Y, et al. The Japanese Society of Hypertension guidelines for the management of hypertension (JSH 2019). Hypertens Res 2019; 42: 1235-1481. PMID: 31375757

160. Heart Outcomes Prevention Evaluation Study Investigators. Effects of ramipril on cardiovascular and microvascular outcomes in people with diabetes mellitus: Results of the HOPE study and MICRO-HOPE substudy. Lancet 2000; 355: 253-259. PMID: 10675071

161. Lindholm LH, Ibsen H, Dahlöf B, Devereux RB, Beevers G, de Faire U, et al, LIFE Study Group. Cardiovascular morbidity and mortality in patients with diabetes in the Losartan Intervention For Endpoint reduction in hypertension study (LIFE): A randomised trial against atenolol. Lancet 2002; 359: 1004-1010. PMID: 11937179

162. Brenner BM, Cooper ME, de Zeeuw D, Keane WF, Mitch WE, Parving $\mathrm{HH}$, et al, RENAAL Study Investigators. Effects of losartan on renal and cardiovascular outcomes in patients with type 2 diabetes and nephropathy. N Engl J Med 2001; 345: 861-869. PMID: 11565518

163. Jamerson K, Weber MA, Bakris GL, Dahlöf B, Pitt B, Shi V, et al, ACCOMPLISH Trial Investigators. Benazepril plus amlodipine or hydrochlorothiazide for hypertension in high-risk 
patients. N Engl J Med 2008; 359: 2417-2428. PMID: 19052124

164. Ogihara T, Saruta T, Rakugi H, Saito I, Shimamoto K, Matsuoka $\mathrm{H}$, et al, COLM Investigators. Combinations of olmesartan and a calcium channel blocker or a diuretic in elderly hypertensive patients: A randomized, controlled trial. $J$ Hypertens 2014; 32: 2054-2063. PMID: 24999799

165. Takihata M, Nakamura A, Kondo Y, Kawasaki S, Kimura M, Terauchi Y. Comparison of azelnidipine and trichlormethiazide in Japanese type 2 diabetic patients with hypertension: The COAT randomized controlled trial. PLoS One 2015; 10: e0125519. PMID: 25938807

166. Yusuf S, Teo KK, Pogue J, Dyal L, Copland I, et al, ONTARGET Investigators. Telmisartan, ramipril, or both in patients at high risk for vascular events. $N$ Engl J Med 2008; 358: $1547-1559$. PMID: 18378520

167. Parving HH, Brenner BM, McMurray JJ, de Zeeuw D, Haffner $\mathrm{SM}$, Solomon SD, et al, ALTITUDE Investigators. Cardiorenal end points in a trial of aliskiren for type 2 diabetes. $N$ Engl $J$ Med 2012; 367: 2204-2213. PMID: 23121378

168. Costa J, Borges M, David C, Vaz Carneiro A. Efficacy of lipid lowering drug treatment for diabetic and non-diabetic patients: Meta-analysis of randomised controlled trials. BMJ 2006; 332: 1115-1124. PMID: 16585050

169. Turner RC, Millns H, Neil HA, Stratton IM, Manley SE, Matthews DR, et al. Risk factors for coronary artery disease in non-insulin dependent diabetes mellitus: United Kingdom Prospective Diabetes Study (UKPDS: 23). BMJ 1998; 316: 823-828. PMID: 9549452

170. Sone H, Tanaka S, Tanaka S, Iimuro S, Oida K, Yamasaki Y, et al, Japan Diabetes Complications Study Group. Serum level of triglycerides is a potent risk factor comparable to LDL cholesterol for coronary heart disease in Japanese patients with type 2 diabetes: Subanalysis of the Japan Diabetes Complications Study (JDCS). J Clin Endocrinol Metab 2011; 96: 3448-3456. PMID: 21865372

171. Hayashi T, Kawashima S, Itoh H, Yamada N, Sone H, Watanabe H, et al, Japan CDM Group. Low HDL cholesterol is associated with the risk of stroke in elderly diabetic individuals: Changes in the risk for atherosclerotic diseases at various ages. Diabetes Care 2009; 32: 1221-1223. PMID: 19509009

172. Sacks FM, Hermans MP, Fioretto P, Valensi P, Davis T, Horton E, et al. Association between plasma triglycerides and high-density lipoprotein cholesterol and microvascular kidney disease and retinopathy in type 2 diabetes mellitus: A global case-control study in 13 countries. Circulation 2014; 129: 999-1008. PMID: 24352521

173. Toth PP, Simko RJ, Palli SR, Koselleck D, Quimbo RA, Cziraky MJ. The impact of serum lipids on risk for microangiopathy in patients with type 2 diabetes mellitus. Cardiovasc Diabetol 2012; 11: 109. PMID: 22978715

174. Heilbronn LK, Noakes M, Clifton PM. Effect of energy restriction, weight loss, and diet composition on plasma lipids and glucose in patients with type 2 diabetes. Diabetes Care 1999; 22: 889-895. PMID: 10372237

175. Colhoun HM, Betteridge DJ, Durrington PN, Hitman GA, Neil HA, Livingstone SJ, et al, CARDS investigators. Primary prevention of cardiovascular disease with atorvastatin in type 2 diabetes in the Collaborative Atorvastatin Diabetes Study (CARDS): Multicentre randomised placebo-controlled trial. Lancet 2004; 364: 685-696. PMID: 15325833

176. Cholesterol Treatment Trialists' (CTT) Collaborators, Kearney PM, Blackwell L, Collins R, Keech A, Simes J, et al. Efficacy of cholesterol-lowering therapy in 18,686 people with diabetes in 14 randomised trials of statins: A meta-analysis. Lancet 2008; 371: 117-125. PMID: 18191683

177. Collins R, Armitage J, Parish S, Sleigh P, Peto R, Heart Protection Study Collaborative Group. MRC/BHF Heart Protection Study of cholesterol-lowering with simvastatin in 5963 people with diabetes: A randomised placebo-controlled trial. Lancet 2003; 361: 2005-2016. PMID: 12814710

178. Keech A, Simes RJ, Barter P, Best J, Scott R, Taskinen MR, et al, FIELD study investigators. Effects of long-term fenofibrate therapy on cardiovascular events in 9795 people with type 2 diabetes mellitus (the FIELD study): Randomised controlled trial. Lancet 2005; 366: 1849-1861. PMID: 16310551

179. Allemann S, Diem P, Egger M, Christ ER, Stettler C. Fibrates in the prevention of cardiovascular disease in patients with type 2 diabetes mellitus: Meta-analysis of randomised controlled trials. Curr Med Res Opin 2006; 22: 617-623. PMID: 16574044

180. Baigent C, Landray MJ, Reith C, Emberson J, Wheeler DC,
Tomson C, et al, SHARP Investigators. The effects of lowering LDL cholesterol with simvastatin plus ezetimibe in patients with chronic kidney disease (Study of Heart and Renal Protection): A randomised placebo-controlled trial. Lancet 2011; 377: 2181-2192. PMID: 21663949

181. Cannon CP, Blazing MA, Giugliano RP, McCagg A, White JA, Theroux $\mathrm{P}$, et al, IMPROVE-IT Investigators. Ezetimibe added to statin therapy after acute coronary syndromes. $N \mathrm{Engl} \mathrm{J} \mathrm{Med}$ 2015; 372: 2387-2397. PMID: 26039521

182. Sabatine MS, Leiter LA, Wiviott SD, Giugliano RP, Deedwania P, De Ferrari GM, et al. Cardiovascular safety and efficacy of the PCSK9 inhibitor evolocumab in patients with and without diabetes and the effect of evolocumab on glycaemia and risk of new-onset diabetes: A prespecified analysis of the FOURIER randomised controlled trial. Lancet Diabetes Endocrinol 2017; 5: 941 -950. PMID: 28927706

183. Antithrombotic Trialists' Collaboration. Collaborative metaanalysis of randomised trials of antiplatelet therapy for prevention of death, myocardial infarction, and stroke in high risk patients. BMJ 2002; 324: 71-86. PMID: 11786451

184. Yasue H, Ogawa H, Tanaka H, Miyazaki S, Hattori R, Saito M, et al, Japanese Antiplatelets Myocardial Infarction Study (JAMIS) Investigators. Effects of aspirin and trapidil on cardiovascular events after acute myocardial infarction. Am J Cardiol 1999; 83: 1308-1313. PMID: 10235086

185. De Berardis G, Sacco M, Strippoli GF, Pellegrini F, Graziano G, Tognoni $\mathrm{G}$, et al. Aspirin for primary prevention of cardiovascular events in people with diabetes: Meta-analysis of randomised controlled trials. BMJ 2009; 339: b4531. PMID: 19897665

186. Ogawa H, Nakayama M, Morimoto T, Uemura S, Kanauchi M, Doi N, et al, Japanese Primary Prevention of Atherosclerosis With Aspirin for Diabetes (JPAD) Trial Investigators. Low-dose aspirin for primary prevention of atherosclerotic events in patients with type 2 diabetes: A randomized controlled trial. JAMA 2008; 300: 2134-2141. PMID: 18997198

187. Saito Y, Morimoto T, Ogawa H, Nakayama M, Uemura S, Doi N, et al, Japanese Primary Prevention of Atherosclerosis With Aspirin for Diabetes Trial Investigators. Low-dose aspirin therapy in patients with type 2 diabetes and reduced glomerular filtration rate: Subanalysis from the JPAD trial. Diabetes Care 2011; 34: 280-285. PMID: 21270185

188. Okada S, Morimoto T, Ogawa H, Kanauchi M, Nakayama M, Uemura S, et al, Japanese Primary Prevention of Atherosclerosis With Aspirin for Diabetes Trial Investigators. Differential effect of low-dose aspirin for primary prevention of atherosclerotic events in diabetes management: A subanalysis of the JPAD trial. Diabetes Care 2011;34: 1277-1283. PMID: 21515838

189. Bhatt DL, Marso SP, Hirsch AT, Ringleb PA, Hacke W, Topol EJ. Amplified benefit of clopidogrel versus aspirin in patients with diabetes mellitus. Am J Cardiol 2002; 90: 625-628. PMID: 12231089

190. Thompson PD, Zimet R, Forbes WP, Zhang P. Meta-analysis of results from eight randomized, placebo-controlled trials on the effect of cilostazol on patients with intermittent claudication. Am J Cardiol 2002; 90: 1314-1319. PMID: 12480040

191. Shinohara Y, Gotoh F, Tohgi H, Hirai S, Terashi A, Fukuuchi $\mathrm{Y}$, et al. Antiplatelet cilostazol is beneficial in diabetic and/or hypertensive ischemic stroke patients: Subgroup analysis of the cilostazol stroke prevention study. Cerebrovasc Dis 2008; 26: 63-70. PMID: 18511873

192. Sardar P, Udell JA, Chatterjee S, Bansilal S, Mukherjee D, Farkouh ME. Effect of intensive versus standard blood glucose control in patients with type 2 diabetes mellitus in different regions of the world: Systematic review and meta-analysis of randomized controlled trials. J Am Heart Assoc 2015; 4: e001577. PMID: 25944874

193. Hemmingsen B, Lund SS, Gluud C, Vaag A, Almdal T, Hemmingsen C, et al. Intensive glycaemic control for patients with type 2 diabetes: Systematic review with meta-analysis and trial sequential analysis of randomised clinical trials. $B M J$ 2011; 343: d6898. PMID: 22115901

194. Boussageon R, Bejan-Angoulvant T, Saadatian-Elahi M, Lafont S, Bergeonneau C, Kassaï B, et al. Effect of intensive glucose lowering treatment on all cause mortality, cardiovascular death, and microvascular events in type 2 diabetes: Meta-analysis of randomised controlled trials. BMJ 2011; 343: d4169. PMID: 21791495

195. Turnbull FM, Abraira C, Anderson RJ, Byington RP, Chalmers JP, et al. Intensive glucose control and macrovascular outcomes in type 2 diabetes. Diabetologia 2009; 52: 2288-2298. 
PMID: 19655124

196. Hayward RA, Reaven PD, Wiitala WL, Bahn GD, Reda DJ $\mathrm{Ge} \mathrm{L}$, et al, VADT Investigators. Follow-up of glycemic control and cardiovascular outcomes in type 2 diabetes. $N$ Engl J Med 2015; 372: 2197-2206. PMID: 26039600

197. Zoungas S, Chalmers J, Neal B, Billot L, Li Q, Hirakawa Y, et al, ADVANCE-ON Collaborative Group. Follow-up of blood-pressure lowering and glucose control in type 2 diabetes. N Engl J Med 2014; 371: 1392-1406. PMID: 25234206

198. Gerstein HC, Miller ME, Ismail-Beigi F, Largay J, McDonald C, Lochnan HA, et al, ACCORD Study Group. Effects of intensive glycaemic control on ischaemic heart disease: Analysis of data from the randomised, controlled ACCORD trial. Lancet 2014; 384: 1936-1941. PMID: 25088437

199. Griffin SJ, Leaver JK, Irving GJ. Impact of metformin on cardiovascular disease: A meta-analysis of randomised trials among people with type 2 diabetes. Diabetologia 2017; 60: 1620-1629. PMID: 28770324

200. Mazzone T, Meyer PM, Feinstein SB, Davidson MH, Kondos GT, D'Agostino RB Sr, et al. Effect of pioglitazone compared with glimepiride on carotid intima-media thickness in type 2 diabetes: A randomized trial. JAMA 2006; 296: 2572-2581. PMID: 17101640

201. Nissen SE, Nicholls SJ, Wolski K, Nesto R, Kupfer S, Perez A, et al, PERISCOPE Investigators. Comparison of pioglitazone vs glimepiride on progression of coronary atherosclerosis in patients with type 2 diabetes: The PERISCOPE randomized controlled trial. JAMA 2008; 299: 1561 -1573. PMID: 18378631

202. van de Laar FA, Lucassen PL, Akkermans RP, van de Lisdonk EH, Rutten GE, van Weel C. $\alpha$-glucosidase inhibitors for patients with type 2 diabetes: Results from a Cochrane systematic review and meta-analysis. Diabetes Care 2005; 28: 154-163. PMID: 15616251

203. Hanefeld M, Cagatay M, Petrowitsch T, Neuser D, Petzinna D, Rupp M. Acarbose reduces the risk for myocardial infarction in type 2 diabetic patients: Meta-analysis of seven long-term studies. Eur Heart J 2004; 25: 10-16. PMID: 14683737

204. Bethel MA, Patel RA, Merrill P, Lokhnygina Y, Buse JB, Mentz RJ, et al, EXSCEL Study Group. Cardiovascular outcomes with glucagon-like peptide-1 receptor agonists in patients with type 2 diabetes: A meta-analysis. Lancet Diabetes Endocrinol 2018; 6: 105-113. PMID: 29221659

205. Zelniker TA, Wiviott SD, Raz I, Im K, Goodrich EL, Furtado RHM, et al. Comparison of the effects of glucagon-like peptide receptor agonists and sodium-glucose cotransporter 2 inhibitors for prevention of major adverse cardiovascular and renal outcomes in type 2 diabetes mellitus. Circulation 2019; 139: 2022-2031. PMID: 30786725

206. Davies MJ, D‘Alessio DA, Fradkin J, Kernan WN, Mathieu C, Mingrone $\mathrm{G}$, et al. Management of hyperglycemia in type 2 diabetes, 2018: A Consensus Report by the American Diabetes Association (ADA) and the European Association for the Study of Diabetes (EASD). Diabetes Care 2018; 41: 2669-2701. PMID: 30291106

207. Cosentino F, Grant PJ, Aboyans V, Bailey CJ, Ceriello A, Delgado V, et al. 2019 ESC guidelines on diabetes, pre-diabetes, and cardiovascular diseases developed in collaboration with the EASD: The Task Force for diabetes, pre-diabetes, and cardiovascular diseases of the European Society of Cardiology (ESC) and the European Association for the Study of Diabetes (EASD). Eur Heart J 2020; 41: 255-323. PMID: 31497854

208. Kimura T, Morimoto T, Furukawa Y, Nakagawa Y, Shizuta $\mathrm{S}$, Ehara N, et al. Long-term outcomes of coronary-artery bypass graft surgery versus percutaneous coronary intervention for multivessel coronary artery disease in the bare-metal stent era. Circulation 2008; 118(Suppl): S199-S209. PMID: 18824755

209. Juutilainen A, Lehto S, Rönnemaa T, Pyörälä K, Laakso M. Type 2 diabetes as a "coronary heart disease equivalent": An 18-year prospective population-based study in Finnish subjects. Diabetes Care 2005; 28: 2901-2907. PMID: 16306552

210. Kasai T, Miyauchi K, Kajimoto K, Kubota N, Kurata T, Daida $H$. Influence of diabetes on $>10$-year outcomes after percutaneous coronary intervention. Heart Vessels 2008; 23: 149-154. PMID: 18484156

211. Motomura N, Miyata H, Tsukihara H, Okada M, Takamoto S. Japan Cardiovascular Surgery Database Organization: First report on 30-day and operative mortality in risk model of isolated coronary artery bypass grafting in Japan. Ann Thorac Surg 2008; 86: 1866-1872. PMID: 19021998

212. BARI Investigators. The final 10-year follow-up results from the BARI randomized trial. J Am Coll Cardiol 2007; 49: 1600-1606. PMID: 17433949

213. BARI Investigators. Seven-year outcome in the Bypass Angioplasty Revascularization Investigation (BARI) by treatment and diabetic status. J Am Coll Cardiol 2000; 35: 1122-1129. PMID: 10758950

214. Farkouh ME, Domanski M, Sleeper LA, Siami FS, Dangas G, Mack M, et al, FREEDOM Trial Investigators. Strategies for multivessel revascularization in patients with diabetes. $N$ Engl $J$ Med 2012; 367: 2375-2384. PMID: 23121323

215. Farkouh ME, Domanski M, Dangas GD, Godoy LC, Mack MJ, Siami FS, et al, FREEDOM Follow-On Study Investigators. Long-term survival following multivessel revascularization in patients with diabetes: The FREEDOM follow-on study. $J \mathrm{Am}$ Coll Cardiol 2019; 73: 629-638. PMID: 30428398

216. Serruys PW, Morice MC, Kappetein AP, Colombo A, Holmes DR, Mack MJ, et al, SYNTAX Investigators. Percutaneous coronary intervention versus coronary-artery bypass grafting for severe coronary artery disease. $N$ Engl J Med 2009; 360: 961-972. PMID: 19228612

217. Banning AP, Westaby S, Morice MC, Kappetein AP, Mohr FW, Berti S, et al. Diabetic and nondiabetic patients with left main and/or 3-vessel coronary artery disease: Comparison of outcomes with cardiac surgery and paclitaxel-eluting stents. $J$ Am Coll Cardiol 2010; 55: 1067-1075. PMID: 20079596

218. Neumann FJ, Sousa-Uva M, Ahlsson A, Alfonso F, Banning AP, Benedetto U, et al. 2018 ESC/EACTS guidelines on myocardial revascularization: The Task Force on myocardial revascularization of the European Society of Cardiology (ESC) and European Association for Cardio-Thoracic Surgery (EACTS). Eur Heart J 2019; 40: 87-165. PMID: 30165437

219. Nasu K, Tsuchikane E, Katoh O, Fujita H, Surmely JF, Ehara M, et al. Plaque characterisation by Virtual Histology intravascular ultrasound analysis in patients with type 2 diabetes. Heart 2008; 94: 429-433. PMID: 17646194

220. Amano T, Matsubara T, Uetani T, Nanki M, Marui N, Kato M, et al. Abnormal glucose regulation is associated with lipid-rich coronary plaque: Relationship to insulin resistance. $J A C C$ Cardiovasc Imaging 2008; 1: 39-45. PMID: 19356403

221. Uetani T, Amano T, Harada K, Kitagawa K, Kunimura A, Shimbo Y, et al. Impact of insulin resistance on post-procedural myocardial injury and clinical outcomes in patients who underwent elective coronary interventions with drug-eluting stents. JACC Cardiovasc Interv 2012; 5: 1159-1167. PMID: 23174640

222. Capes SE, Hunt D, Malmberg K, Gerstein HC. Stress hyperglycaemia and increased risk of death after myocardial infarction in patients with and without diabetes: A systematic overview. Lancet 2000; 355: 773-778. PMID: 10711923

223. Ishihara M, Inoue I, Kawagoe T, Shimatani Y, Kurisu S, Nishioka K, et al. Effect of acute hyperglycemia on the ischemic preconditioning effect of prodromal angina pectoris in patients with a first anterior wall acute myocardial infarction. $A m J$ Cardiol 2003; 92: 288-291. PMID: 12888134

224. Ishii H, Ichimiya S, Kanashiro M, Amano T, Matsubara T, Murohara T. Effects of intravenous nicorandil before reperfusion for acute myocardial infarction in patients with stress hyperglycemia. Diabetes Care 2006; 29: 202-206. PMID: 16443860

225. Cavender MA, Steg PG, Smith SC Jr, Eagle K, Ohman EM, Goto S, et al, REACH Registry Investigators. Impact of diabetes mellitus on hospitalization for heart failure, cardiovascular events, and death: Outcomes at 4 years from the Reduction of Atherothrombosis for Continued Health (REACH) registry. Circulation 2015; 132: 923-931. PMID: 26152709

226. Kenchaiah S, Evans JC, Levy D, Wilson PW, Benjamin EJ, Larson MG, et al. Obesity and the risk of heart failure. $N$ Engl J Med 2002; 347: 305-313. PMID: 12151467

227. Nichols GA, Gullion CM, Koro CE, Ephross SA, Brown JB. The incidence of congestive heart failure in type 2 diabetes: An update. Diabetes Care 2004; 27: 1879-1884. PMID: 15277411

228. Aune D, Sen A, Norat T, Janszky I, Romundstad P, Tonstad $\mathrm{S}$, et al. Body mass index, abdominal fatness, and heart failure incidence and mortality: A systematic review and dose-response meta-analysis of prospective studies. Circulation 2016; 133: 639-649. PMID: 26746176

229. Pandey A, LaMonte M, Klein L, Ayers C, Psaty BM, Eaton $\mathrm{CB}$, et al. Relationship between physical activity, body mass index, and risk of heart failure. J Am Coll Cardiol 2017; 69: 1129-1142. PMID: 28254175

230. Savji N, Meijers WC, Bartz TM, Bhambhani V, Cushman M, 
Nayor M, et al. The association of obesity and cardiometabolic traits with incident HFpEF and HFrEF. JACC Heart Fail 2018; 6: 701-709. PMID: 30007554

231. Pandey A, Garg S, Khunger M, Darden D, Ayers C, Kumbhani DJ, et al. Dose-response relationship between physical activity and risk of heart failure: A meta-analysis. Circulation 2015; 132: 1786-1794. PMID: 26438781

232. Echouffo-Tcheugui JB, Butler J, Yancy CW, Fonarow GC. Association of physical activity or fitness with incident heart failure: A systematic review and meta-analysis. Circ Heart Fail 2015; 8: 853-861. PMID: 26175539

233. Gregg EW, Jakicic JM, Blackburn G, Bloomquist P, Bray GA, et al, Look AHEAD Research Group. Association of the magnitude of weight loss and changes in physical fitness with long-term cardiovascular disease outcomes in overweight or obese people with type 2 diabetes: A post-hoc analysis of the Look AHEAD randomised clinical trial. Lancet Diabetes Endocrinol 2016; 4: 913-921. PMID: 27595918

234. Gaede P, Lund-Andersen H, Parving HH, Pedersen O. Effect of a multifactorial intervention on mortality in type 2 diabetes. N Engl J Med 2008; 358: 580-591. PMID: 18256393

235. Gæde P, Oellgaard J, Carstensen B, Rossing P, Lund-Andersen $\mathrm{H}$, Parving $\mathrm{HH}$, et al. Years of life gained by multifactorial intervention in patients with type 2 diabetes mellitus and microalbuminuria: 21 years follow-up on the Steno-2 randomised trial. Diabetologia 2016; 59: 2298 -2307. PMID: 27531506

236. Oellgaard J, Gæde P, Rossing P, Rørth R, Køber L, Parving HH, et al. Reduced risk of heart failure with intensified multifactorial intervention in individuals with type 2 diabetes and microalbuminuria: 21 years of follow-up in the randomised Steno-2 study. Diabetologia 2018; 61: 1724-1733. PMID: 29850922

237. Granger CB, McMurray JJ, Yusuf S, Held P, Michelson EL, Olofsson B, et al, CHARM Investigators and Committees. Effects of candesartan in patients with chronic heart failure and reduced left-ventricular systolic function intolerant to angiotensinconverting-enzyme inhibitors: The CHARM-Alternative trial. Lancet 2003; 362: 772-776. PMID: 13678870

238. McMurray JJ, Ostergren J, Swedberg K, Granger CB, Held P, Michelson EL, et al, CHARM Investigators and Committees. Effects of candesartan in patients with chronic heart failure and reduced left-ventricular systolic function taking angiotensinconverting-enzyme inhibitors: The CHARM-Added trial. Lancet 2003; 362: 767-771. PMID: 13678869

239. Shekelle PG, Rich MW, Morton SC, Atkinson CS, Tu W, Maglione M, et al. Efficacy of angiotensin-converting enzyme inhibitors and beta-blockers in the management of left ventricular systolic dysfunction according to race, gender, and diabetic status: A meta-analysis of major clinical trials. $\mathrm{J} \mathrm{Am} \mathrm{Coll} \mathrm{Cardiol}$ 2003; 41: 1529-1538. PMID: 12742294

240. Deedwania PC, Giles TD, Klibaner M, Ghali JK, Herlitz J, Hildebrandt P, et al, MERIT-HF Study Group. Efficacy, safety and tolerability of metoprolol CR/XL in patients with diabetes and chronic heart failure: Experiences from MERIT-HF. Am Heart J 2005; 149: 159-167. PMID: 15660048

241. Haas SJ, Vos T, Gilbert RE, Krum H. Are $\beta$-blockers as efficacious in patients with diabetes mellitus as in patients without diabetes mellitus who have chronic heart failure? A meta-analysis of large-scale clinical trials. Am Heart J 2003; 146: 848-853. PMID: 14597934

242. Bakris GL, Fonseca V, Katholi RE, McGill JB, Messerli FH, Phillips RA, et al, GEMINI Investigators. Metabolic effects of carvedilol vs metoprolol in patients with type 2 diabetes mellitus and hypertension: A randomized controlled trial. JAMA 2004; 292: 2227-2236. PMID: 15536109

243. Arnold SV, Spertus JA, Lipska KJ, Lanfear DE, Tang F, Grodzinsky A, et al. Type of $\beta$-blocker use among patients with versus without diabetes after myocardial infarction. Am Heart J 2014; 168: 273-279.e1. PMID: 25173537

244. Zannad F, McMurray JJ, Krum H, van Veldhuisen DJ, Swedberg K, Shi H, et al, EMPHASIS-HF Study Group. Eplerenone in patients with systolic heart failure and mild symptoms. $N$ Engl J Med 2011; 364: 11-21. PMID: 21073363

245. Pitt B, Zannad F, Remme WJ, Cody R, Castaigne A, Perez A, et al, Randomized Aldactone Evaluation Study Investigators. The effect of spironolactone on morbidity and mortality in patients with severe heart failure. N Engl J Med 1999; 341: 709-717. PMID: 10471456

246. Aguilar D, Bozkurt B, Ramasubbu K, Deswal A. Relationship of hemoglobin A1C and mortality in heart failure patients with diabetes. J Am Coll Cardiol 2009; 54: 422-428. PMID: 19628117
247. Elder DH, Singh JS, Levin D, Donnelly LA, Choy AM, George $\mathrm{J}$, et al. Mean $\mathrm{HbAlc}$ and mortality in diabetic individuals with heart failure: A population cohort study. Eur J Heart Fail 2016; 18: 94 -102. PMID: 26663216

248. Connelly KA, Yan AT, Leiter LA, Bhatt DL, Verma S. Cardiovascular implications of hypoglycemia in diabetes mellitus. Circulation 2015; 132: 2345-2350. PMID: 26667098

249. Bozkurt B, Aguilar D, Deswal A, Dunbar SB, Francis GS, Horwich T, et al. American Heart Association Heart Failure and Transplantation Committee of the Council on Clinical Cardiology; Council on Cardiovascular Surgery and Anesthesia; Council on Cardiovascular and Stroke Nursing; Council on Hypertension; and Council on Quality and Outcomes Research. Contributory risk and management of comorbidities of hypertension, obesity, diabetes mellitus, hyperlipidemia, and metabolic syndrome in chronic heart failure: A Scientific Statement from the American Heart Association. Circulation 2016; 134: e535-e578. PMID: 27799274

250. DeFronzo RA, Chilton R, Norton L, Clarke G, Ryder RE, Abdul-Ghani M. Revitalization of pioglitazone: The optimum agent to be combined with a sodium-glucose co-transporter-2 inhibitor. Diabetes Obes Metab 2016; 18: 454-462. PMID: 26919068

251. Eurich DT, Majumdar SR, McAlister FA, Tsuyuki RT, Johnson JA. Improved clinical outcomes associated with metformin in patients with diabetes and heart failure. Diabetes Care 2005; 28: 2345-2351. PMID: 16186261

252. Andersson C, Olesen JB, Hansen PR, Weeke P, Norgaard ML, Jørgensen $\mathrm{CH}$, et al. Metformin treatment is associated with a low risk of mortality in diabetic patients with heart failure: A retrospective nationwide cohort study. Diabetologia 2010; 53: 2546-2553. PMID: 20838985

253. Aguilar D, Chan W, Bozkurt B, Ramasubbu K, Deswal A. Metformin use and mortality in ambulatory patients with diabetes and heart failure. Circ Heart Fail 2011; 4: 53-58. PMID: 20952583

254. Eurich DT, Weir DL, Majumdar SR, Tsuyuki RT, Johnson JA, Tjosvold L, et al. Comparative safety and effectiveness of metformin in patients with diabetes mellitus and heart failure: Systematic review of observational studies involving 34,000 patients. Circ Heart Fail 2013; 6: 395-402. PMID: 23508758

255. Crowley MJ, Diamantidis CJ, McDuffie JR, Cameron CB, Stanifer JW, Mock CK, et al. Clinical outcomes of metformin use in populations with chronic kidney disease, congestive heart failure, or chronic liver disease: A systematic review. Ann Intern Med 2017; 166: 191-200. PMID: 28055049

256. Scirica BM, Bhatt DL, Braunwald E, Steg PG, Davidson J, Hirshberg B, et al, SAVOR-TIMI 53 Steering Committee and Investigators. Saxagliptin and cardiovascular outcomes in patients with type 2 diabetes mellitus. N Engl J Med 2013; 369: 1317-1326. PMID: 23992601

257. White WB, Cannon CP, Heller SR, Nissen SE, Bergenstal RM, Bakris GL, et al, EXAMINE Investigators. Alogliptin after acute coronary syndrome in patients with type 2 diabetes. $N$ Engl J Med 2013; 369: 1327-1335. PMID: 23992602

258. Green JB, Bethel MA, Armstrong PW, Buse JB, Engel SS, Garg J, et al, TECOS Study Group. Effect of sitagliptin on cardiovascular outcomes in type 2 diabetes. $N$ Engl J Med 2015; 373: $232-242$. PMID: 26052984

259. Rosenstock J, Perkovic V, Johansen OE, Cooper ME, Kahn SE, Marx N, et al, CARMELINA Investigators. Effect of linagliptin vs placebo on major cardiovascular events in adults with type 2 diabetes and high cardiovascular and renal risk: The CARMELINA randomized clinical trial. JAMA 2019; 321: 69-79. PMID: 30418475

260. Gerstein HC, Colhoun HM, Dagenais GR, Diaz R, Lakshmanan $\mathrm{M}$, Pais $\mathrm{P}$, et al, REWIND Investigators. Dulaglutide and cardiovascular outcomes in type 2 diabetes (REWIND): A double-blind, randomised placebo-controlled trial. Lancet 2019; 394: 121-130. PMID: 31189511

261. Hernandez AF, Green JB, Janmohamed S, D'Agostino RB Sr, Granger CB, Jones NP, et al, Harmony Outcomes committees and investigators. Albiglutide and cardiovascular outcomes in patients with type 2 diabetes and cardiovascular disease (Harmony Outcomes): A double-blind, randomised placebocontrolled trial. Lancet 2018; 392: 1519-1529. PMID: 30291013

262. Holman RR, Bethel MA, Mentz RJ, Thompson VP, Lokhnygina Y, Buse JB, et al, EXSCEL Study Group. Effects of once-weekly exenatide on cardiovascular outcomes in type 2 diabetes. $N$ Engl J Med 2017; 377: 1228-1239. PMID: 28910237 
263. Husain $M$, Birkenfeld AL, Donsmark $M$, Dungan $K$, Eliaschewitz FG, Franco DR, et al, PIONEER 6 Investigators. Oral semaglutide and cardiovascular outcomes in patients with type 2 diabetes. $N$ Engl $J$ Med 2019; 381: 841-851. PMID: 31185157

264. Marso SP, Bain SC, Consoli A, Eliaschewitz FG, Jódar E, Leiter LA, et al, SUSTAIN-6 Investigators. Semaglutide and cardiovascular outcomes in patients with type 2 diabetes. $N$ Engl J Med 2016; 375: 1834-1844. PMID: 27633186

265. Marso SP, Daniels GH, Brown-Frandsen K, Kristensen P, Mann JF, Nauck MA, et al, LEADER Steering Committee. Liraglutide and cardiovascular outcomes in type 2 diabetes. $N$ Engl J Med 2016; 375: 311-322. PMID: 27295427

266. Pfeffer MA, Claggett B, Diaz R, Dickstein K, Gerstein HC, Køber LV, et al, ELIXA Investigators. Lixisenatide in patients with type 2 diabetes and acute coronary syndrome. $N$ Engl $J$ Med 2015; 373: 2247-2257. PMID: 26630143

267. Margulies KB, Hernandez AF, Redfield MM, Givertz MM, Oliveira GH, Cole R, et al, NHLBI Heart Failure Clinical Research Network. Effects of liraglutide on clinical stability among patients with advanced heart failure and reduced ejection fraction: A randomized clinical trial. JAMA 2016; 316: 500-508. PMID: 27483064

268. Sharma A, Cooper LB, Fiuzat M, Mentz RJ, Ferreira JP, Butler J, et al. Antihyperglycemic therapies to treat patients with heart failure and diabetes mellitus. JACC Heart Fail 2018; 6: 813-822. PMID: 30098964

269. Zelniker TA, Wiviott SD, Raz I, Im K, Goodrich EL, Bonaca MP, et al. SGLT2 inhibitors for primary and secondary prevention of cardiovascular and renal outcomes in type 2 diabetes: A systematic review and meta-analysis of cardiovascular outcome trials. Lancet 2019; 393: 31 -39. PMID: 30424892

270. Butler J, Hamo CE, Filippatos G, Pocock SJ, Bernstein RA, Brueckmann M, et al. EMPEROR Trials Program: The potential role and rationale for treatment of heart failure with sodiumglucose co-transporter 2 inhibitors. Eur J Heart Fail 2017; 19: 1390-1400. PMID: 28836359

271. McMurray JJV, DeMets DL, Inzucchi SE, Køber L, Kosiborod MN, Langkilde AM, et al, DAPA-HF Committees and Investigators. A trial to evaluate the effect of the sodium-glucose co-transporter 2 inhibitor dapagliflozin on morbidity and mortality in patients with heart failure and reduced left ventricular ejection fraction (DAPA-HF). Eur J Heart Fail 2019; 21: 665-675. PMID: 30895697

272. McMurray JJV, Solomon SD, Inzucchi SE, Køber L, Kosiborod MN, Martinez FA, et al, DAPA-HF Trial Committees and Investigators. Dapagliflozin in patients with heart failure and reduced ejection fraction. $N$ Engl J Med 2019; 381: 1995-2008. PMID: 31535829

273. Tadic M, Cuspidi C. Type 2 diabetes mellitus and atrial fibrillation: From mechanisms to clinical practice. Arch Cardiovasc Dis 2015; 108: 269-276. PMID: 25858534

274. Wyse DG, Waldo AL, DiMarco JP, Domanski MJ, Rosenberg Y, Schron EB, et al, Atrial Fibrillation Follow-up Investigation of Rhythm Management (AFFIRM) Investigators. A comparison of rate control and rhythm control in patients with atrial fibrillation. $N$ Engl J Med 2002; 347: 1825-1833. PMID: 12466506

275. Inoue H, Atarashi H, Kamakura S, Koretsune Y, Kumagai K, Mitamura H, et al, JCS Joint Working Group. Guidelines for pharmacotherapy of atrial fibrillation (JCS 2013). Circ J 2014; 78: 1997-2021. PMID: 24965079

276. Katoh T, Inuma H, Inoue H, Ohe T, Ogawa S, Kasanuki H, et al. Multicenter prospective nonrandomized study of long-term antiarrhythmic drug therapy in patients with tachyarrhythmias: Japanese Antiarrhythmics Long-Term Study-2 (JALT-2 Study). Jpn Circ J 2001; 65: 275-278. PMID: 11316122

277. Ogawa S, Yamashita T, Yamazaki T, Aizawa Y, Atarashi H, Inoue $\mathrm{H}$, et al, J-RHYTHM Investigators. Optimal treatment strategy for patients with paroxysmal atrial fibrillation: J-RHYTHM Study. Circ J 2009; 73: 242 -248. PMID: 19060419

278. Della Rocca DG, Mohanty S, Trivedi C, Di Biase L, Natale A.
Percutaneous treatment of non-paroxysmal atrial fibrillation: A paradigm shift from pulmonary vein to non-pulmonary vein trigger ablation? Arrhythm Electrophysiol Rev 2018; 7: 256-260. PMID: 30588313

279. Pisters R, Lane DA, Nieuwlaat R, de Vos CB, Crijns HJ, Lip GY. A novel user-friendly score (HAS-BLED) to assess 1-year risk of major bleeding in patients with atrial fibrillation: The Euro Heart Survey. Chest 2010; 138: 1093-1100. PMID: 20299623

280. Lip GY, Frison L, Halperin JL, Lane DA. Comparative validation of a novel risk score for predicting bleeding risk in anticoagulated patients with atrial fibrillation: The HAS-BLED (Hypertension, Abnormal Renal/Liver Function, Stroke, Bleeding History or Predisposition, Labile INR, Elderly, Drugs/Alcohol Concomitantly) score. J Am Coll Cardiol 2011; 57: 173-180. PMID: 21111555

281. Sato H, Ishikawa K, Kitabatake A, Ogawa S, Maruyama Y, Yokota Y, et al, Japan Atrial Fibrillation Stroke Trial Group. Low-dose aspirin for prevention of stroke in low-risk patients with atrial fibrillation: Japan Atrial Fibrillation Stroke Trial. Stroke 2006; 37: 447-451. PMID: 16385088

282. Hart RG, Sherman DG, Easton JD, Cairns JA. Prevention of stroke in patients with nonvalvular atrial fibrillation. Neurology 1998; 51: 674-681. PMID: 9748009

283. Connolly SJ, Ezekowitz MD, Yusuf S, Eikelboom J, Oldgren J, Parekh A, et al, RE-LY Steering Committee and Investigators. Dabigatran versus warfarin in patients with atrial fibrillation. N Engl J Med 2009; 361: 1139-1151. PMID: 19717844

284. Giugliano RP, Ruff CT, Braunwald E, Murphy SA, Wiviott SD, Halperin JL, et al, ENGAGE AF-TIMI 48 Investigators. Edoxaban versus warfarin in patients with atrial fibrillation. $N$ Engl J Med 2013; 369: 2093-2104. PMID: 24251359

285. Patel MR, Mahaffey KW, Garg J, Pan G, Singer DE, Hacke W, et al, ROCKET AF Investigators. Rivaroxaban versus warfarin in nonvalvular atrial fibrillation. $N$ Engl J Med 2011; 365: 883-891. PMID: 21830957

286. Granger CB, Alexander JH, McMurray JJ, Lopes RD, Hylek EM, Hanna M, et al, ARISTOTLE Committees and Investigators. Apixaban versus warfarin in patients with atrial fibrillation. $N$ Engl J Med 2011; 365: 981-992. PMID: 21870978

287. Hori M, Matsumoto M, Tanahashi N, Momomura S, Uchiyama S, Goto S, et al, J-ROCKET AF study investigators. Rivaroxaban vs. warfarin in Japanese patients with atrial fibrillation: The J-ROCKET AF study. Circ J 2012; 76: 2104-2111. PMID: 22664783

288. Evans IL, Sayers MS, Gibbons AJ, Price G, Snooks H, Sugar AW. Can warfarin be continued during dental extraction? Results of a randomized controlled trial. Br J Oral Maxillofac Surg 2002; 40: 248-252. PMID: 12054719

289. Japanese Society of Dentistry for Medically Compromised Patients, Japanese Society of Oral Maxillofacial Surgery, and Japanese Society of Gerodontology. Scientific evidence-based guidelines for dental extraction in patients with antithrombotic therapy. Tokyo: Gakujutsusha, 2010 [in Japanese].

290. Fujimoto K, Fujishiro M, Kato M, Higuchi K, Iwakiri R, Sakamoto C, et al. Japan Gastroenterological Endoscopy Society: Guidelines for gastroenterological endoscopy in patients undergoing antithrombotic treatment. Dig Endosc 2014; 26: 1-14. PMID: 24215155

291. Kato M, Uedo N, Hokimoto S, Ieko M, Higuchi K, Murakami $\mathrm{K}$, et al. Guidelines for gastroenterological endoscopy in patients undergoing antithrombotic treatment: 2017 appendix on anticoagulants including direct oral anticoagulants. Dig Endosc 2018; 30: 433-440. PMID: 29733468

292. van Veldhuisen DJ, Van Gelder IC, Ahmed A, Gheorghiade M. Digoxin for patients with atrial fibrillation and heart failure: Paradise lost or not? Eur Heart J 2013; 34: 1468-1470. PMID: 23324547

293. Mujović N, Marinković M, Lenarczyk R, Tilz R, Potpara TS Catheter ablation of atrial fibrillation: An overview for clinicians. Adv Ther 2017; 34: 1897-1917. PMID: 28733782 